NUREG/CR- -5660

TI92 000104

\title{
Static and Simulated Seismic Testing of the TRG-7 Through -16 Shear Wall Structures
}

Manuscript Completed: July 1991

Date Published: September 1991

Prepared by

C. R. Farrar, W. E. Baker'1, R. C. Dove ${ }^{2}$

\section{DISCLAIMER}

Los Alamos National Laboratory

Los Alamos, NM 87545

This report was prepared as an account of work sponsored by an agency of the United States Government. Neither the United States Government nor any agency thereof, nor any of their employees, makes any warranty, express or implied, or assumes any legal liability or responsibility for the accuracy, completeness, or usefulness of any information, apparatus, product, or process disclosed, or represents that its use would not infringe privately ou'ned rights. Reference herein to any specific commercial product, process, or service by trade name, trademark, manufacturer, or otherwise does not necessarily constitute or imply its endorsement, recommendation, or favoring by the United States Government or any agency thereof. The views

Prepared for

Division of Engineering United States of authors expressed herein do not necessarily state or reflect those of the Office of Nuclear Regulatory Research

U.S. Nuclear Regulatory Commission

Washington, DC 20555

NRC FIN A7221

'University of New Mexico, Albuquerque, NM 87131

2Consultant at Los Alamos, 0764 C.R. 65, Del Norte, CO 81132

\section{MASTER}

DISTRIBUTION OF IHIS DOOUIVIENT IS UNNI!MITED

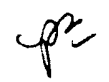




\section{PREVIOUS REPORTS IN THE SERIES}

E. G. Enclobrock and R. C. Dove, "Seismic Response of Nonlinear Systems," Los Alamos ivational Laboratory report LA-8981-MS, NUREG/CR-2310 (September 1981).

E. G. Endebrock, R. C. Dove, and C. A. Anderson, "Margins to Failure Category I Structures Program: Background and Experimental Plan," Los Alamos National Laboratory report LA-9030-MS, NUREG/CR-2347 (December 1981).

E. G. Endebrock, R. C. Dove, and W. E. Dunwoody, "Analysis and Tests on Small-Scale Shear Walls--FY 82 Final Report," Los Alamos National Laboratory report LA-10443-MS, NUREG/CR-4274 (September 1985).

R. C. Dove and J. G. Bennett, "Scale Modeling of Reinforced Concrete Category I Structures Subjected to Seismic Loading," Los Alamos National Laboratory report LA-10624-MS, NUREG/CR-4474 (January 1986).

R. C. Dove, J. G. Bennett, C. Farrar, and C. A. Anderson, "Seismic Category I Structures Program: Final Report, FY 1983-84," Los Alamos National Laboratory report LA-11013MS, NUREG/CR-4924 (September 1987).

J. G. Bennett, R. C. Dove, W. E. Dunwoody, E. G. Endebrock, C. R. Farrar, and P. Goldman, "Simulated Seismic Tests on 1/42- and 1/14-Scale Category I, Auxiliary Buildings," Los Alamos National Labəratory report LA-11093-MS, NUREG/CR-4987 (October 1987).

J. G. Bennett, R. C. Dove, W. E. Dunwoody, C. R. Farrar, and P. Goldman, "The Seismic Category I Structures Program: Results for FY 1985," Los Alamos National Laboratory report LA-11117-MS, NUREG/CR-4998 (December 1987).

C. R. Farrar and J. G. Bennett, "Experimental Assessment of Damping in Low Aspect Ratio, Reinforced Concrete Shear Wall Structures," Los Alamos National Laboratory report LA-11325-MS, NUREG/CR-5154 (August 1988).

J. G. Bennett, R. C. Dove, W. E. Dunwoody, C. R. Farrar, and P. Goldman, "The Seismic Category I Structures Program: Results for FY 1986," Los Alamos National Laboratory report LA-11377-MS, NUREG/CR-5182 (September 1988).

C. R. Farrar and C. M. Alvord, "Use of Linear Reduced-Stiffness Analytical Models to Predict Seismic Response of Darhaged Concrete Structures," Lcs Alamos National Laboratory report LA-11444-MS, NUREG/CR-5237 (May 1989).

C. R. Farrar, J. G. Bennett, W. E. Dunwoody, and W. E. Baker, "Static Load Cycle Testing of a Low-Aspect-Ratio Six-inch Wall, TRG-type Structure TRG-4-6 (1.0, 0.25)," Los Alamos National Laboratory report LA-11422-MS, NUKEG/CR-5222 (June 1989).

C. R. Farrar, J. G. Bennett, W. E. Dunwoody, W. E. Baker, "The Seismic Category I Structures Program Results for FY 1987," Los Alamos National Laboratory report LA11607-MS, NUREG/CR-5369 (October 1990).

C. R. Farrar, J. G. Bennett, W. E. Dunwoody, W. E. Baker, "Static Load Cycle Testing of a Low-Aspect-Ratio Four-Inch Wall, TRG-Type Structure

TRG-5-4 (1.0, 0.56)." Los Alamos National Laboratory report LA-11739-MS, NUREG/CR5487 (November 1990).

C. R. Farrar, J. G. Bennett, W. E. Baker, W. E. Dunwoody,"Static Load Cycle Testing of a Very Low-Aspect-Ratio Six-Inch Wall TRG-Type Structure TRG-6-6 $(0.27,0.50)$, "Los Alamos National Laboratory report LA-11796-MS, NUREG/CR-5533 (November 1990). 


\begin{abstract}
Results from the static, simulated seismic base excitation, and experimental modal analysis tests performed on the TRG-7 through -16 structures are reported. These results were used to establish the scalability of static and dynamic response measured on small structural models to the dynamic response of conventional concrete structures. In addition, these tests provided information concerning cumulative damage effects that occur in concrete structures when they are subjected to different dynamic load sequences. In contrast to previous results obtained in the early part of this program, TRG-7 through -16 responded to simulated seismic excitations with theoretical stiffness values until peak nominal base shear stress levels of 150 psi were reached. A summary of all experimental data obtained during this program is provided.
\end{abstract}




\section{CONTENTS}

ABSTRACT

I. INTRODUCTION.........................................................................

II. SELECTION OF MODEL GEOMETRIES AND TEST SEQUENCE.......... 2

III. MODEL CONSTRUCTION AND MATERIAL PROPERTIES..................... 5

IV. EXPERIMENTAL MODAL ANALYSIS ................................................. 9

V. SELECTION OF INPUT-SIGNAL, TIME-SCALE, AND AMPLITUDE LEVELS FOR THE SIMULATED SEISMIC TESTS................................ 17

VI. SIMULATED SEISMIC TESTING AND RESULTS................................ 25

A. Instrumentation and Test Setup.................................................... 25

B. Test Results (Accelerometer Data).............................................. $\quad 30$

C. Test Results (Strain Gage Data)................................................. 39

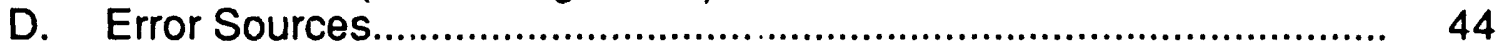

E. Comparison of Strain Gage Data With Accelerometer Data............. 46

F. Damping Data....................................................................... 52

VII. STATIC TESTING AND RESULTS................................................... 53

A. Instrumentation and Test Setup.................................................... 53

B. $\quad$ Test Results (Displacement Transducers) .................................... $\quad 59$

C. Test Results (Strain Gages) .......................................................... 61

VIII. SUMMARY AND CONCLUSIONS ........................................................ 64

REFERENCES

APPENDICES

A. SEISMIC CATEGORY I STRUCTURES PROGRAM BACKGROUND AND

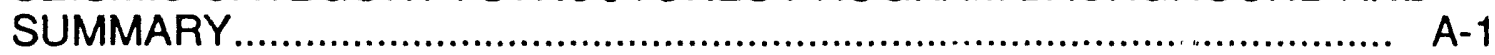

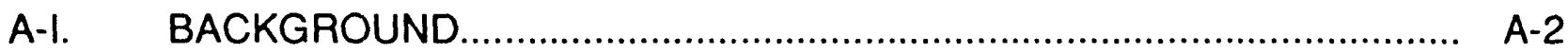

A-II. REVIEW OF PREVIOUS DYNAMIC TEST RESULTS OBTAINED IN THE SEISMIC CATEGORY 1 STRUCTURES PROGRAM............................ A-6

1. Isolated Shear Walls........................................................... A-6

2. Diesel Generator Buildings.................................................... A-12

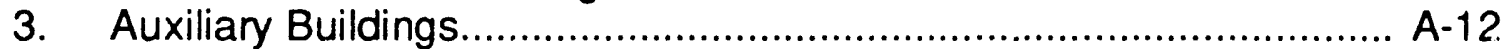

4. TRG-Type Structures.............................................................. A-12 
A-III. REVIEW OF PREVIOUS STATIC TEST RESULTS OBTAINED IN THE SEISMIC CATEGORY 1 STRUCTURES PROGRAM............................. A-19

I. Isolated Shear Walls.......................................................... A-19

2. 1/30-Scale, Single-Story, Diesel Generator Buildings........................ A-22

3. TRG-Type Structures................................................................ A-22

A-IV. COMPARISON OF STIFFNESSES MEASURED FROM STATIC AND

DYNAMIC TEST RESULTS ................................................... A-23

1. Isolated Shear Walls................................................................... A-23

2. 1/30-Scale, Single-Story, Diesel Generator Buildings...................... A-P.3

3. TRG-1 and TRG-3..................................................................... A

B. EVALUATING EQUIVALENT VISCOUS DAMPING RATIOS FROM HYSTERETIC ENERGY LOSSES..................................................... B-1

FIGURES

1. TRG-4 geometry.............................................................................

2. TRG-7 through -16 geometry ..............................................................

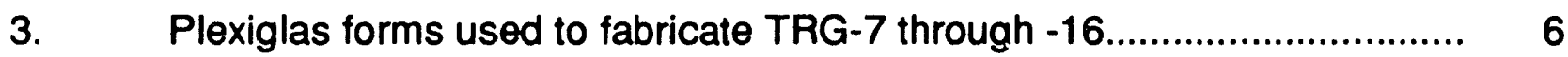

4. Experimental modal analysis test setup................................................ 11

5. Experimental modal analysis shaker attachment................................... 12

6. Experimental modal analysis measurement points................................. 13

7. Undeformed mesh and first three modes, determined by finite element analysis.

8. Comparison of the experimentally measured mode shape with the corresponding mode, determined by finite element analysis for TRG-12... 15

9. Comparison of the first modes measured on TRG-4 with the first mode measured on TRG-12

10. Response spectrum for the north-south component of the 1940 EI Centro earthquake normalized to $1 \mathrm{~g}$

11. First mode identified by finite element analysis....................................... 22

12. Response spectrum for the scaled 1940 El Centro earthquake................ 22

13. 1940 El Centro earthquake acceleration-time history normalized to $1 \mathrm{~g}$ and time scaled by a factor of 12 . 
14. 1940 El Centro earthquake velocity-time history corresponding to Fig. 13.

15. 1940 El Centro earthquake displacement-time history corresponding to Fig. 13

16. Free body diagram of the shake table and attached structure................... 25

17. Accelerometer locations for the simulated seismic test.............................. 26

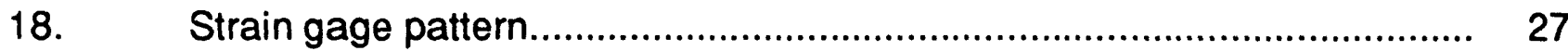

19. Strain gages mounted on TRG-13......................................................... 28

20. Stiffness reductions determined from resonant frequency measurements 38

21. Frequency response function, TRG-13 first seismic pulse, Ch.3y/Ch.2y... 39

22. Method for determining horizontal displacements from internal gage readings.

23. Free-body diagram of a TRG-type structure...........................................

24. Acceleration-time history of the top mass during the second seismic pulse on TRG-10.

25. Relative displacements determined from strain gage readings during the second seismic pulse on TRG-10.

26. D.C. shift in the strain gage reading that results from cracking of the structure.

27. Comparison of the response spectrum generated from the command signal and the response spectrum generated from the measured base excitation (Ch.2y) of TRG-14 during the first seismic pulse (4\% damping)

28. Frequency response function Ch.4y/Ch.3y, third seismic pulse on TRG-13.

29. A comparison of the acceleration-time histories from Ch.1y and Ch.2y during the strong motion portion of test TRG15;7

30. A comparison of the acceleration-time histories from Ch.9y and Ch.3y during the strong motion portion of test TRG15;7.

31. A comparison of the acceleration-time histories from $\mathrm{Ch} .2 \mathrm{v}$ and $\mathrm{Ch} .6 \mathrm{v}$ during the strong motion portion of test TRG15;1

32. Power spectral density plot, Ch.2v, test TRG-15;1 
33. Power spectral density plot, Ch.6v, test TRG-15;1 ................................. 49

34. Power spectral density plot, Ch.2v, test TRG-15;2................................ 49

35. Power spectral density plot, Ch.6v, test TRG-15;2................................ 50

36. A comparison of the acceleration-time histories from Ch.2v and Ch.6

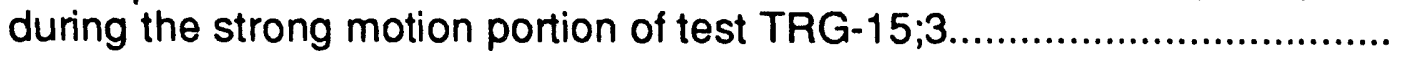

37. Stiffness reductions determined from strain gage data compared with stiffness reductions determined from resonant frequency measurements.

38. Displacement transducer locations....................................................... 55

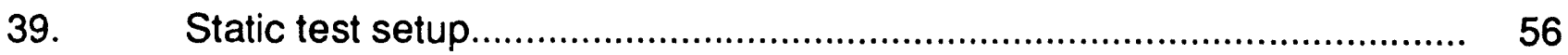

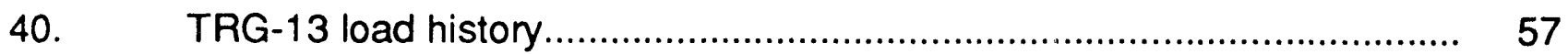

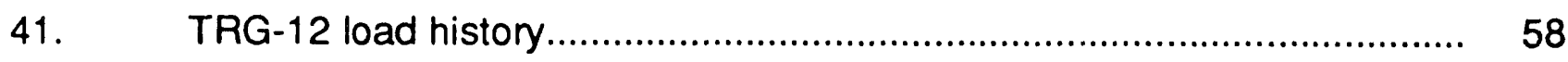

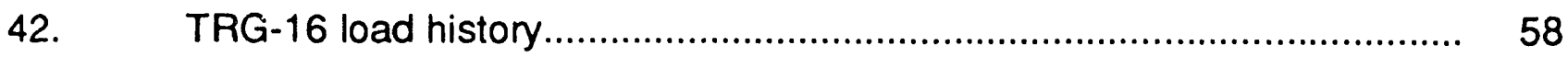

43. Force versus displacement from the average of the internal relative displacement gage readings on TRG-13............................................. 59

44. Cracks in the TRG-12 structure after failure ..............................................6 65

45. A comparison of the stress-strain curve from conventional rebar to the stress-strain curve of the wire mesh rebar used in TRG-7 through $-16 \ldots . .$.

46. A comparison of the internal relative displacement measurements determined by integrating strain gage readings with similar measurements made with displacement transducers during a 50-psi NBSS cycle.

47. All credible stiffness data obtained from the TRG test series................... 68

A-1. TRG-1 through TRG-6 geometry .................................................. A-5

A-2. Isolated shear wall structures with added mass.................................... A-8

A-3. Two-story diesel generator building models....................................... A-15

A-4. Three-story auxiliary building models................................................ A-17

B-1. Quantities used to calculate the hysteretic energy loss and the associated equivalent viscous damping ratio 


\section{TABLES}

I. LOS ALAMOS SEISMIC TEST FACILITY SPECIFICATION.................... 4

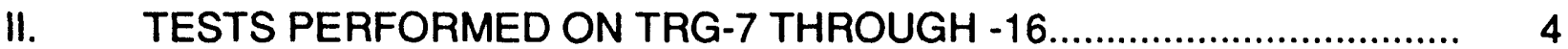

III. 3/8-in. AGGREGATE MIX PROPORTIONS.......................................... 7

IV. MICROCONCRETE MIX PROPORTIONS.............................................. 7

V. COMPARISON OF THE 3/8-in. AGGREGATE MIX PROPERTIES WITH THE TRG-4 3/4-in. AGGREGATE MIX PROPERTIES.

VI. MEASURED MATERIAL PROPERTIES.............................................. 10

VII. COMPARISON OF EXPERIMENTAL MODAL ANALYSIS RESULTS WITH ANALYTICAL MODAL ANALYSIS RESULTS.

VIII. COMPARISON OF SCALED EXPERIMENTALLY MEASURED MODAL FREQUENCIES AND UNSCALED EXPERIMENTALLY MEASURED MODAL DAMPING VALUES FROM TRG-7 THROUGH -16 TO MEASURED MODAL FREQUENCIES AND DAMPING VALUES FROM TRG-4.

IX. TRG-4 TEST RESULTS AND PREDICTED 1/3-SCALE MODEL TEST RESULTS.

X. TEST MATRIX FOR THE 1/3-SCALE STRUCTURES........................... 23

XI. TRG-8 DYNAMIC TEST RESULTS................................................. 31

XII. TRG-9 DYNAMIC TEST RESULTS ................................................. 32

XIII. TRG-10 DYNAMIC TEST RESULTS................................................. 33

XIV. TRG-11 DYNAMIC TEST RESULTS.............................................. 34

XV. TRG-13 DYNAMIC TEST RESULTS............................................... 35

XVI. TRG-14 DYNAMIC TEST RESULTS.................................................. 36

XVII. TRG-15 DYNAMIC TEST RESULTS..................................................... 37

XVIII. VISCOUS DAMPING RATIO VALUES MEASURED ON STRUCTURES USED IN THE SEISMIC TEST SERIES................................................. 54

XIX. TRG-13 STATIC TEST RESULTS...................................................... 60

XX. TRG-12 STATIC TEST RESULTS .................................................... 62 
XXI. TRG-16 STATIC TEST RESULTS

XXII. COMPARISON OF THE FIRST CRACK LOADS MEASURED ON TRG-12 AND - 16 WITH THE FIRST CRACK LOAD MEASURED ON TRG-4

A-I. MEASURED PIROPERTIES FOR DYNAMIC TEST SPECIMENS

A-II. RESULTS OF SINE-SWEEP TESTS ON ISOLATED SHEAR WALLS..... A-9

A-III. ISOLATED SHEAR WALL MODEL 21 SIMULATED SEISMIC TEST RESULTS.

A-IV. ISOLATED SHEAR WALL MODEL 23 SIMULATED SEISMIC TEST RESULTS

A-V. ISOLATED SHEAR WALL MODEL 2-2 SIMULATED SEISMIC TEST RESULTS

A-VI. 1/30-SCALE DIESEL GENERATOR BUILDING MODELS DYNAMIC TEST RESULTS.

A-VII. TWO-STORY DIESEL GENERATOR BUILDING SIMULATED SEISMIC TEST RESULTS.

A-VIII. 1/42-SCALE AUXILIARY BUILDING MODEL SIMULATED SEISMIC TEST RESULTS.

A-IX. A COMPARISON OF RESONANT FREQUENCIES IDENTIFIED FROM THE EXPERIMENTAL MODAL ANALYSIS WITH THE RESONANT FREQUENCIES IDENTIFIED FROM THE ANALYTICAL MODAL ANALYSIS FOR THE LARGE TRG-STRUCTURES.

A-X. PREVIOUS STATIC TEST RESULTS 


\title{
STATIC AND SIMULATED SEISMIC TESTING OF THE TRG-7 THROUGH -16 SHEAR WALL STRUCTURES
}

\author{
by
}

\author{
Charles R. Farrar, William E. Baker, and Pichard C. Dove
}

\section{INTRODUCTION}

Previous work that has been carried out at Los Alamos National Laboratory (LANL) as part of the Seismic Category I Structures Program for the U.S. Nuclear Regulatory Commission (NRC) Office of Nuclear Regulatory Research has consistently measured stiffnesses less than mechanics-of-materials theory (herein referred to simply as theory) would predict for scale models of low-aspect-ratio shear wall structures subjected to working loads. In this context, working loads refer to load levels equivalent to those experienced by a structure during an operating basis earthquake (OBE), and would produce nominal base shear stresses (NBSS) of 50- to 100-psi. The models tested thus far have been made of both microconcrete and conventional concrete and have been tested statically and dynamically.

Based on these test results, the NRC initiated a program to investigate the implications of this reduced stiffness on plant risk using probabilistic risk assessment (PRA) methods. Because all prior simulated seismic data from this program were obtained by subjecting structures to monotonically increasing, peak amplitude, seismic excitations, no information was available concerning the response of a virgin structure to a single, highlevel seismic pulse. The PRA investigators recommended that the NRC have a series of tests performed to investigate the cumulative damage effects that might have occurred during previous testing and to investigate the response of a virgin structure subjected to an initial high-level seismic input. These tests were performed on five structures, designated TRG-7 through -11 . These structures were 1/3-scale models of a conventional concrete structure, TRG-4 [1], previously tested to failure statically. To conclude the experimental effort of this program, five more structures, TRG-12 through -16, were tested either statically or dynamically. These structures, which are the same size as TRG-7 through -11, were used to small structural models to the dynamic response of conventional concrete structures. This report summarizes the results from the TRG-7 through -16 series of tests. For the reader who may be unfamiliar with the program objectives and history, a summary, to date, is provided in Appendix A. 


\section{SELECTION OF MODEL GEOMETRIES AND TEST SEQUENCE}

Because the program has made extensive use of small-scale microconcrete models to predict the seismic response of nuclear power plant structures, and because these models have yielded controversial results (that is, the reduced stiffness at low NBSS levels), there was a need to verify the scalability of the results obtained from these models to the response of conventional concrete structures. TRG-4 (Fig. 1) was a conventional concrete structure that, when tested using experimental modal analysis techniques and when tested in a static, cyclic manner, exhibited a precracking stiffness that agreed almost exactly with theory. Based on the results obtained from TRG-4, the final study on cumulative damage effects and scalability was performed using 1/3-scale models of TRG-4 made with both 3/8-in. aggregate and microconcrete. Models of this size enable direct comparisons to be made between microconcrete and 3/8-in. aggregate structures of the same size (length scale $\mathrm{N}_{\mathrm{h}}=1$ ), as well as comparisons with results from the TRG-4 structure. Figure 2 shows the dimensions of the TRG-7 through -16 test structures.

The structures designed for this investigation had to be scaled to permit testing on an existing seismic simulation test facility. The test facility at LANL was selected so that the structures could be tested with minimum handling and shipping between the fabrication site and the test facility. The specifications of the LANL seismic test facility appear in Table I.

The calculated weight of these structures was $1060 \mathrm{lb}$ (assuming a concrete unit weight of $144 \mathrm{lb} / \mathrm{ft}^{3}$ ), and with the two steel plates attached to the top surface, the total weight on the shake table was $2550 \mathrm{lb}$. This is much less than the allowable dead weight that can be supported by the shake table. However, it was judged to be the largest practical load when the test facility's force and overturning moment limits were considered (see Sec. V).

Table II summarizes the type of aggregate used in each structure and the tests that each structure experienced. TRG-7 through -13 were constructed with $3 / 8$-in. aggregate concrete. TRG-14 through -16 were constructed with microconcrete (sand passing the No. 8 sieve). Before doing any severe testing, experimental modal analyses were performed on each structure. Similar experiments had been performed on TRG-4; hence, the dynamic properties of TRG-4 (resonant frequencies, mode shapes, and modal demping values) can be compared with similar properties obtained from tests on TRG-7 through -16. This information allows the scalability of dynamic properties at low excitation levels to be addressed.

TRG-12, -13 and -16 were tested in a static cyclic manner similar to the loading that TRG-4 experienced. From these tests the scalability of static response between microconcrete and 3/8-in. aggregate structures of the same size can be addressed, and results from the 1/3-scale models can be compared with similar results from the conventional concrete prototypes. 


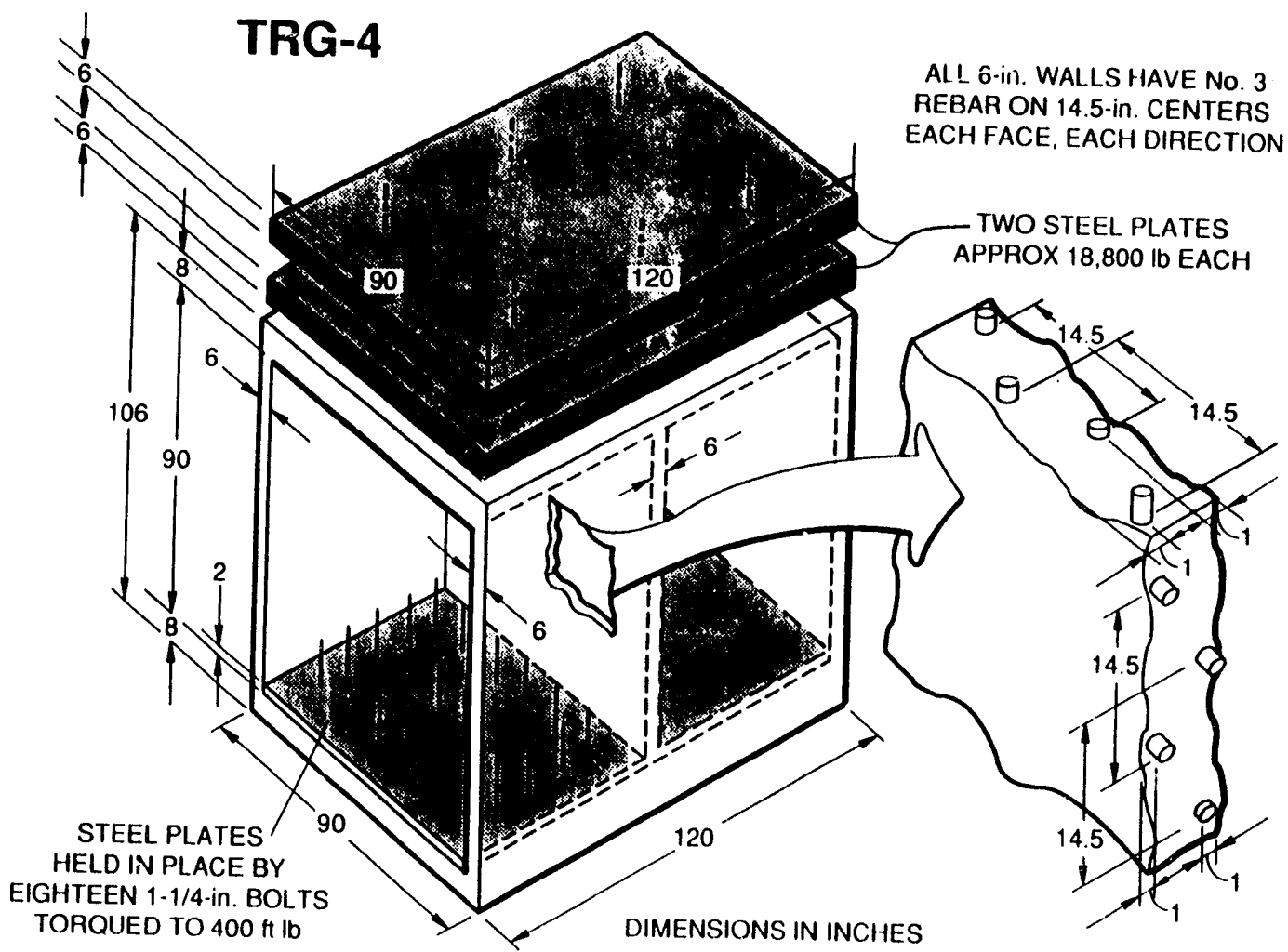

Fig. 1. TRG-4 geometry.

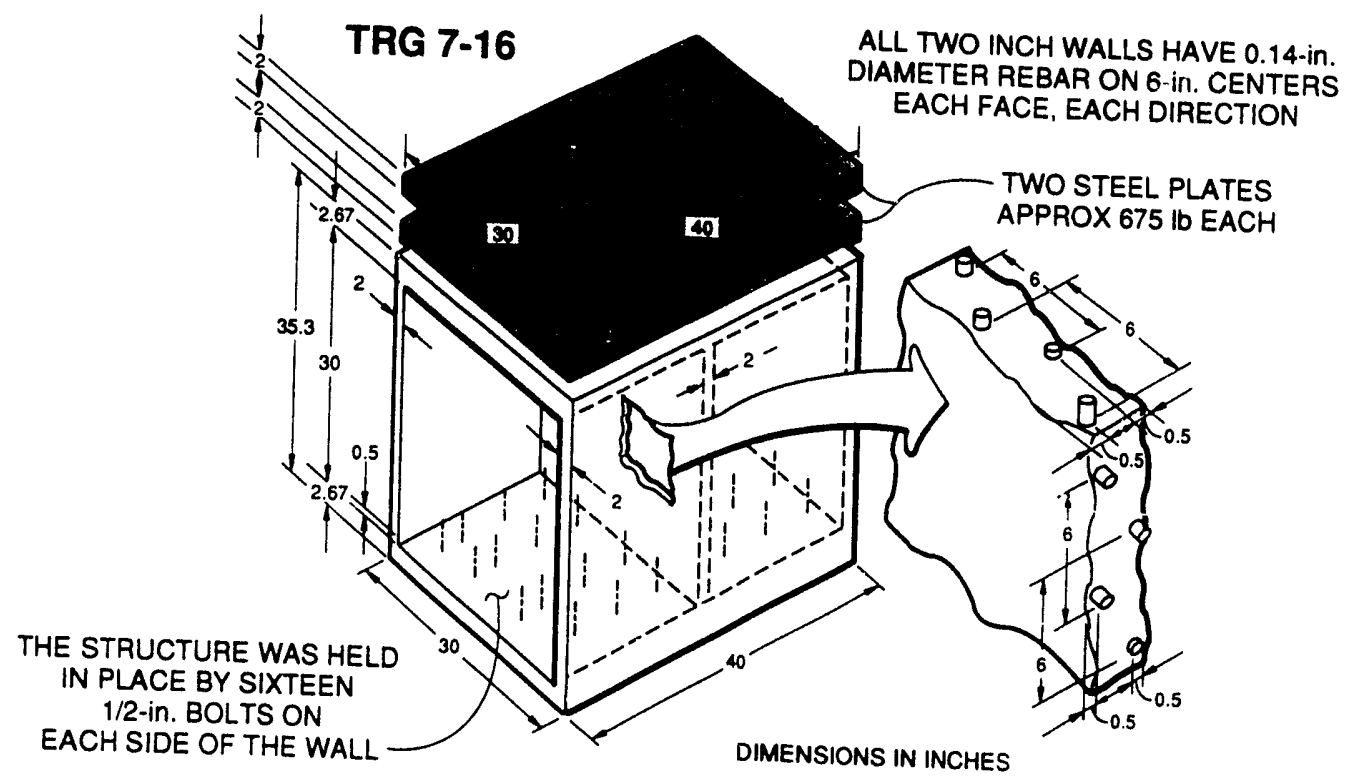

\begin{tabular}{l|c|c}
\multicolumn{1}{c|}{ STRUCTURE } & MATERIAL & TESTING \\
\hline TRG 7 THROUGH 11 & 3/8 in. AGGREGATE & S.S." \\
TRG 12 & 3/8 in. AGGREGATE & STATIC \\
TRG 13. & 3/8 in. AGGREGATE & STATIC, S.S \\
TRG 14,15 & MICROCONCRETE & S.S. \\
TRG 16 & MICROCONCRETE & STATIC
\end{tabular}

Fig. 2. TRG-7 through -16 geometry. 
TABLE I

LOS ALAMOS SEISMIC TEST FACILITY SPECIFICATIONS

Type: $\quad$ Electrodynamic, Unholtz-Dickie Model T-4000 Driver General Radio Control System

Specification:

Frequency:

Max. Force:

5 to $5000 \mathrm{~Hz}$

$36,000 \mathrm{lb}$, sinusoidal

$33,000 \mathrm{lb}$, random

Max. Velocity: 85 in./s

Max. Displacement: $\quad \pm 0.5$ in

Table:

Moment Limits

- Pitch, $4.2 \times 10^{6}$ in. Ib

- Roll, $2.7 \times 10^{6} \mathrm{in}$. Ib

- yaw, $2.4 \times 10^{6}$ in. Ib

Moving Weight: $\quad 966 \mathrm{lb} \quad$ (armature, $245 \mathrm{lb}$ ) coupler, $135 \mathrm{lb}$ table, $586 \mathrm{lb})$

TABLE II

TESTS PERFORMED ON TRG-7 THROUGH -16

Structure

Aggregate

Size

Type of Test

\begin{tabular}{|c|c|c|c|c|}
\hline Structure & $\begin{array}{l}\text { Aggregate } \\
\text { Size }\end{array}$ & $\begin{array}{l}\text { Experimental } \\
\text { Model Analysis }\end{array}$ & $\begin{array}{l}\text { Static } \\
\text { Cyclic }\end{array}$ & $\begin{array}{l}\text { Simulated } \\
\text { Seismic }\end{array}$ \\
\hline TRG-7 & 3/8-in. & Yes & No & Yes \\
\hline TRG-8 & 3/8-in. & Yes & No & Yes \\
\hline TRG-9 & 3/8-in. & Yes & No & Yes \\
\hline TRG-10 & 3/8-in. & Yes & No & Yes \\
\hline TRG-11 & 3/8-in. & Yes & No & Yes \\
\hline TRG-12 & 3/8-in. & Yes & Yes & No \\
\hline TRG-13 & 3/8-in. & Yes & Yes & Yes \\
\hline TRG-14 & Micro & Yes & No & Yes \\
\hline TRG-15 & Micro & Yes & No & Yes \\
\hline TRG-16 & Micro & Yes & Yes & No \\
\hline
\end{tabular}


TRG-7 through -11 and -13 through -15 were tested on a shake table with simulated seismic inputs. Results from these tests provide information concerning cumulative damage effects, as well as information concerning the scalability of seismic response between microconcrete structures and 3/8-in. aggregate structures of the same size. Because TRG-13 was tested first statically (without introducing damage) and then seismically, a direct comparison can be made between the static response and the dynamic response of a structure similar stress levels up to 100 psi NBSS.

\section{MODEL CONSTRUCTION AND MATERIAL PROPERTIES}

The primary conce' $n$ in the construction of these models was to build ten structures that were sound, that is, structures with no major cracking from the curing process, and that were as identical as possible. As discussed previously, these structures were intended to be 1/3-scale models of TRG-4.

Reinforcement was No. 10-gauge (0.134-in. diam) welded-wire fabric that had a nominal yield strength of 70,000 psi and that conformed to the ASTM standard for welded wire fabric [2]. Wire spacing was 6-in. by 6-in. Two layers of this mesh (one layer near each outer surface) yielded a reinforcement percentage of $0.24 \%$ by area in each direction, as compared with $0.25 \%$ used in TRG-4. The welded wire fabric was not deformed or heat treated as was the conventional reinforcement in TRG-4, but budget and time constraints precluded the use of special model rebar with these properties. The effects of the different rebar properties on the models' responses are discussed in Sec. VII. Development lengths for the reinforcement were specified such that the requirements in American Concrete Institute (ACI) $349\left[3^{*}\right]$, Sec. 12-8, were met. The two layers of welded wire fabric provided the minimum amount of reinforcement allowed by $\mathrm{ACl} 349$. TRG-4 also had the minimum amount of reinforcement allowed by $\mathrm{ACl} 349$.

As shown in Fig. 2, a minimum 0.5-in. cover was provided for all reinforcement. This would scale to $1.5 \mathrm{in}$. of cover on a prototype. Because these structures would not experience any adverse environmental conditions before or during testing, the 0.5 -in. cover was considered acceptable even though it is less than the 0.75 -in. cover specified for interior walls in ACI 349.

All ten structures were formed with Plexiglas so that the surfaces could be visually monitored during the concrete placement and compaction. Figure 3 shows the reinforcement and spacer rods inside the Plexiglas forms. Aluminum spacer rods were used to maintain proper clearances between the welded wire fabric and the forms during the concrete placement. Because these structures were to model the dynamic responses of prototype structures over the entire load range of interest, the model material was selected to have properties as similar as possible to those of the prototype structure. Table III lists the mix portions and design strengths for the 3/8-in. aggregate concrete, and Table IV provides similar information for the microconcrete.

\footnotetext{
"Unless otherwise noted, design parameters and requirements of $A C l 349$ [3] are identical to $\mathrm{ACl} 318$ [4].
} 


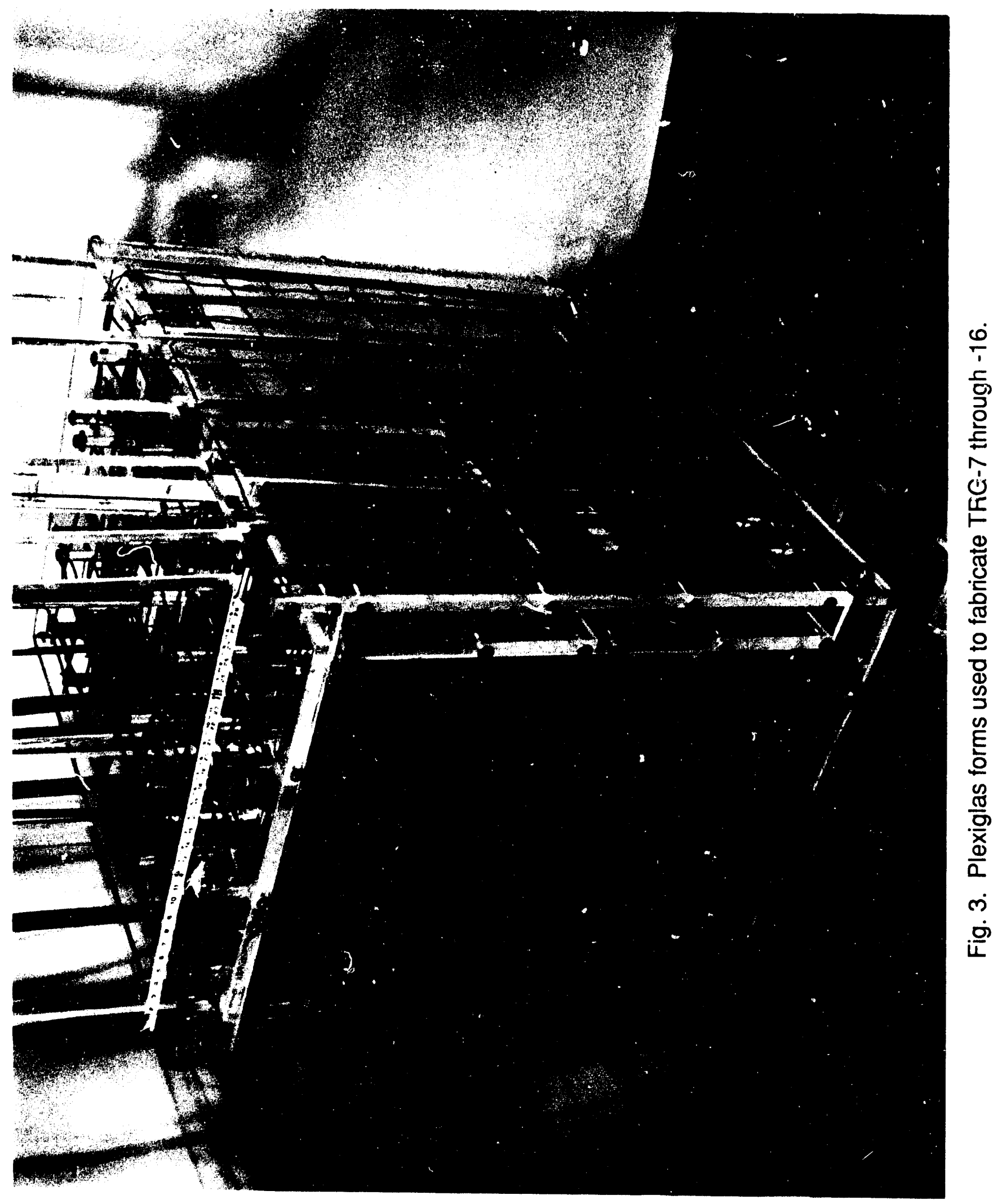


TABLE III

3/8-IN. AGGREGATE MIX PROPORTIONS

Cement, Type I-II Ideal Cement

Water

Coarse aggregate (3/8 in., max)

Fine aggregate

Design ultimate strength

Design slump
$553 \mathrm{lb} / \mathrm{yd}^{3}$

$23 \mathrm{gal} / \mathrm{yd}^{3}$

$600 \mathrm{lb} / \mathrm{yd}^{3}$

$2280 \mathrm{lb} / \mathrm{yd}^{3}$

4000 psi

5.25 in.

TABLE IV

MICROCONCRETE MIX PROPORTIONS

Cement, Type I-II Ideal cement

Water

Course aggregate

Fine aggregate ${ }^{a}$

Design ultimate strength

Design slump

$\begin{array}{rl}875 & \mathrm{lb} / \mathrm{yd}^{3} \\ 20 & \mathrm{gal} / \mathrm{yd} \mathrm{d}^{3} \\ \text { none } & \\ 2835 & \mathrm{lb} / \mathrm{yd}^{3} \\ 4000 & \mathrm{psi} \\ 3-5 & \text { in. }\end{array}$

aAll material passed the No. 8 sieve.

Prior to construction of the models, a sample of the 3/8-in. aggregate mix was ordered and 10 standard cylinders, 6 in. by 12 in., were cast. Four of these cylinders were tested for ultimate strength ( $f_{c}$ ASTM C39) [5] and modulus of elasticity ( $E_{c}$, ASTM C469) [6] after 7 curing days, and the remaining six cylinders were tested in a similar fashion after 28 curing days. Results of these tests are summarized and compared with
similar results from TRG-4 test cylinders in Table V.

In addition to placing sample cylinders, a deep beam 30 -in. long by 12 -in. deep by 2 -in. wide was cast to verify the feasibility of constructing 2 in. walls with $0.24 \%$ reinforcement and $3 / 8$-in. aggregate concrete. This beam was found to have no surface voids when the forms were removed. When the beam was tested in a three-point bending configuration after 28 days of curing, the measured stiffness was within $1 \%$ of the theoretical stiffness. In this calculation, shear defcrmation was accounted for and the average measured modulus was used. Note that tive average measured modulus ( $3.58 \times 10^{6} \mathrm{psi}$, from Table V) and the modulus calculated from the ACl empirical formula using the design ultimate strength of $4000 \mathrm{psi}\left(57,000 \sqrt{4000}=3.60 \times 10^{6} \mathrm{psi}\right)$ have less
than a $1 \%$ difference.

The concrete for TRG-7, $-8,-9$ and -11 was placed on March 6, 1989. Because of the number of technicians available and because of the limited amount of time the concrete can remain in a mixer, only two models could be placed at that time. TRG-7 and -8 were placed from the 1 cubic yard of concrete that arrived at 9:30 a.m. The slump was measured per ASTM C143 [7] and was initially found to be 1 in. A half gallon of water 
COMPARISON OF THE 3/8-IN. AGGREGATE MIX PROPERTIES WITH THE TRG-4 3/4-IN. AGGREGATE MIX PROPERTIES

\begin{tabular}{|c|c|c|c|}
\hline & & $\begin{array}{l}\text { Design } \\
\text { Values }\end{array}$ & $\begin{array}{l}\text { TRG-4 } \\
\text { Values }^{\mathrm{a}}\end{array}$ \\
\hline 7-day ultimate stı 3 ngth (psi) & $\begin{array}{l}2950 \text { avg } \\
2970 \text { high } \\
2910 \text { low }\end{array}$ & & \\
\hline 28-day ultimate strength (psi) & $\begin{array}{l}4200 \text { avg } \\
4440 \text { high } \\
3950 \text { low }\end{array}$ & 4000 & $\begin{array}{l}4150 \text { avg } \\
4560 \text { high } \\
3770 \text { low }\end{array}$ \\
\hline 7-day modulus (psi $\times 10^{-6}$ ) & $\begin{array}{l}3.01 \text { avg } \\
3.14 \text { high } \\
2.84 \text { low }\end{array}$ & & \\
\hline 28-day modulus (psi $\times 10^{-6}$ ) & $\begin{array}{l}3.58 \text { avg } \\
3.71 \text { high } \\
3.54 \text { low }\end{array}$ & $3.60^{b}$ & $\begin{array}{l}3.23 \text { avg } \\
3.71 \text { high } \\
2.96 \text { low }\end{array}$ \\
\hline
\end{tabular}

aThe TRG-4 cy linders were tested after curing for 45 days.

bComputed per $\mathrm{ACl} 349, \mathrm{E}_{\mathrm{C}}=57,000 \sqrt{\mathrm{f}_{\mathrm{C}}}$

was added to the mix, and the slump increased to 6 in. This concrete was used to place the base of each model first and was compacted with mechanical vibrators. Next, the walls were placed and compacted manually by rodding the concrete as the aluminum spacer bars were removed. TRG-7 and -8 were completely placed by 11:30 a.m.

TRG-9 and -11 were placed from ihe 1 cubic yard of concrete that arrived at 1:30 p.m. The initial slump was again approximately 1 in. An additional half gallon of water was added to the mix to bring the siump to over 4 in. Placement of these structures was carried out in a manner identical to that used for TRG-7 and -8 , and the placement was completed by 3:00 p.m.

TRG-10 was placed from the 1 cubic yard of concrete that arrived at 10:30 a.m. on March 7,1989. The initial slump was less than $1 \mathrm{in}$. Three-quarters of a gallon of water was added to the mix to bring the slump up to $5 \mathrm{in}$. Placement of this structure was again done in a manner identical to those used in the previous structures, and TRG-10 was complete by $11: 45$ a.m.

The 3/8-in. aggregate concrete for TRG-12 and -13 was placed on june 2, 1989. These structures were placed simultaneously from the 1.5 cubic yards of concrete that arrived at 9:00 a.m. The slump was initially measured at 2-1/8 in. Although this was less than the design slump, the concrete appeared to have the workability necessary to complete the placement and, hence, no additional water was added. TRG-12 and-13 were completely placed by 10:30 a.m. 
The microconcrete for TRG-14 through -16 was placed on August 10, 1989. These structures were again placed simultaneously from the 2 yards of concrete that arrived at 11:20 a.m. The slump was initially measured at 6.5 in., and no additional water was added. Placement of the microconcrete was carried out in a manner similar to the placements in all the previous structures. Placemement was completed at 12:40 p.m.

No defects were noticed on the surface of the models after the compaction was complete. However, shrinkage cracks were noticed in the end walls of all the structures after the forms were removed. The shrinkage cracking was much more pronounced in the microconcrete structures. All models were left in their forms for a 28-day curing period and exposed surfaces were kept moist and covered with a tarp.

During the placements, 15 standard 6 -in.-diam by 12 -in.-high test cylinders were taken per ASTM C172 [8] and ASTM C31 [9]. Fifteen 2-in.-diam by 4-in. high test cylinders were also made to see whether curing of the thinner cylinders had a noticeable effect on the measured mechanical properties. Both sets of cylinders were left in their molds and cured with the models for 28 days. Tests on the cylinders included ultimate compressive strength, modulus of elasticity, and split cylinder tensile strength (ASTM C496) [10]. Because TRG-12 and -13 were placed simultaneously, one set of cylinders (6-in. or 2-in.) is assumed to be representative of bisth structures. TRG-14, -15 and -16 were also poured simultanecusly; therefore, one set of cylinders is also assumed to be representative of these three stiuctures. The 6-in.-diam cylinders were tested by Western Technologies, Inc., in Alt,uquerque, New Mexico and the 2-in.-diam cylinders were tested by students in the Mechanical Engineering Department at the University of New Mexico under the superyision of Dr. William Baker, a consultant to this program. Table VI summarizes the results of the cylinder tests and compares these results with the results from TRG-4 tests. From each group of 15 cylinders (either the 6 -in. or 2-in.) 9 were tested for ultimate strength and modulus, and 5 were tested for split cylinder tensile strength. The consistently higher ultimate strengths measured on the 2-in.-diam cylinders were attributed to the care taken in applying a uniaxial load to the specimen. With these smaller cylinders greater care could be taken in capping the specimens and, hence, the effect of loading anomalies was minimized.

\section{EXPERIMENTAL MODAL ANALYSES}

Experimental modal analyses were performed on TRG-7 through - 16 before the simulated seismic or static, cyclic testing. In this context experimental modal analysis refers to the procedure whereby a measured excitation (random, sine, or impact force) is applied to a structure and the structure's response (acceleration, velocity, or displacement), is measured at discrete locations that are representative of the structure's motion. Both the excitation and the response time histories are transformed into the frequency domain so that modal parameters (resonant frequencies, mode shapes, modal damping) can be determined by curve fitting the measured frequency domain data to a Laplace domain representation of the equations of motion [11]. These tests were performed to demonstrate that the dynamic properties of these structures can be accurately 
TABLE VI

MEASURED MATERIAL PROPERTIES

6-in-Diam Cylinders

\begin{tabular}{cccc}
\hline Average & Average & Average & Average \\
$f_{C}$ & Measured & $E_{c}=57,000 \sqrt{f_{C}^{\prime}}$ & Tensile \\
& $E_{c}$ & & Strength \\
$(p s i)$ & $\left(p s i \times 10^{-6}\right)$ & $\left(p s i \times 10^{-6}\right)$ & $(p s i)$
\end{tabular}

$\begin{array}{lcccc}\text { TRG-4 } & 4150 & 3.23 & 3.67 & 360 \\ \text { TRG-7 } & 3860 & 3.33 & 3.54 & 420 \\ \text { TRG-8 } & 3970 & 3.17 & 3.59 & 420 \\ \text { TRG-9 } & 3340 & 3.11 & 3.29 & 380 \\ \text { TRG-10 } & 3870 & 3.24 & 3.64 & 380 \\ \text { TRG-11 } & 3260 & 2.96 & 3.25 & 390 \\ \text { TRG-12,-13 } & 4070 & 3.75 & 3.64 & 450 \\ \text { TRG-14,-15,-16 } & 5800 & 3.38 & 4.34 & 480 \\ \text { Design } & 4000 & -- & 3.60 & -- \\ & & & & \\ & & \text { in. Diam Cylinders } & & 420 \\ \text { TRG-7 } & & 3.31 & 4.11 & 440 \\ \text { TRG-8 } & 5210 & 3.19 & 3.93 & 490 \\ \text { TRG-9 } & 4760 & 3.27 & 3.89 & 390 \\ \text { TRG-10 } & 4650 & 3.00 & 3.81 & 430 \\ \text { TRG-11 } & 4460 & 2.95 & 3.70 & 470 \\ \text { TRG-12,-13 } & 4210 & 4.00 & 4.06 & 580 \\ \text { TRG-14,-15,-16 } & 5070 & 3.62 & 4.48 & -- \\ \text { Design } & 6170 & -- & 3.60 & \end{array}$

predicted at very low excitation levels by finite element analysis. Also, because a similar test was performed on TRG-4, results from these tests can be used to examine the scalability of the dynamic properties.

Test conditions that were used with TRG-4 (see [1]) were duplicated or, when appropriate, scaled to make the experimental modal analyses as identical as possible. TRG-7 through - 16 were supported with four air bearings under their base to simulate free-boundary conditions, as shown in Fig. 4. Free-boundary conditions were chosen because they can be most easily and accurately obtained during experiments; hence, these test results are best for comparison with analytical results from finite element analysis (FEA).

A 100-lb-peak force shaker was attached to the base of the structures midway between the end of the wing wall and the shear wall using a thin rod that transmits primarily axial force (stinger), as shown in Fig. 5. A transducer, located between the stinger and the model measured force as the input quantity. A random excitation signal with a uniform power spectral density between $\mathrm{O} \mathrm{Hz}$ and $600 \mathrm{~Hz}$ was used to drive the 


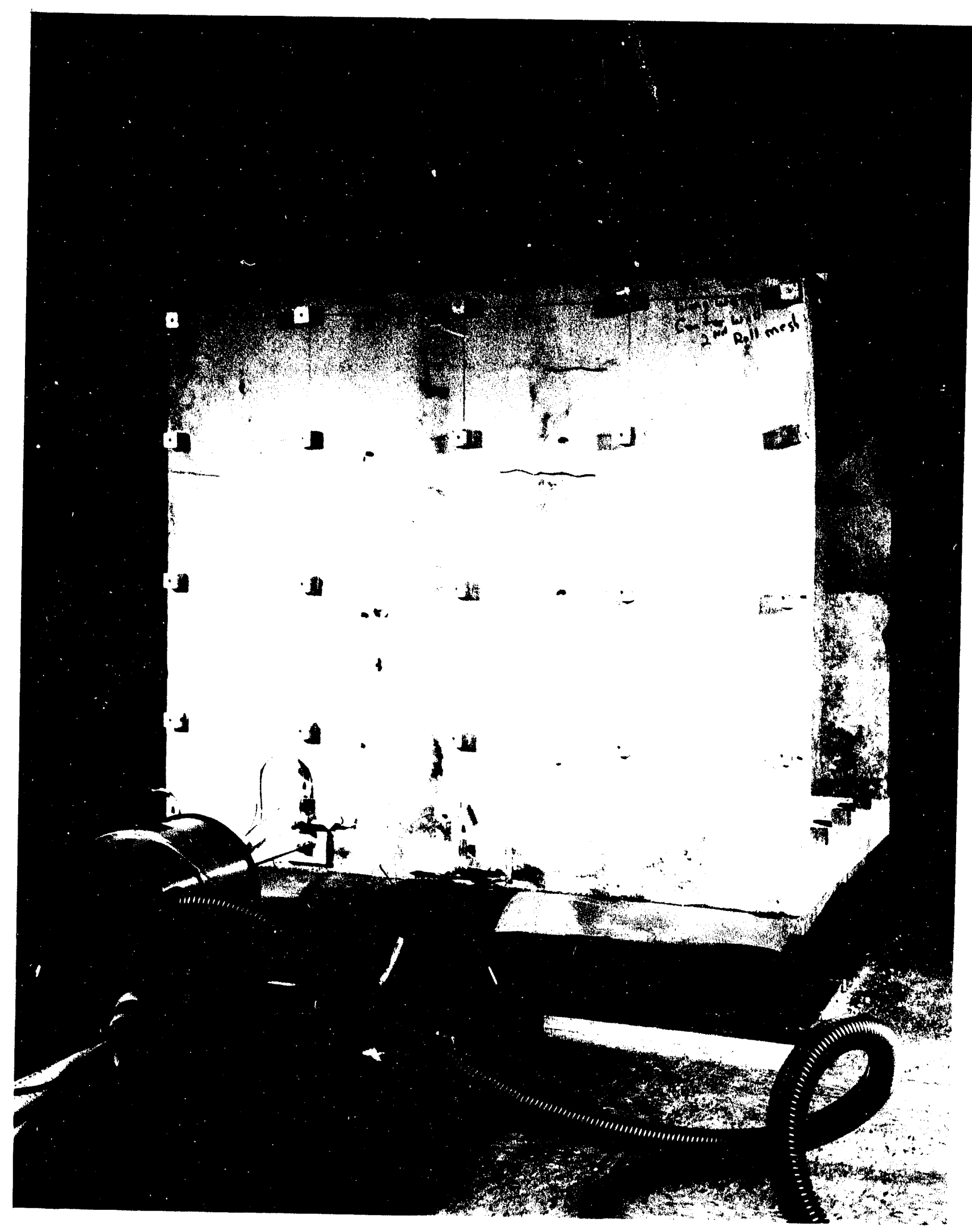

Fig. 4. Experimendtal modal analysis test set-up. 


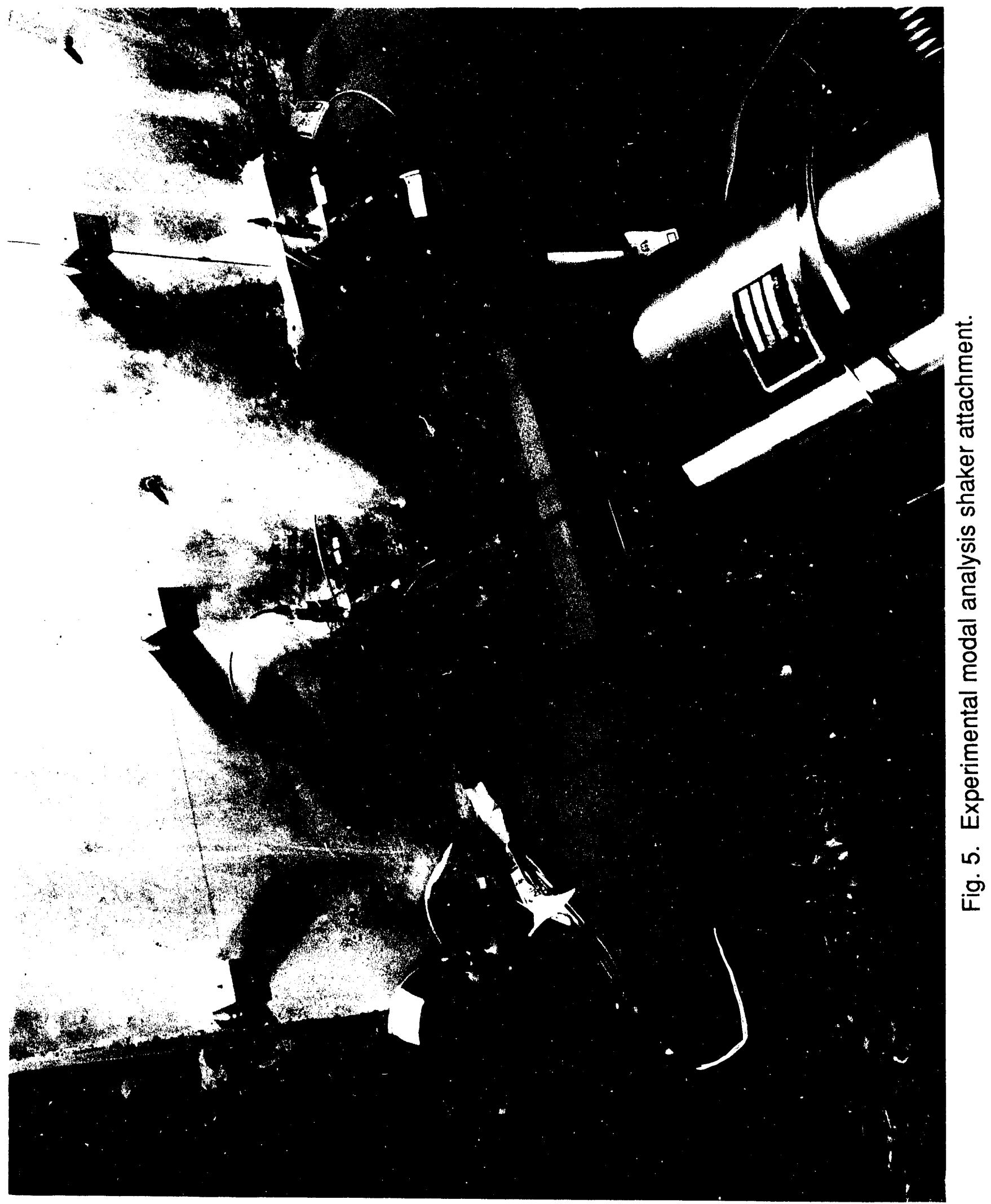


shaker. Acceleration response was measured in three orthogonal directions at 89 points on the structure. The excitation point and measurement points are shown in

Fig. 6 (some of the measurement points are not visible because of hidden line removal).

A finite element analytical modal analysis was also run for comparison with the experimental modal analysis. Half the structure was modeled. Free boundany conditions were specified at the base, and appropriate boundary conditions were applied along the plane of symmetry so that all modes below $600 \mathrm{~Hz}$ could be identified. The undeformed mesh and the first three modes are shown in Fig. 7. A direct comparison between an experimentally identified mode and FEA mode is shown in Fig. 8.

Table VII summarizes the results from the experimental modal analysis for the first five modes. Included in this table are the results from the finite element analysis using the design modulus of elasticity, $3.6 \times 10^{6} \mathrm{psi}$. In Table VIII the experimental modal analysis results are compared with the results from TRG-4. In this table, the modal frequencies have been normalized to a modulus of elasticity of $3.23 \times 10^{6} \mathrm{psi}$, the average measured modulus for TRG-4. As an example, the average measured modulus from the $6 \times 12$ cylinders for TRG-12 was $3.75 \times 10^{6} \mathrm{psi}$; hence, the normalizing factor would be $\left(3.23 \times 10^{6} / 3.75 \times 10^{6}\right)^{1 / 2}$. All modal frequencies measured on TRG-12 were multiplied by this factor for comparison with the TRG-4 results. In addition, the frequency scale of onethird was applied to the normalized frequencies measured on TRG-7 through -16 for direct comparison with the TRG-4 results.

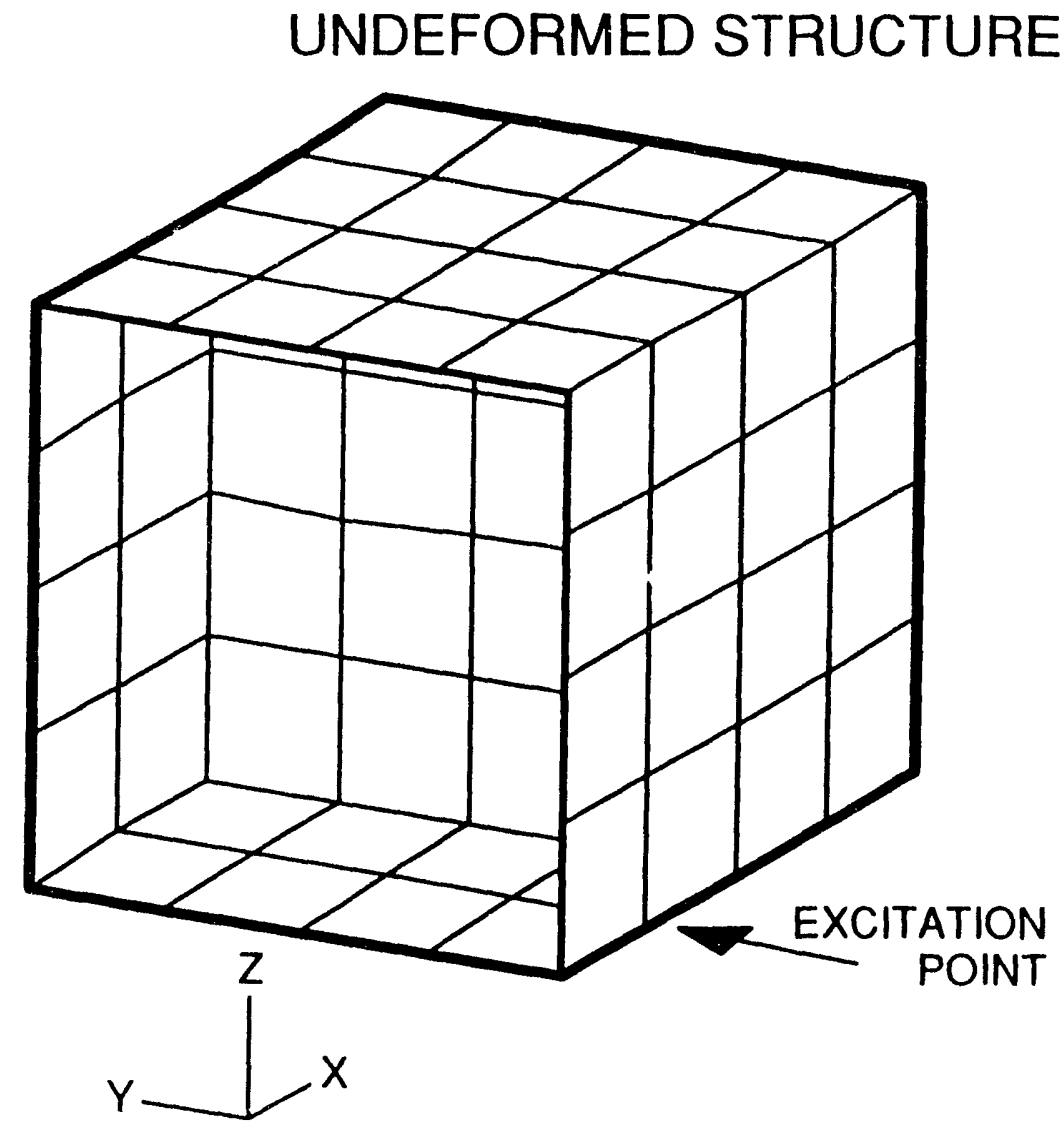

Fig. 6. Experimental modal analysis measurement points. 


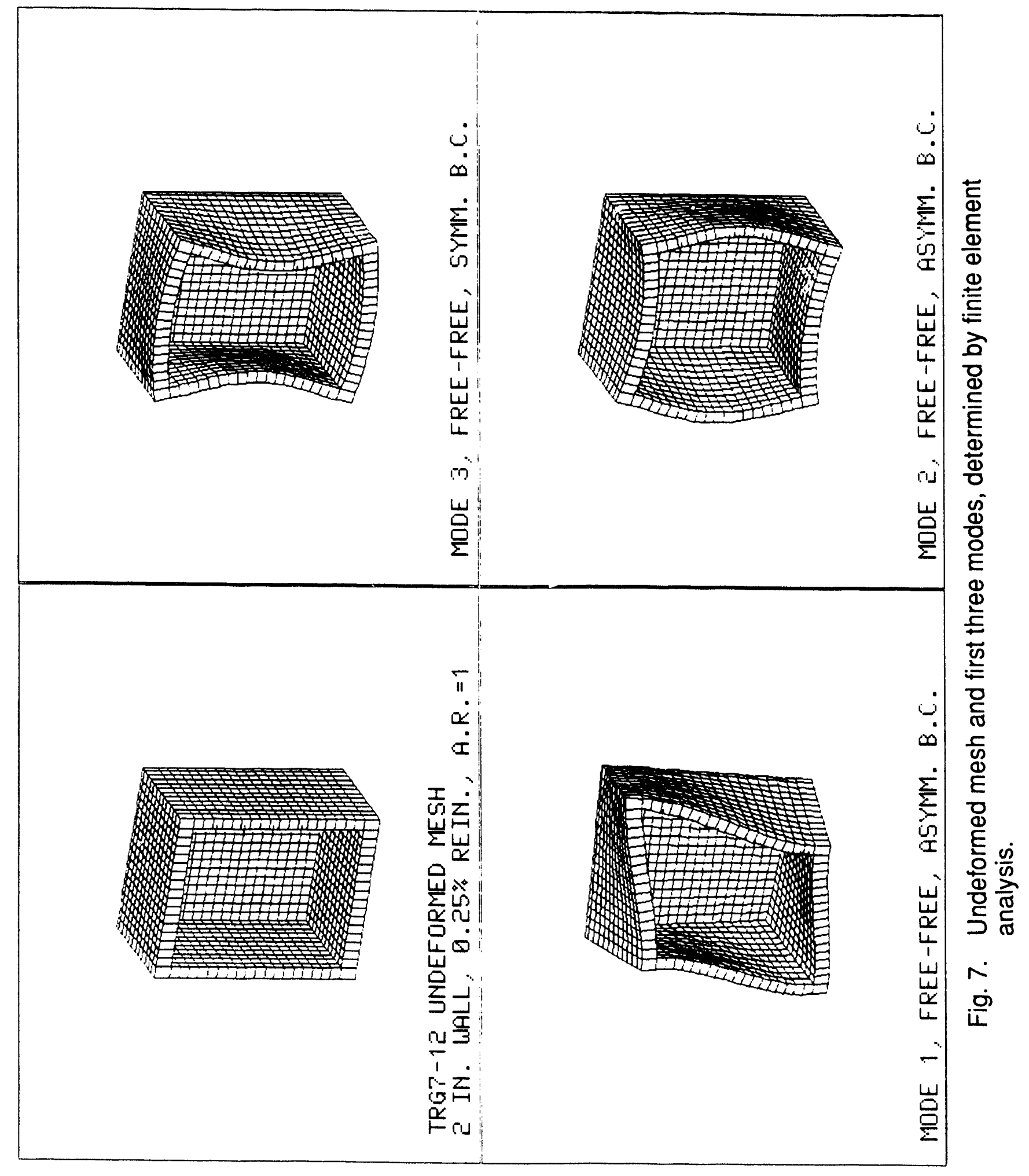




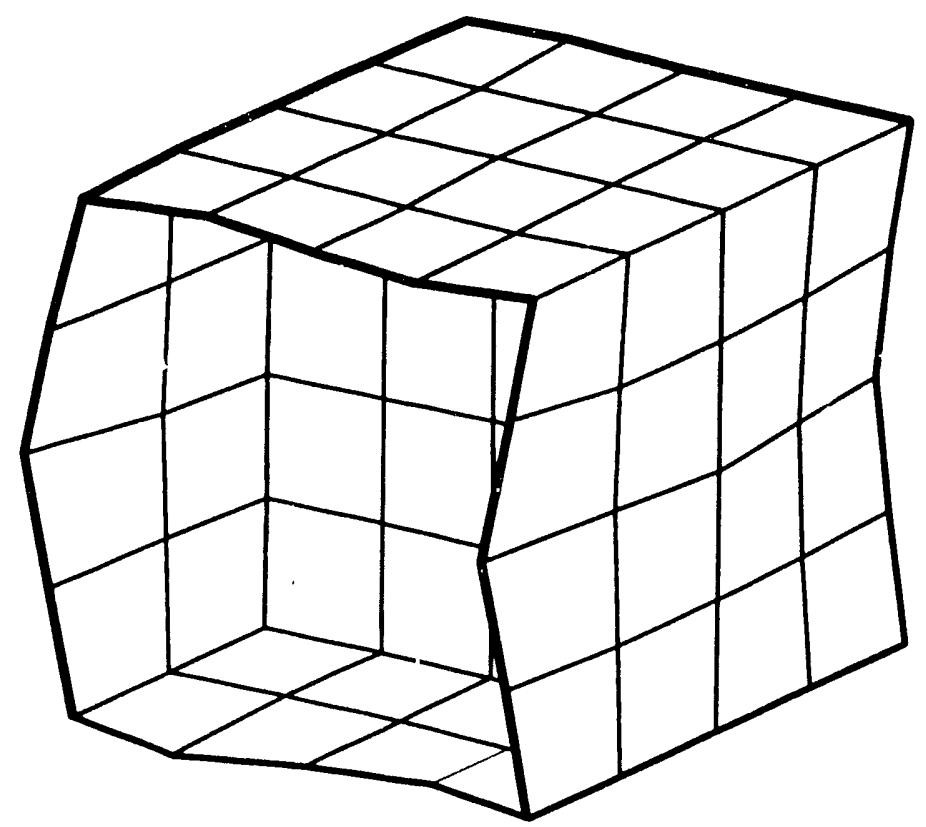

MODE No. 5

EXPERIMENTALLY DETERMINED

Freq $=362 \mathrm{~Hz}$

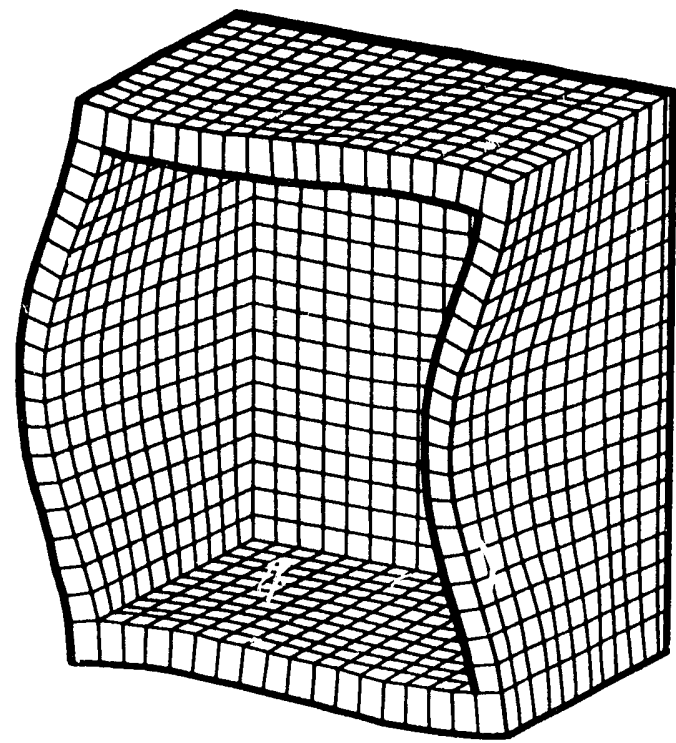

MODE No. 5

DETERMINED FROM FINITE ELEMENT ANALYSIS

USING E!ASTICITY

DESIGN MODULUS

Freq $=303 \mathrm{~Hz}$

Fig. 8. Comparison of the experimentally measured mode shape with the corresponding mode, determined by finite element analysis for TRG-12.

Table VIII compares the average results measured on TRG-7 through -16, after the appropriate normalizing and scaling factors have been applied. No scale factor was applied to the modal damping results. From the results in Table VIII it is evident that both the microconcrete and the $3 / 8$-in. aggregate, 1/3-scale models accurately simulate the modal frequencies of the prototype structure. The maximum difference in the modal frequencies was in mode 1 , a $5.7 \%$ difference for the $3 / 8$-in. aggregate models and a $7.0 \%$ difference for the microconcrete models.

In terms of percent error, the modal damping estimates appear to be significantly different between the models and the prototype. If TRG-7 through -16 are accurate models of TRG-4, and if the damping mechanism is structural or hysteretic (displacement dependent), no distortion in the damping ratio would be expected, that is, the damping scale factor is 1, see [12]. For a viscous damping mechanism the scale factor would be

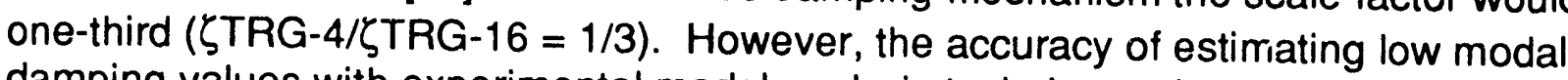
damping values with experimental modal analysis techniques depends on the frequency resolution of the frequency response function measurement. Because the frequency resolution was not scaled between the tests on TRG-7 through -16 and the 


$$
\begin{aligned}
& \text { 岀 인 }
\end{aligned}
$$

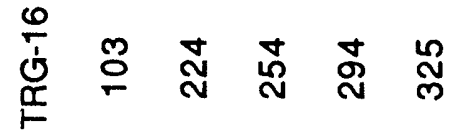

$$
\begin{aligned}
& \text { 영 }
\end{aligned}
$$

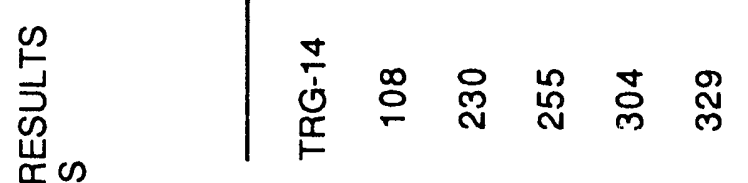

$$
\begin{aligned}
& \text { 舟点 } \\
& \text { के } \\
& \text { 运崖 }
\end{aligned}
$$

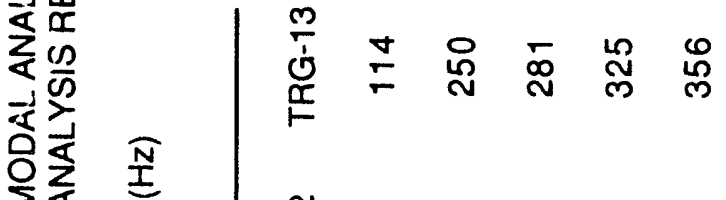

$$
\begin{aligned}
& \text { ¡ } \sum \sum \\
& \text { 荘芯志 }
\end{aligned}
$$

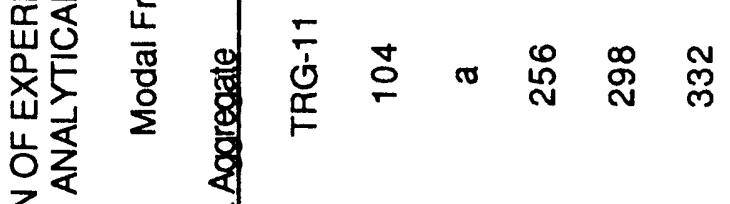

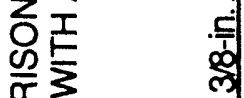

$$
\begin{aligned}
& \text { 윰 } \\
& \text { 界 }
\end{aligned}
$$

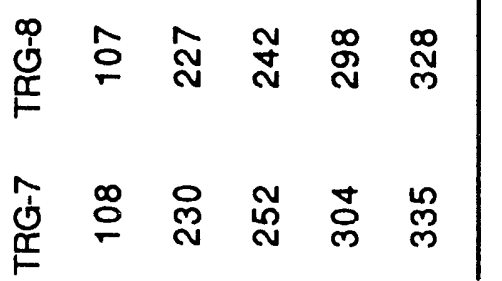

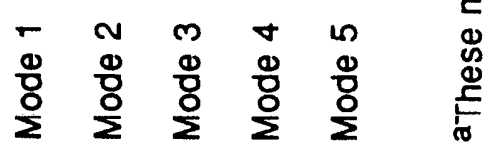


TABLE VIII

COMPARISON OF SCALED EXPERIMENTALLY MEASURED MODAL FREQUENCIES AND UNSCALED EXPERIMENTALLY MEASURED MODAL DAMPING VALUES FROM TRG-7 THROUGH -16 TO MEASURED MODAL FREQUENCIES AND DAMPING VALUES FROM TRG-4

\begin{tabular}{ccc} 
& \multicolumn{2}{c}{ 3/8-in. Aqaregate } \\
Mode & $\begin{array}{c}\text { Avg. } \\
\text { Avg. } \\
\text { Modal } \\
\text { Frequency } \\
(H z)\end{array}$ & $\begin{array}{c}\text { Modal } \\
\text { Damping } \\
\text { (\% of } \\
\text { Critical) }\end{array}$ \\
\cline { 2 - 3 } 1 & 35.0 & 1.0 \\
2 & 76.1 & 1.0 \\
3 & 83.3 & 1.0 \\
4 & 99.3 & 1.1 \\
5 & 109. & 1.1
\end{tabular}

Micreconcrete

\begin{tabular}{cl} 
Avg. & \multicolumn{1}{c}{ Avg. } \\
Modal & \multicolumn{1}{c}{ Damping } \\
Frequency & $(\%$ of \\
$(H z)$ & Critical) \\
\hline
\end{tabular}

1.2

1.6

1.1

1.1

1.5
TRG-4

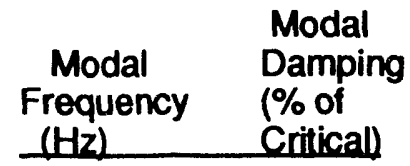

$\begin{array}{cl}37.1 & 1.4 \\ 79.2 & 0.67 \\ 88.3 & 0.77 \\ 100 . & 0.79 \\ 111 . & 0.73\end{array}$

tests on TRG-4, significant distortion in the modal damping estimates was possible. At these levels of damping, predictions of the protoiype structure's response would not be adversely affected by the distortions in the damping coefficients.

A visual inspection of the animated mode shapes measured on the models and prototype (TRG-4) shows that the mode shapes are also accurately predicted by the 1/3scale models. Figure 9 compares the first mode measured on TRG-12 to the first mode measured on TRG-4.

\section{SELECTION OF INPUT-SIGNAL, TIME-SCALE, AND AMPLITUDE LEVELS FOR THE SIMULATED SEISMIC TESTS}

Because the mass has been scaled geometrically (that is, mass is scaled by the length scale cubed), the structures used in these tests will be Case 1 models of the TRG4 structures [12]. The length scale, $N_{h}$, is defined as

$$
N_{h}=\frac{L_{p}}{L_{m}},
$$

where $L_{p}$ and $L_{m}$ are length in the prototype and model, respectively. For this test series, $N_{h}=3$. Accelerations are scaled by the reciprocal of the length scale $\left(N_{h}\right)$, that is, the acceleration scale $\left(\mathrm{N}_{\ddot{\mathrm{x}}}\right)$ is defined as

$$
N_{\ddot{x}}=\frac{\text { Prototype Acc. }\left(\ddot{X}_{p}\right)}{\text { Model Acc. }\left(\ddot{X}_{m}\right)}=\frac{1}{N_{h}}
$$




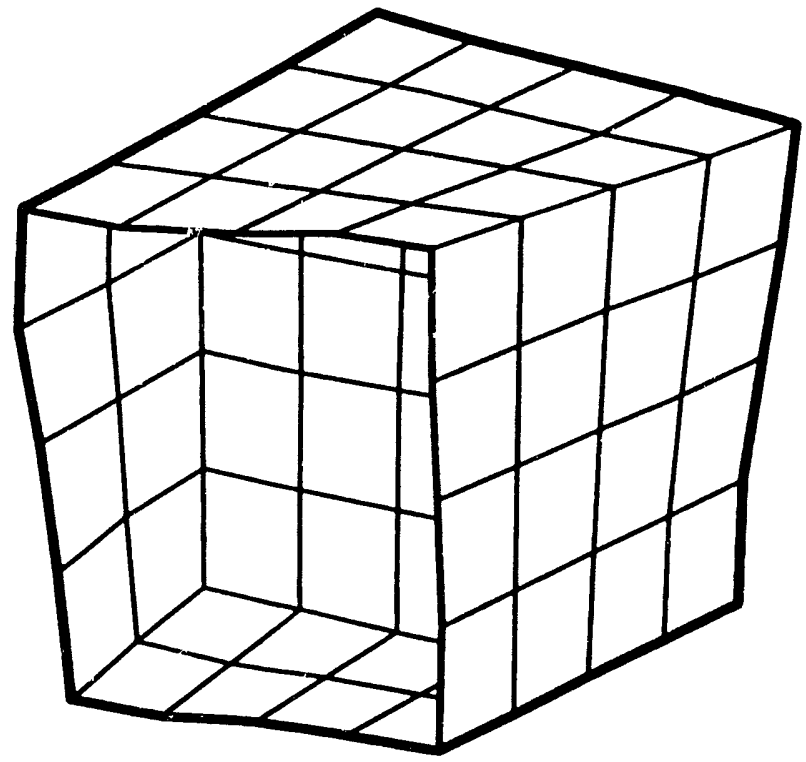

MODE 1 MEASURED ON TRG-12

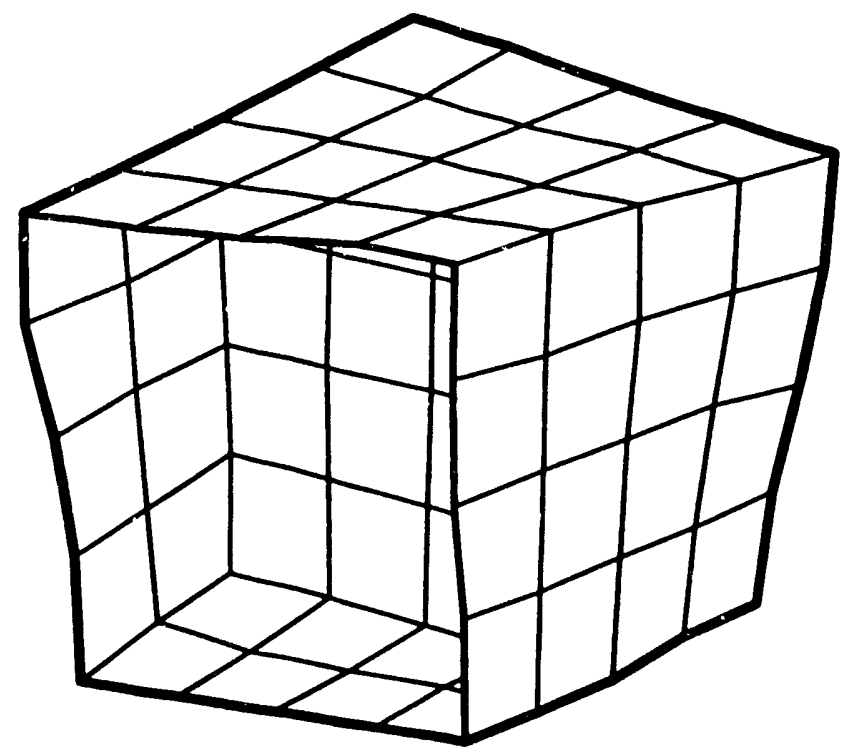

MODE 1 MEASURED ON TRG-4

Fig. 9. Comparison of the first modes mesured on TRG-4 with the first mode measured on TRG-12.

Forces (except for gravity forces) are scaled as the length scale squared, that is,

$$
N_{\mathrm{F}}=F_{\mathrm{p}} / F_{\mathrm{mi}}=N_{h}^{2} .
$$

where $N_{F}$ is the force scale,

$F_{p}$ is force acting on the protytype, and

$F_{m}$ is force acting on the model.

Time is scaled as the length scale,

$$
N_{T}=T_{p} / T_{m}=N_{h},
$$

where $N_{T}$ is the time scale,

$T_{p}$ is the time associated with the prototype, and

$T_{m}$ is the time associated with the model.

Finally, frequency is scaled by the reciprocal of the length scale

$$
N_{f}=f_{p} / f_{m}=1 / N_{h} \text {. }
$$


where $N_{f}$ is the frequency scale,

$f_{p}$ is the frequency of the prototype, and

$f_{f i n}$ is the frequency of the model.

Using these scale factors, the behavior of these new test structures can be predicted from the static and modal test results obtained from the TRG-4 structure.

Results from the TRG-4 tests are shown in Table IX, together with the predicted values from the 1/3-scale model structures tc be used in the current tests.

The predicted ultimate and first cracking loads can be used to establish the acceleration levels in the current test series. For example, with seismic excitations sufficient to produce a peak acceleration of $4.8 \mathrm{~g}$ 's, the test structures are expected to experience cracking, and at $8.52 \mathrm{~g}$ 's the structure is expected to fail.

\section{TABLE IX}

\section{TRG-4 TEST RESULTS AND PREDICTED 1/3-SCALE} MODEL TEST RESULTS

Modal frequencies

(free-free boundary

conditions, no added mass)

First cracking load, $F_{\text {cr }}$

Top mass acceleration to produce $F_{\text {cr }}$ (steel plates

attached)

Ultimate load, $F_{\text {ult }}$

(per ACl 349-85)

Top mass acceleration to produce $F_{\text {ult }}$

$$
\begin{aligned}
& \frac{\text { IRG-4 }}{f_{1}=37.1 \mathrm{~Hz}} \\
& f_{2}=79.2 \mathrm{~Hz} \\
& f_{3}=88.3 \mathrm{~Hz}
\end{aligned}
$$

$71,000 \mathrm{lb}$

$1.6 \mathrm{~g}$ 's

$126,000 \mathrm{lb}$

$2.84 \mathrm{~g}$ 's
$14,000 \mathrm{Ib}^{\mathrm{C}}$

1/3-Scale Models

$f_{1}=111.3 \mathrm{~Hz}^{\mathrm{a}}$

$f_{2}=237.6 \mathrm{~Hz}^{\mathrm{a}}$

$f_{3}=264.9 \mathrm{~Hz}^{\mathrm{a}}$

$7990 \mathrm{lb}^{\mathrm{b}}$

$4.8 \mathrm{~g}$ 's

$8.52 \mathrm{~g}$ 's

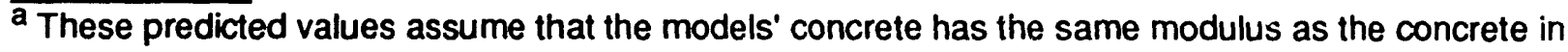
TRG-4.

b This prediction assumes that the models' concrete has the same tensile strength as the concrete in TRG-4.

$c^{c}$ In addition to $a$ and $b$, the assumption is made that the stress-strain characteristics of the reinforcement are identical in the model and the prototype. 
After the proposed test structure had been scaled to match the capabilities of the seismic test facility, the next step was to select the appropriate frequency scale factor to be applied to the selected test signal (the $1940 \mathrm{El}$ Centro, N-S, acceleration-time history). Had the assumed prototype (TRG-4) been seismically tested, scaling the seismic signal used during the prototype test would have been a straightforward matter. However, the assumed prototype was not seismically tested, so a less direct approach to time and frequency scale selection was required.

A response spectrum plot of the 1940 El Centro, N-S, acceleration history for $5 \%$ damping (Fig. 10) shows that, for this signal, maximum response is experienced in structures that have a resonant frequency in the range of 2 to $3 \mathrm{~Hz}$. Using standard analysis procedures that do not account for stiffness reduction, typical Category I shear wall structures are found to have a first-mode frequency approximately 3 to 4 times this frequency of maximum response.

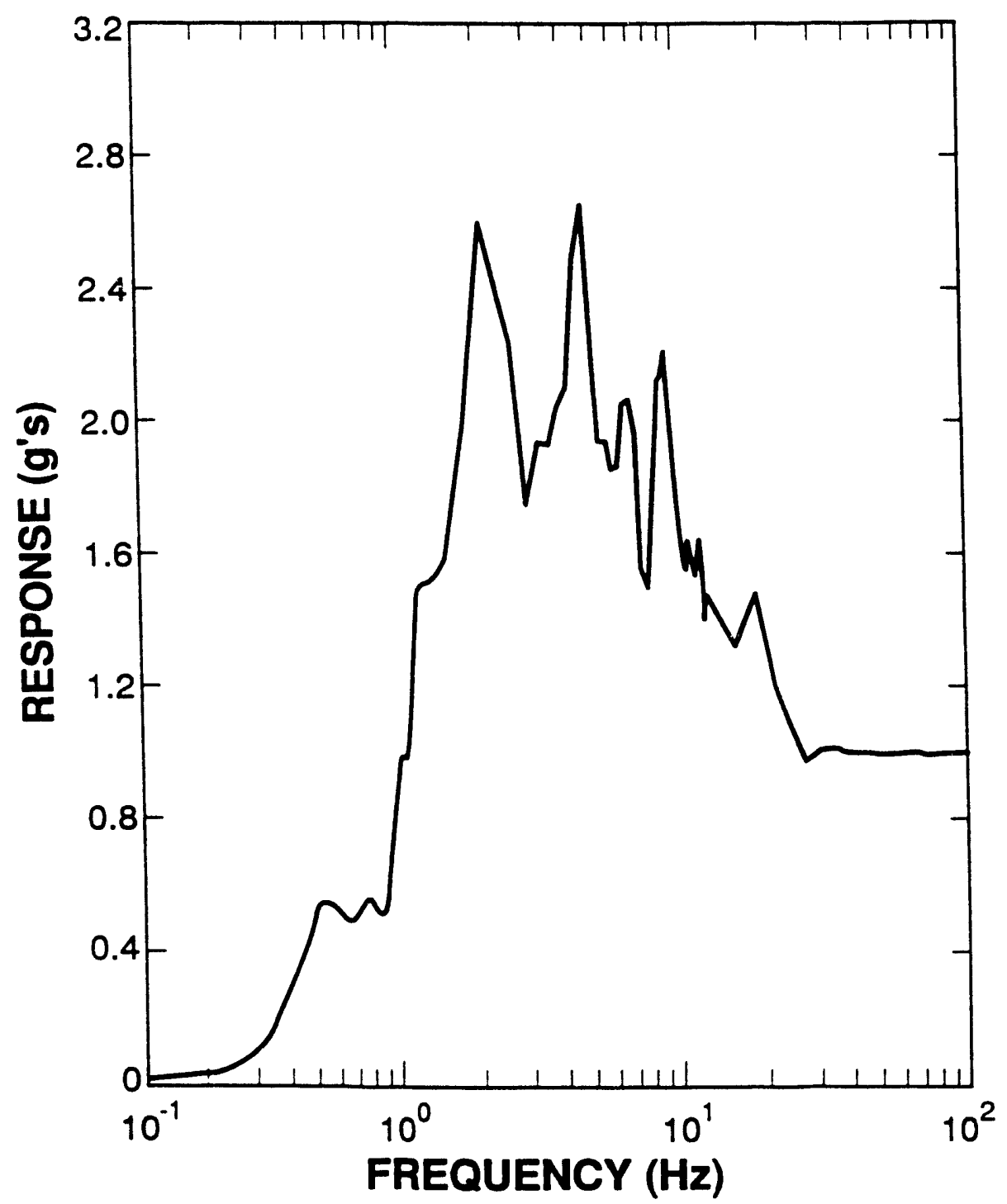

Fig. 10. Response spectrum for the north-south component of the $1940 \mathrm{El}$ Centro earthquake normalized to $1 \mathrm{~g}$. 
Therefore, it is assumed that a realistic seismic test will require the seismic input to be frequency-scaled so that the test structure's design, first-mode frequency, will be approximately 3 times the test signal frequency of maximum response. For the structure shown in Fig. 2, with the top mass attached and the base clamped, the first-mode frequency, as determined by FEA, is $102 \mathrm{~Hz}^{*}$ if we assume that the concrete modulus is 3.6 $\times 10^{6} \mathrm{psi}$ (see the Section III discussion on material selection). Therefore, the seismic signal should be frequency-scaled so that the frequency of maximum acceleration response is approximately $34 \mathrm{~Hz}(102 / 3)$. This suggests frequency-scaling the $1940 \mathrm{EI}$ Centro, $\mathrm{N}$-S signal by a factor of $12\left(N_{f}=12\right)$ to produce a maximum response in the frequency range of $24 \mathrm{~Hz}(2 \mathrm{~Hz} \times 12)$ to $36 \mathrm{~Hz}(3 \mathrm{~Hz} \times 12)$. Therefore, the time duration of the base motion seismic signal would be is scaled by a factor of $1 / 12$, and the acceleration amplification for a $102-\mathrm{Hz}$ structure would be approximately 1.7 (assuming $5 \%$ damping). (See Fig. 12.)

With these values, a matrix of simulated seismic tests was constructed that brackets the load level necessary to produce first cracking in the test structures. This matrix is shown in Table $X$. The virgin condition tests on each of the seven structures are Tests 1,5 , 8 , and 10 . Note that TRG-11 was initially subjected to a load equal to its ultimate load, as calculated by $\mathrm{ACl} 349-85$ in Test 10 .

Because the first cracking load will be developed by a base input with a peak acceleration of $2.82 \mathrm{~g}$ 's (that is, $4.8 / 1.7$, where 1.7 is assumed amplification), TRG-9 should be initially tested (Test 5 ) to just under the load required to produce first cracking. TRG-10 should be initially tested (Test 8 ) to just above the load required to produce first cracking.

Comparison of the measured results (modal frequency and damping) from Tests 1 , 5,8 , and 10 should demonstrate the differences in response of virgin structures to seismic events of different magnitudes. A comparison of results from Tests 2 and $5 ; 3,6$, and 8 ; or $4,7,9$, and 10 should demonstrate the cumulative damage effects.

Finally, having developed a test matrix, it was necessary to compare the required test conditions to the capabilities of the test facility. The simulated seismic signal (1940 El Centrol, $N-S$, scaled by a factor of 12 ) is shown in Fig. 13. From Fig. 14 the maximum velocity required is $3.16 \mathrm{in} . / \mathrm{s} / \mathrm{g}$ base acceleration. From Fig. 15 the maximum displacement required is $0.069 \mathrm{in} . / \mathrm{g}$ base acceleration. Therefore, tests to $8.5 \mathrm{~g}$ 's peak top acceleration (Tests $4,7,9$, and 10 in Table $X$ ) will require system base acceleration, velocity, and displacement capabilities of $5 \mathrm{~g}$ 's (8.5 g's/1.7), $15.8 \mathrm{in.} / \mathrm{s}$ (3.16 in./s/g's $x$ $5 \mathrm{~g}$ 's), and 0.34 in. (0.068 in. $/ \mathrm{g} \times 5 \mathrm{~g}$ 's), respectively. The required velocity and displacements are well within the system's limits (see Table I).

\footnotetext{
"Figure 11 shows the finite element model and the first mode corresponding to a fixedbase boundary condition with the top steel plates in place for the TRG-7 through - 16 test structures.
} 


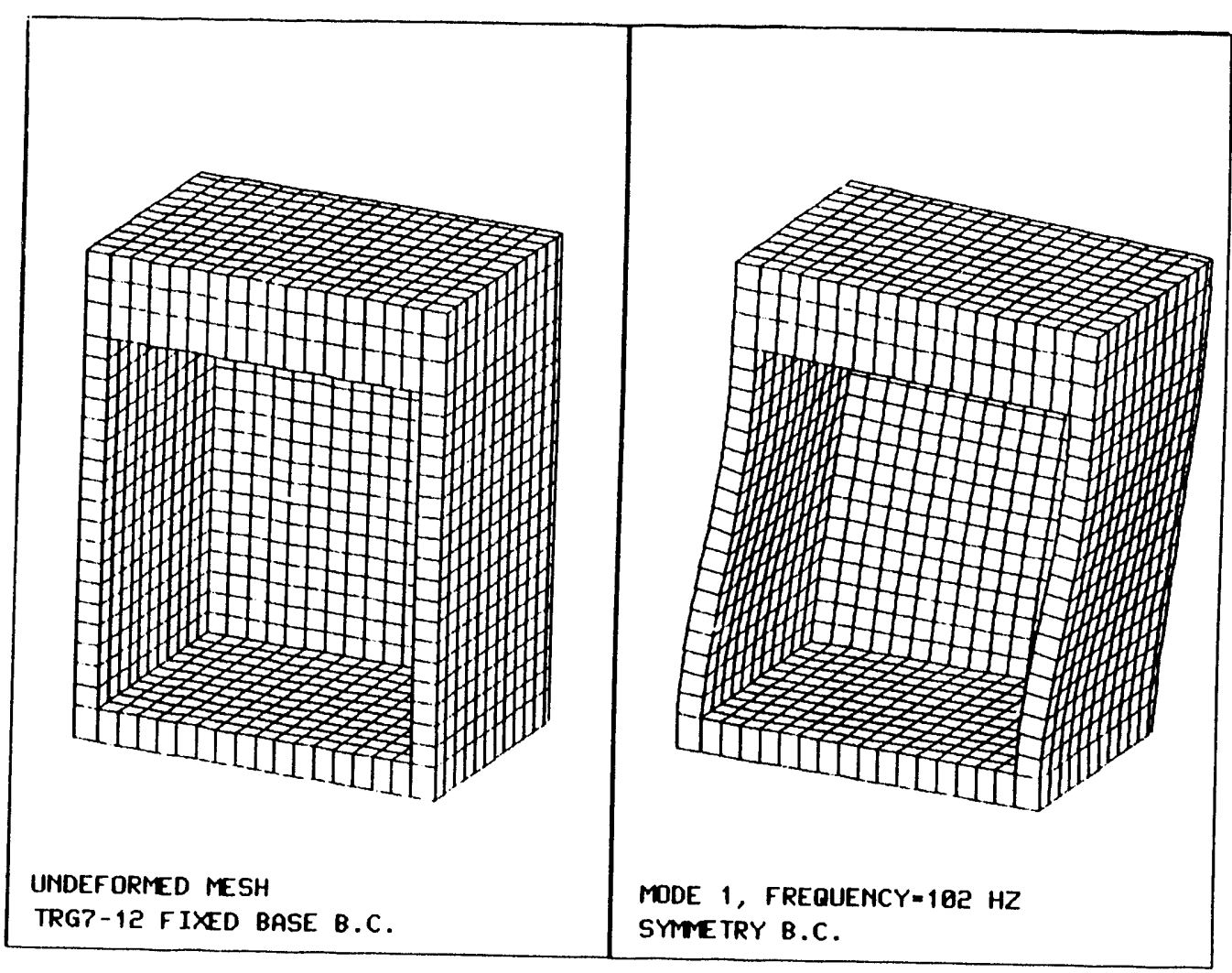

Fig. 11. First mode identified by finite element analysis.

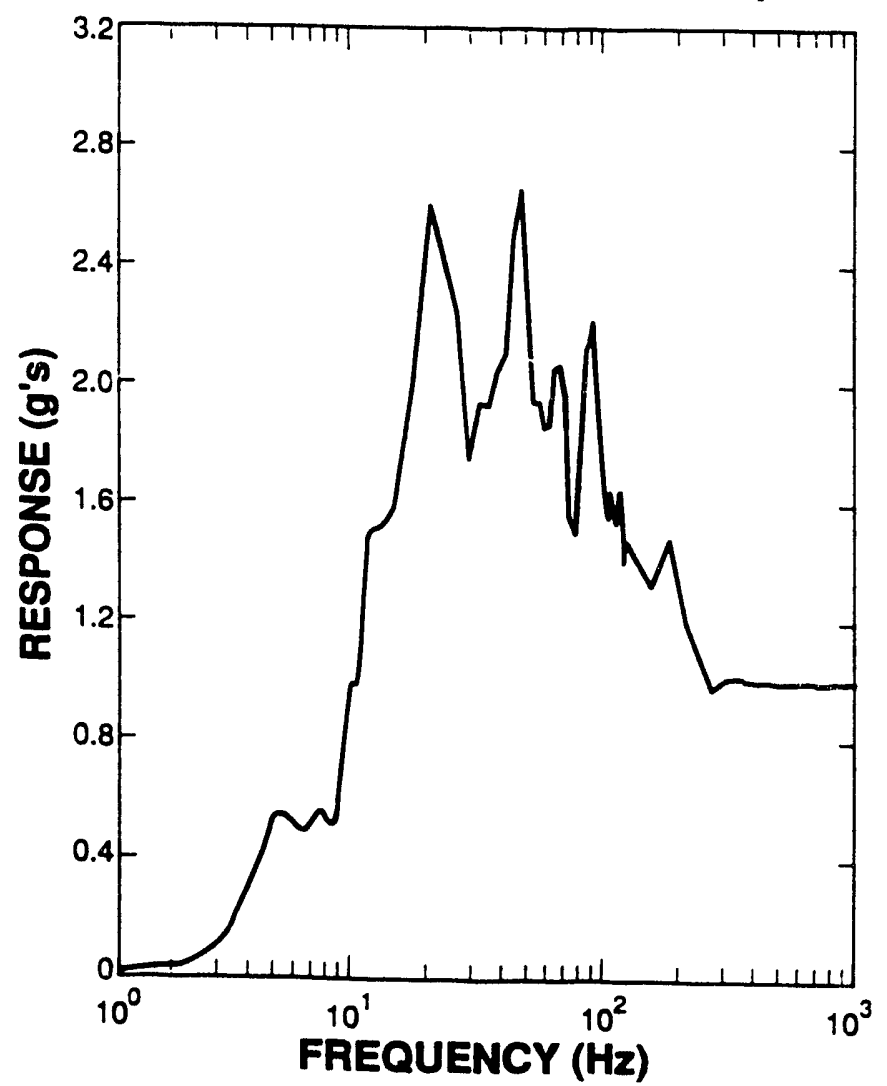

Fig. 12. Response spectrum for the scaled 1940 El Cento earthquake.

22 
TABLE $X$

TEST MATRIX FOR THE 1/3-SCALE STRUCTURES

Model Ne

TRG-8,-13,-14,-15

TRG-9

TRG-10

IRG-11

Excitation level $(g \text { 's })^{b}$

Percent of $\mathrm{ACl}$ 349-85

Ultimate Strength
Seismic Test Sequence

$1^{a}$

2
5

2.5

$50 \%$

$25 \%$

$50 \%$

aThese numbers refer to the sequence in which the models were to be tested.

bThese levels assume an amplification factor of 1.7; hence, a 5.0-g's base excitation will produce a top slab acceleration of $5.0 \times 1.7=8.5 \mathrm{~g}$ 's.

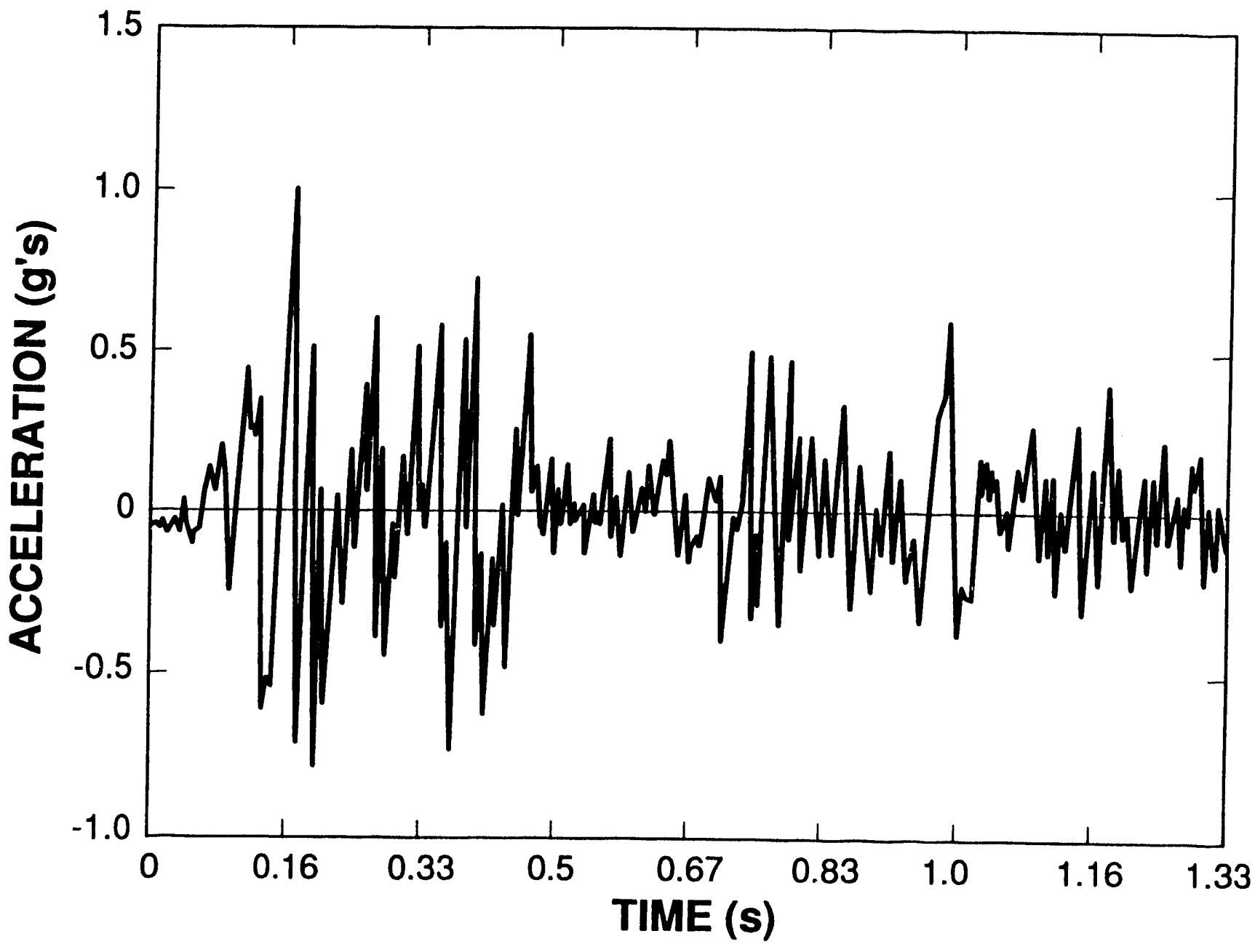

Fig. 13. 1940 El Centro earthquake acceleration-time history normalized to $1 \mathrm{~g}$ and time scaled by a factor of 12 . 


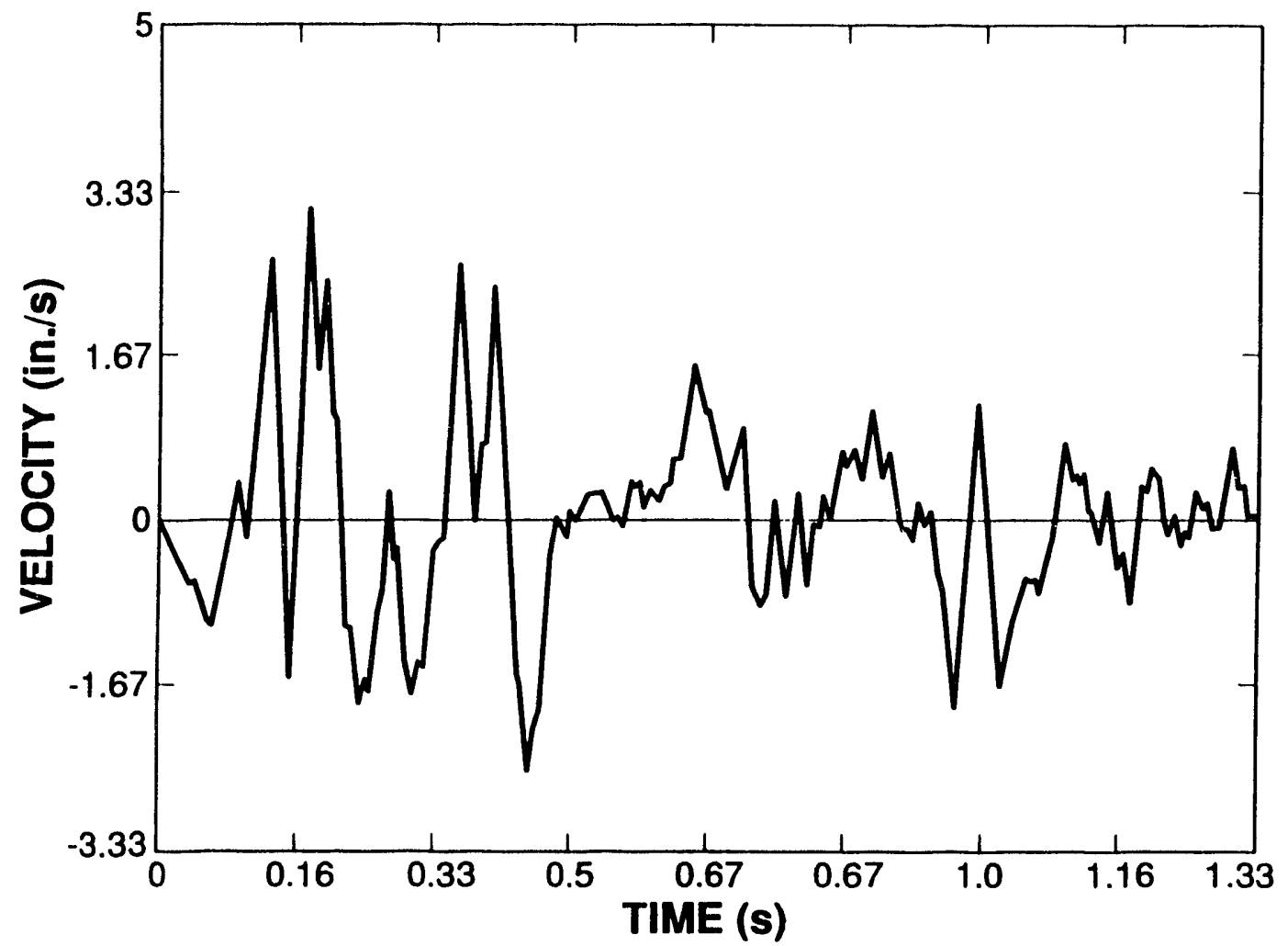

Fig. 14. $1940 \mathrm{El}$ Centro earthquake velocity-time history corresponding to Fig. 13.

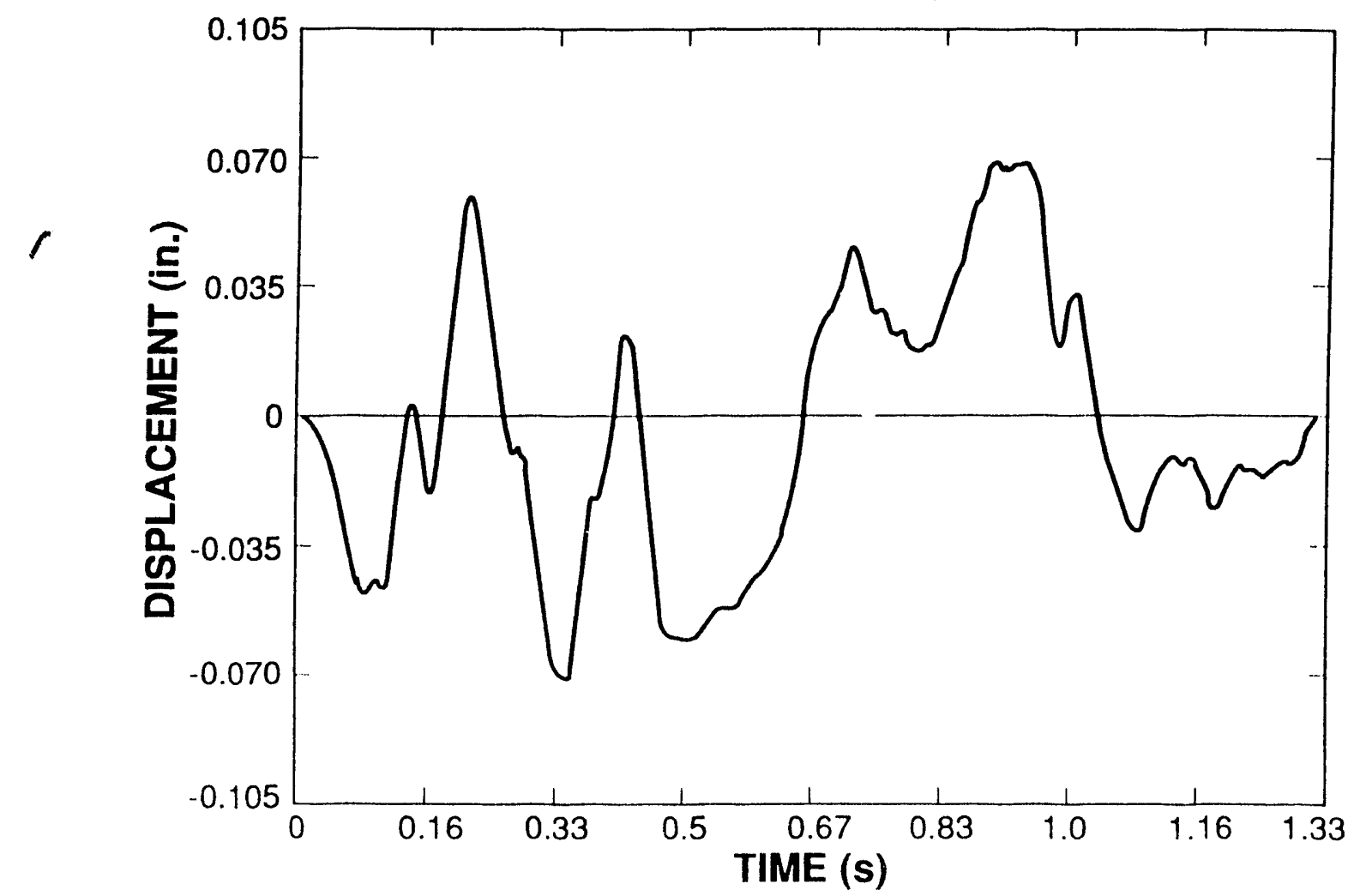

Fig. 15. $1940 \mathrm{El}$ Centro earthquake displacement-time history corresponding to Fig. 13. 
The force required to produce a 5-g's peak base acceleration excitation is easily computed from the free-body diagram shown in Fig. 16 by using the total accelerated weight [model with attached steel plates $(2550 \mathrm{lb})$, table $(721 \mathrm{lb})$, and shaker armature $(245 \mathrm{lb})]$ as $F_{\text {req'd }}=2550 \mathrm{lbm} \times 8.5 \mathrm{~g}$ 's $+966 \mathrm{lbm} \times 5 \mathrm{~g} ' \mathrm{~s}=26530 \mathrm{lb}$. This force is within the facility's rated capacity.

\section{SIMULATED SEISMIC TESTING AND RESULTS}

\section{A. Instrumentation and Test Setup}

The data taken during this sequence of tests consisted of acceleration and strain measurements. Twenty channels of acceleration data were taken, and the locations of these accelerometers are shown in Fig. 17. The redundant measurements permitted checks on slippage of the model relative to the base, on slippage of the top plates relative to the model, and on the torsional response of the top slab.
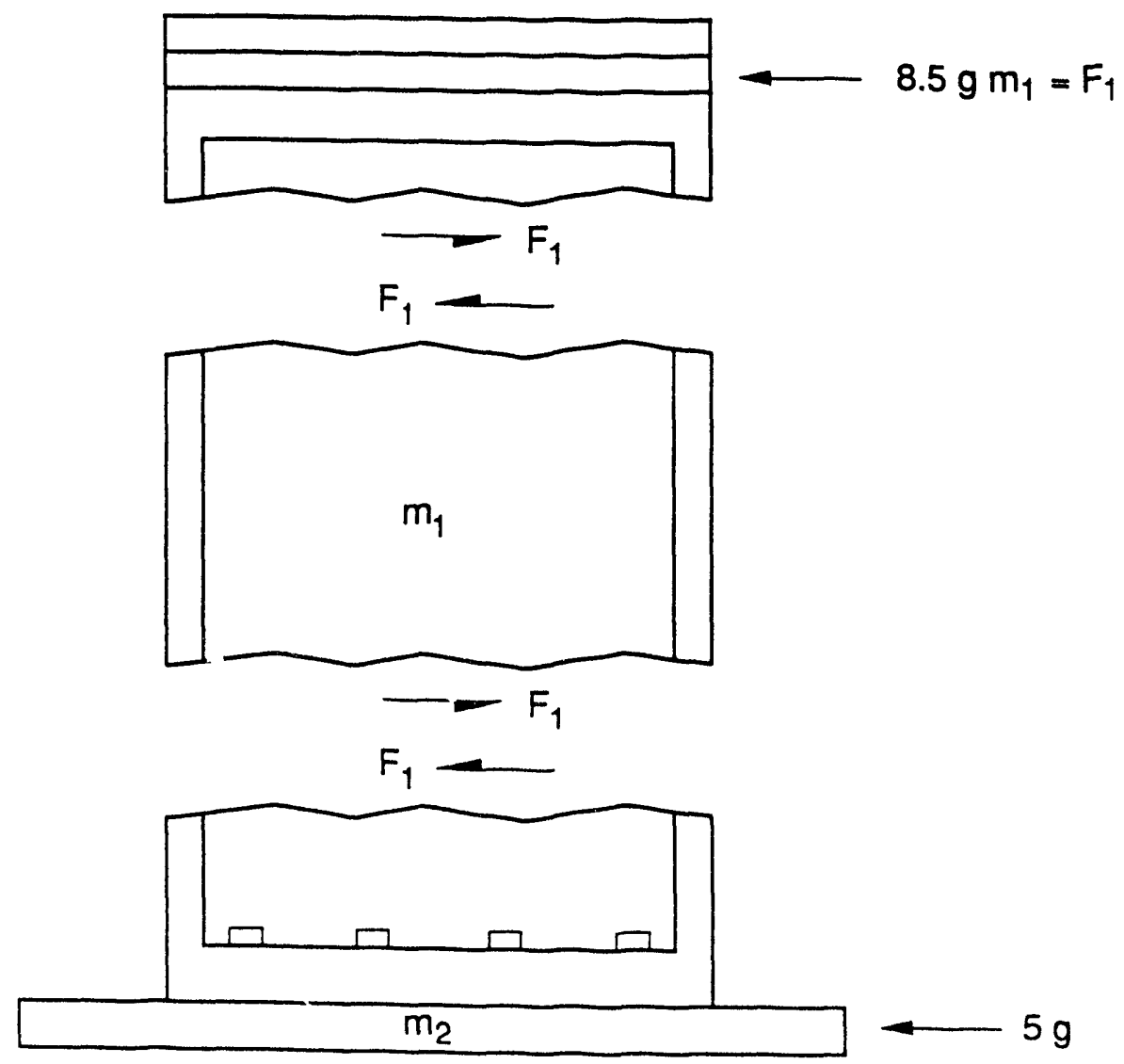

$m_{1}=$ MASS OF THE STRUCTURE WITH ATTACHED STEEL PLATES

$m_{2}=$ MASS OF THE ARMATURE, COUPLING, TABLE

TOTAL INPUT FORCE REQ'D $=8.5 \mathrm{~g}$ 's $\mathrm{m}_{1}+5 \mathrm{~g} \mathrm{~g}^{\mathrm{s}} \mathrm{m}_{2}$

Fig. 16. Tree body diagram of the shake tabie and atiached structure. 


\section{5}
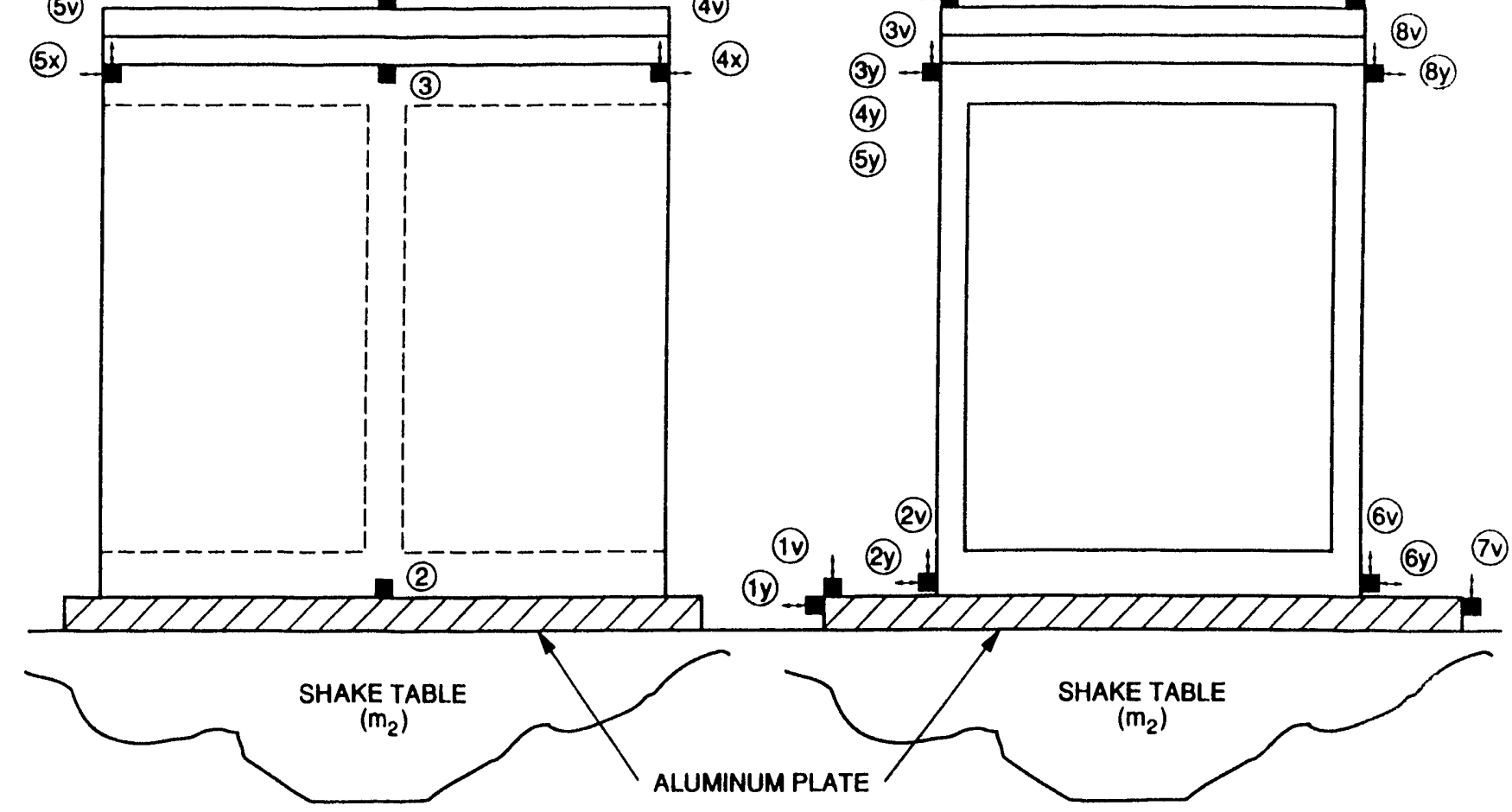

- ACCELEROMETERS

Fig. 17. Accelerometer locations for the simulated seismic test.

Because the test reported in [1] showed that the stiffness values determined from relative displacement readings during static tests agreed well with stiffness values determined by mechanics-of-materials beam theory analysis that accounts for shear deformation, and because this method of displacement measurement is independent of baseslip and rigid-body motion, a similar measurement method was sought for dynamic tests. The method used for the static tests could not be used for the dynamic tests because the digital displacement transducers do not have adequate frequency response and because the response of the mounting hardware would invalidate any readings obtained. The displacement transducers and their hardware were replaced with a series of strain gages between the two points for which the relative displacement was needed.

Four channels of strain were measured during each test series. The strain measurements were converted to displacement readings that corresponded to the relative displacements measured on TRG-4 during the static load deformation tests. Large gage-length strain gages were mounted on diagonal and vertical lines on the shear wall. The arrangement is shown in Figs. 18 and 19. An identica! pattern was bonded to the opposite side of the shear wall. 


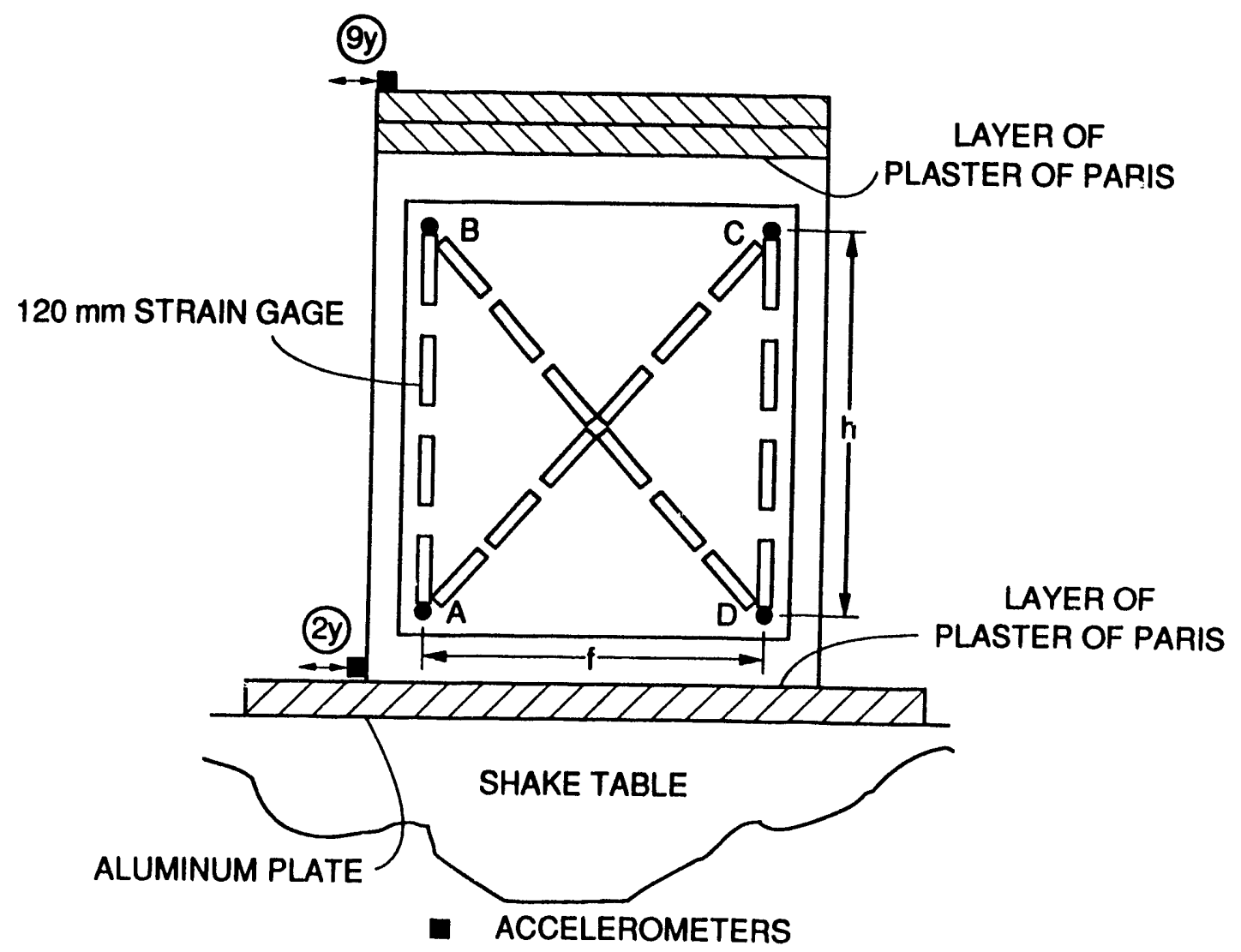

Fig. 18. Strain gage pattern.

It may be shown that the change in resistance of a strain gage is proportional to the relative displacement of the two ends of the gage. Thus, in actual use, the gage measures the average strain over the gage length, independent of the strain gradient within the gaged length. By mounting gages end-to-end between two points and connecting them in series, a long gage-length strain gage is obtained whose signal may be converted to relative displacement.

To reduce the installation time, 120-mm-long gages were used. It should be noted that segment $A B$ in Fig. 18 is $660 \mathrm{~mm}$, and the "gage-length" of the series of four gages used to span this length is $480 \mathrm{~mm}$, giving 73 percent coverage. Similarly, segment AC is $865 \mathrm{~mm}$, and the "gage-length" of the six gages used in this measurement is $720 \mathrm{~mm}$, giving 83 percent coverage. Because the gages do not cover the entire distance between the points, the signal from the four gages along $A B$, when connected in series, (or the six gages along $A C$ ) will not necessarily be converted to displacement by multiplying the indicated strain by the distance $A B$ (or $A C$ ).

To evaluate the effect of the strain gradient between the two end points, a finite element analysis of the structure was made. This analysis showed that the strain gradient along $A B$ is essentially linear, and the strains along $A C$ are essentially constant. In these two cases, the strain gradients are such that multiplying the strain reading by the gage length will convert the reading to a displacement. 


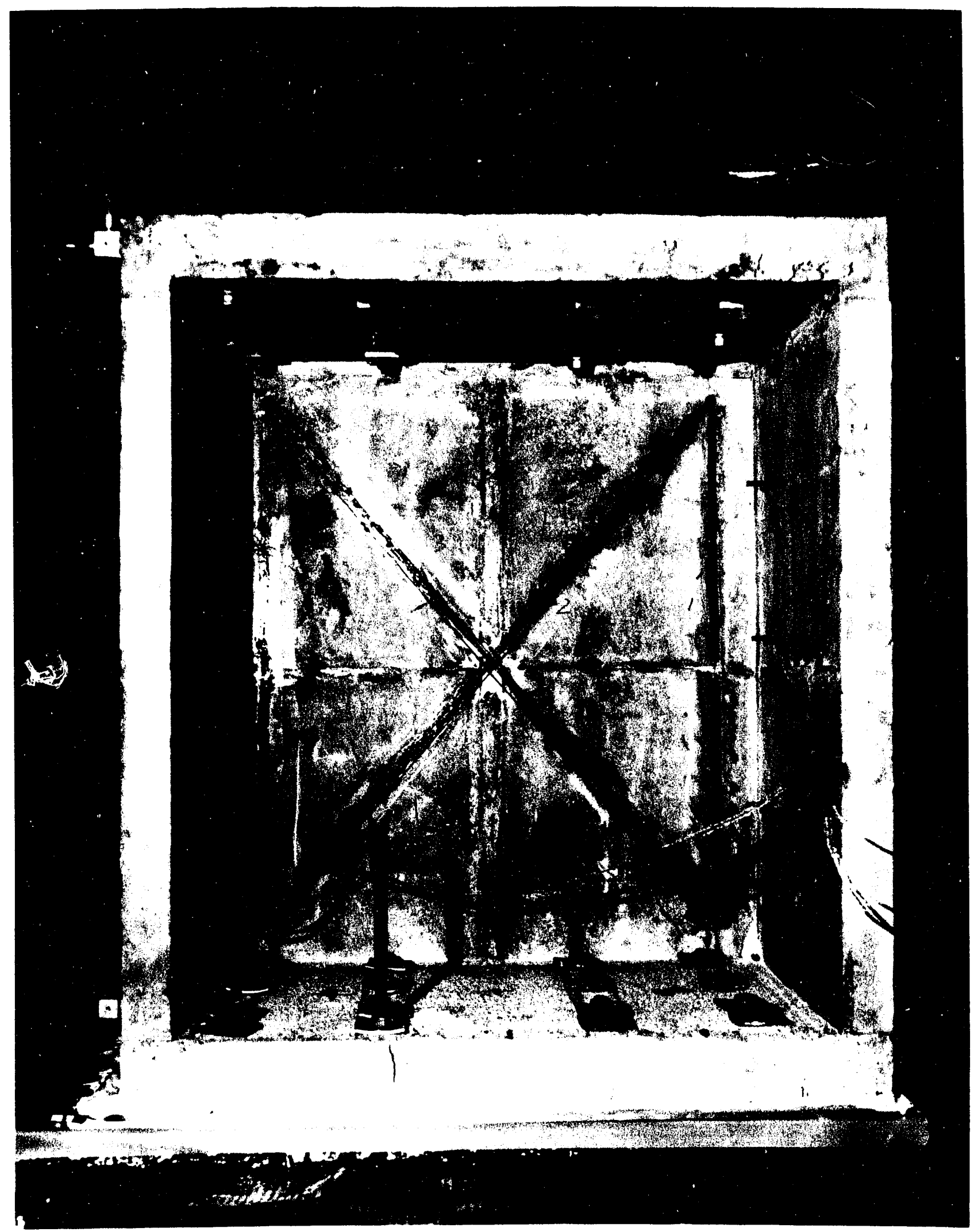

Fig. 19. Strain gages mounted on TRG-13. 
Four bridge circuits were used to convert the changes in resistance to voltage. The "strain gage" along AB was placed in a leg opposite from the corresponding gage on the other side of the shear wall to obtain additive output. Fixed resistors were used to complete the bridge for the dynamic tests. Similar bridges were formed from the gages along $\mathrm{DC}, \mathrm{BD}$, and $\mathrm{AC}$.

Static, cyclic tests performed on TRG-16 were used to verify that integrated strain data would accurately measure the relative displacement between the two end points of the gages. A discussion of these test results is provided in Section VII. These tests showed that the strain gages can accurately measure the displacements between the two end points. Strain gages were mounted on structures TRG $-8,-9,-10,-12,-14,-15$, and -16 .

A 1.5-in.-thick aluminum plate was bolted to the shake-table with fifty-six 0.5 -in.diam countersunk bolts torqued to $65 \mathrm{ft}-\mathrm{lb}$. The aluminum plate was required by the shake-table operators to stiffen the table and to prevent warping from occurring when the test structures were bolted down. TRG-7 and -13 were placed on the aluminum plate and used as practice models so that the shake-table control parameters could be established. On TRG-8 and on all subsequent test structures, a layer of plaster-of-Paris was placed between the base of the structure and the aluminum plate to provide an even bearing surface that would conform to the base of the structure. Tests on TRG-7 had shown that the bottom and top surfaces of the structure were out-of-plane to the point that cracking could be introduced by tightening the studs through the base or the bolts through the top slab to $30 \mathrm{ft}-\mathrm{lb}$. A layer of plaster-of-Paris was placed on the top of the structures, between the concrete slabs and the steel plates, to provide a bearing surface that would conform to the model and to the steel plates. This was done to eliminate the slippage of the steel plates relative to the concrete slab that occurred during the TRG-8 tests.

The structures were bolted to the aluminum plate with thirty-two 0.5 -in.-diam studs torqued to $30 \mathrm{ft}-\mathrm{lb}$. Each structure (with the exception of TRG-13, which had the steel plates already in place from previous static tests) was subjected to a series of low-level, burst-random pulses ( $1 \mathrm{~g}$ 's nominal peak base-input acceleration) without the steel plates attached, then again with the steel plates in place. These random excitation tests are referred to as loop checks. These checks on the shake table control system were necessary to correct for the mass and for compliance of the test structure. Because the input power from these signals was at frequencies considerably above the first-mode frequencies of the structure, these tests provided the data necessary to determine the initial dynamic properties of the structure without introducing damage. The NBSS during these tests was less than 16 psi. For all dynamic tests the NBSS stress was calculated as

$$
P=\frac{M_{\text {eff }} \ddot{Y}_{\text {peak }}}{A},
$$


and

$M_{\text {eff }}=M_{s}+M_{c}+M_{d}$,

where $P=$ nominal base shear stress (psi),

$\ddot{Y}_{\text {peak }}=$ peak acceleration measured at the centerline of the end wall, on the top slab, directly above the shear wall ( $g$ 's)

$\mathrm{A}=$ cross-sectional area of the shear wall, 60 in.2 for all cases,

$M_{s} \quad=$ mass of the steel plates, if present, $(1360 \mathrm{lbm})$,

$M_{c}=$ mass of the top concrete slab $(267 \mathrm{lbm})$,

$M_{d}$ = distributed mass of the wall that must be lumped with $M_{s}$ and $M_{c}$ in a single degree-of-freedom model of the structure $(207 \mathrm{lbm})$.

$M_{d}$ was calculated by comparing the resonant frequencies predicted from FEA of the structure, with and without its added mass. In the model without the added mass, the stiffening effects of the top steel plates were left in so that the following relationship could be estabiished

$$
\left(\frac{f_{n m}}{f_{m}}\right)^{2}=\frac{M_{s}+M_{d}+M_{c}}{M_{c}+M_{d}},
$$

where $f_{n m}=$ shear/bending mode resonant frequency without the steel plates, and

$f_{m}=$ shear/bending mode resonant frequency with the steel plates.

\section{B. Test Results (Accelerometer Data)}

Summaries of the simulated seismic tests performed on TRG-8 through -11 and TRG-13 through -15 are provided in Tables XI through XVII, respectively. Figure 20 shows the stiffness reductions, as inferred from resonant frequency measurements and finite element resonant frequency calculations (using the measured modulus of elasticity), plotted against the peak NBSS level for each test. The measured resonant frequency values were determined from the peaks in the magnitude of the frequency response function, (FRF, Fourier transform of the response, Ch.3y, divided by the Fourier transform of the input, Ch.2y). The FRFs were determined by averaging the FRFs from eight 0.25 -s blocks of data. Each block of data was discretized with 1024 points. With this sampling rate, frequencies up to $2000 \mathrm{~Hz}$ can be measured, and the FRF will have a 4- $\mathrm{Hz}$ resolution. If the structure were to crack during a transient, the frequency identified from the FRF calculation corresponds to the frequency of a linear model that best fits the data in a least-squares sense. Figure 21 shows a typical FRF magnitude plot for the first seismic pulse on TRG-13. 


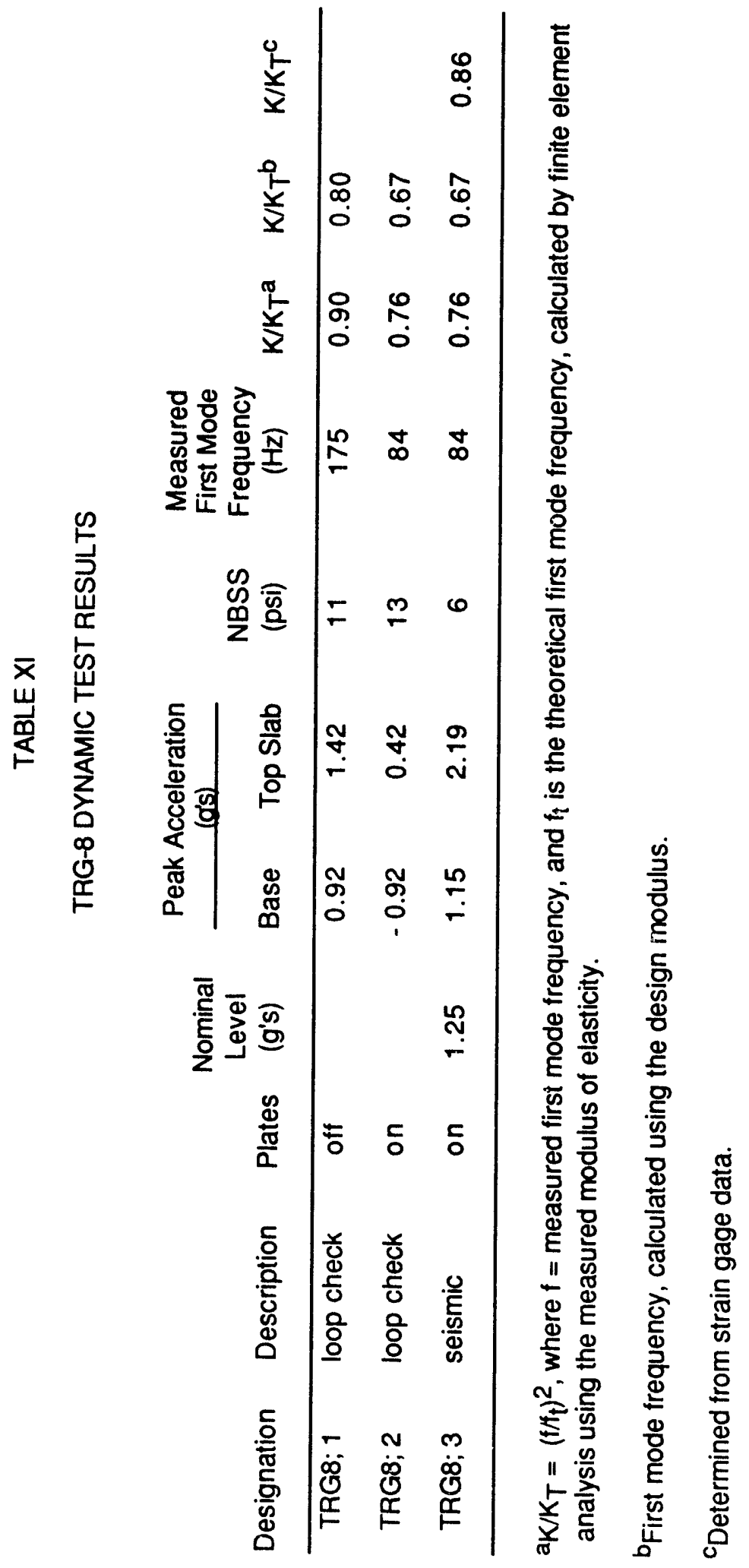




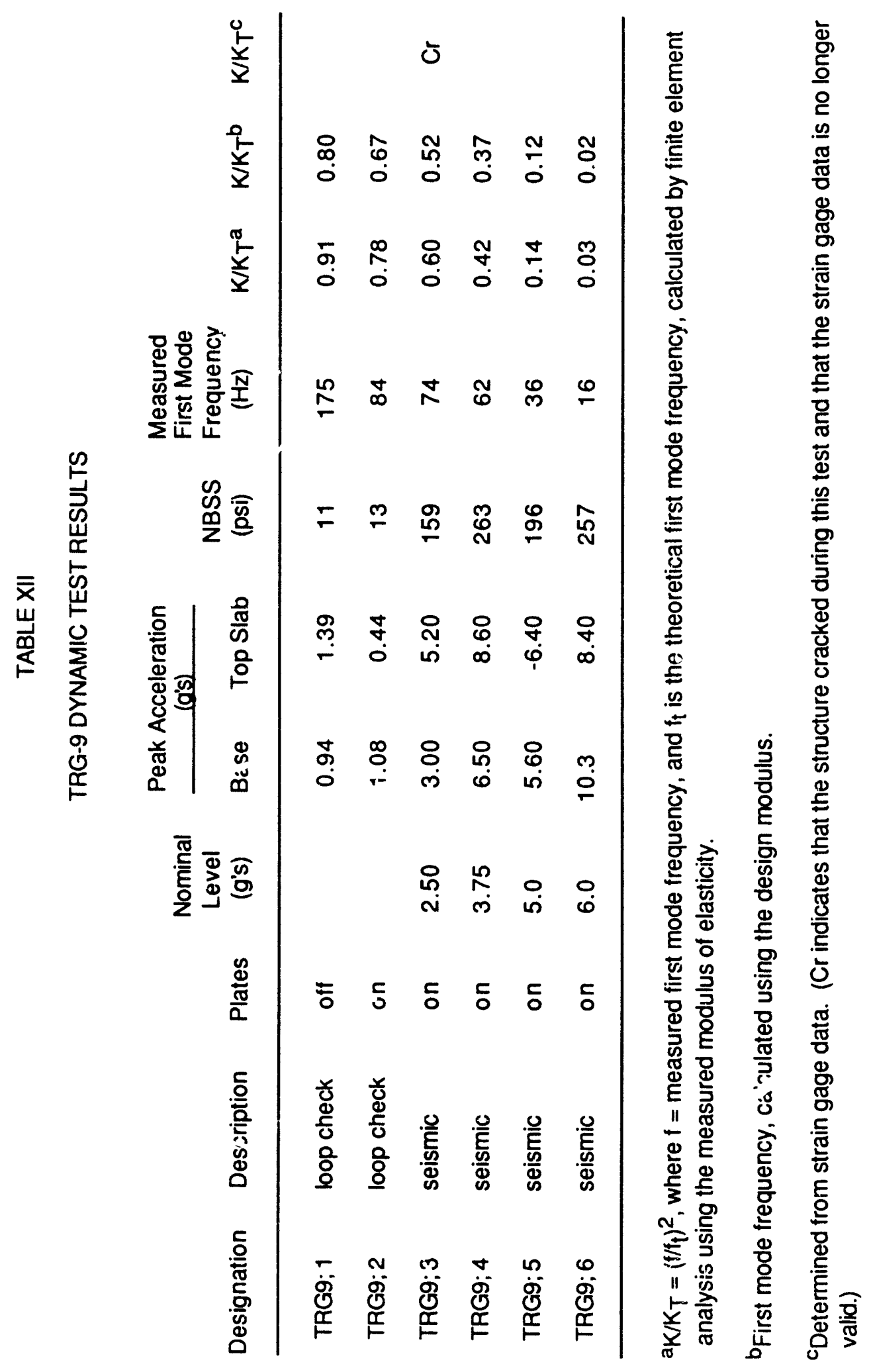




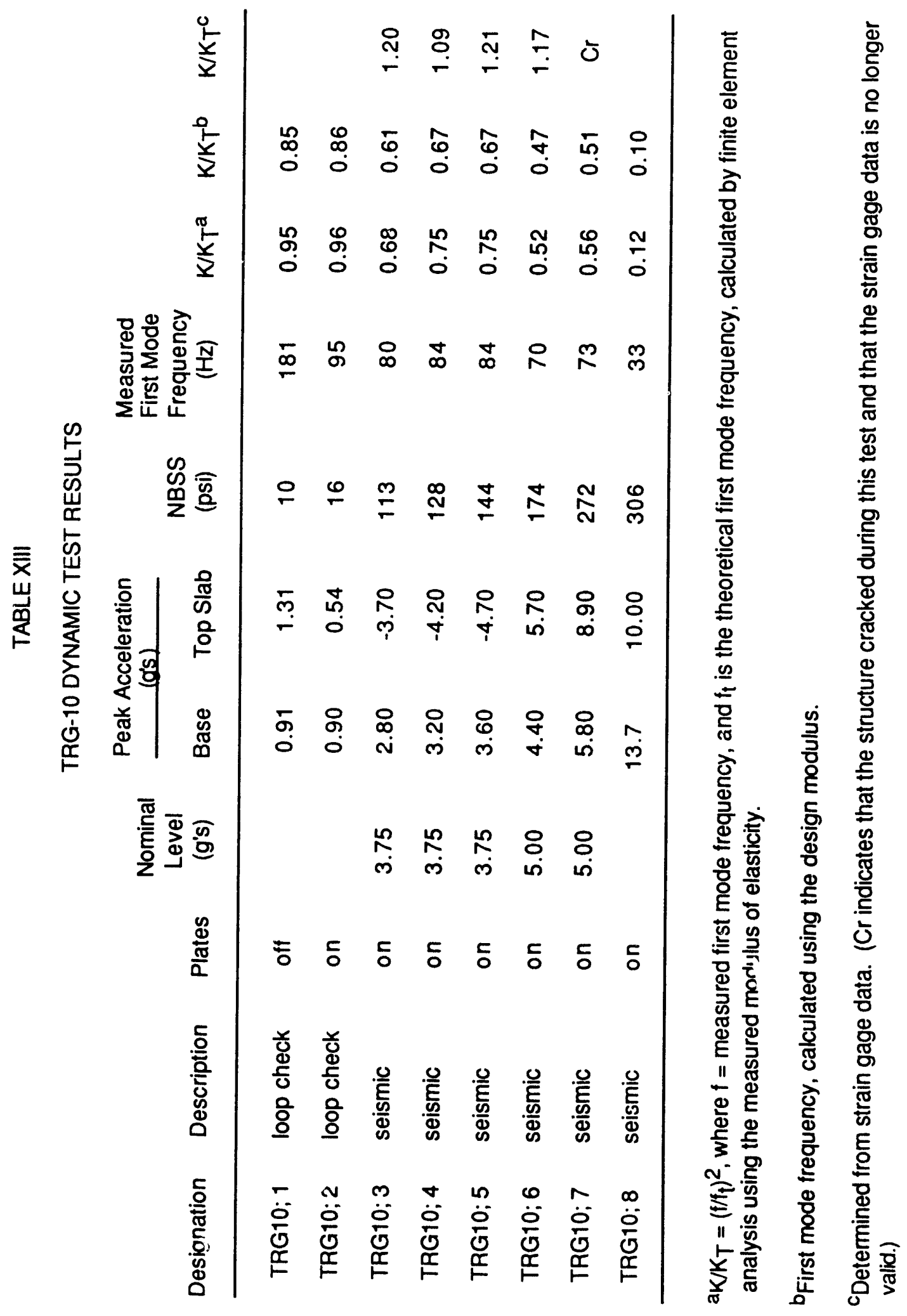




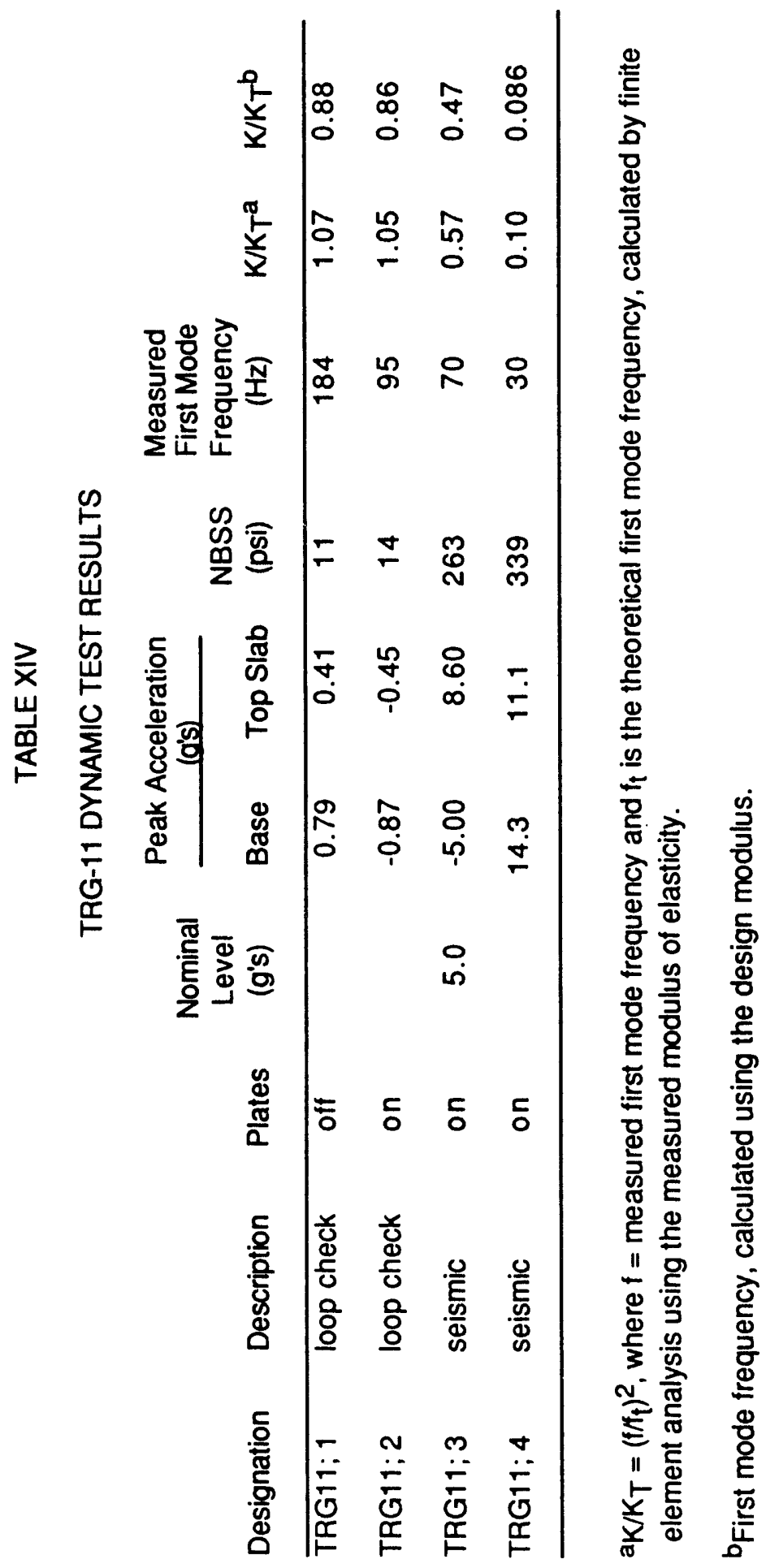




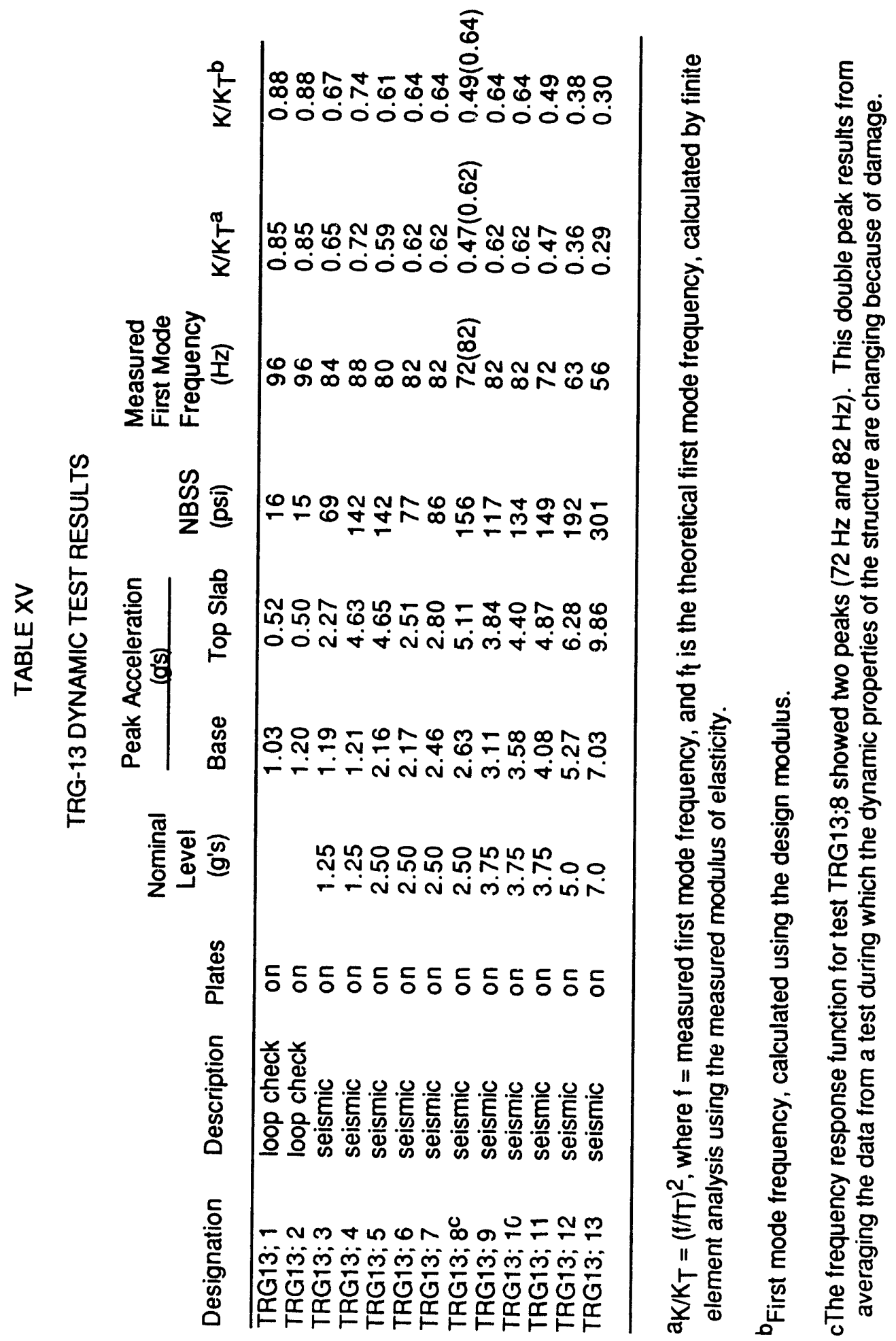




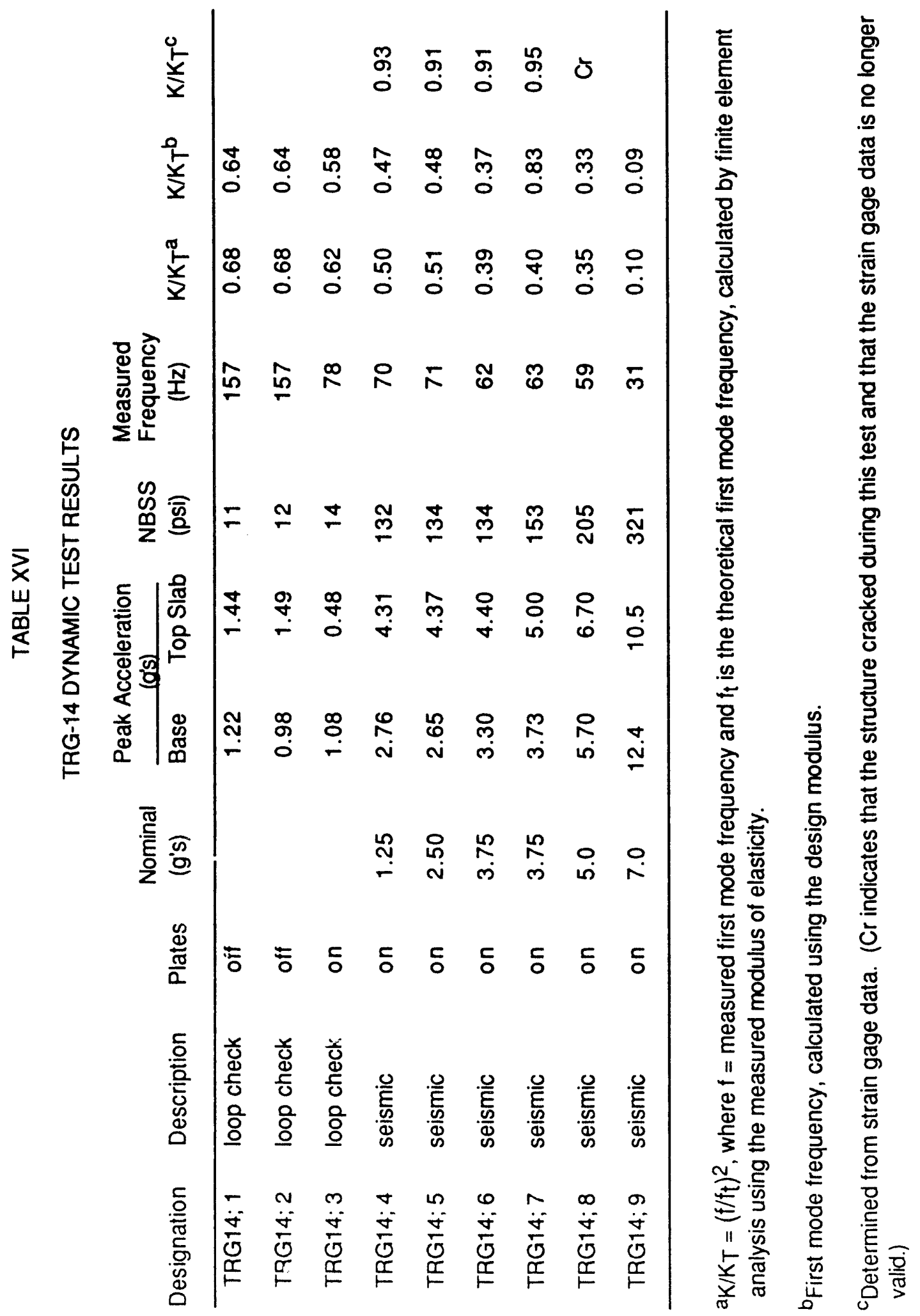




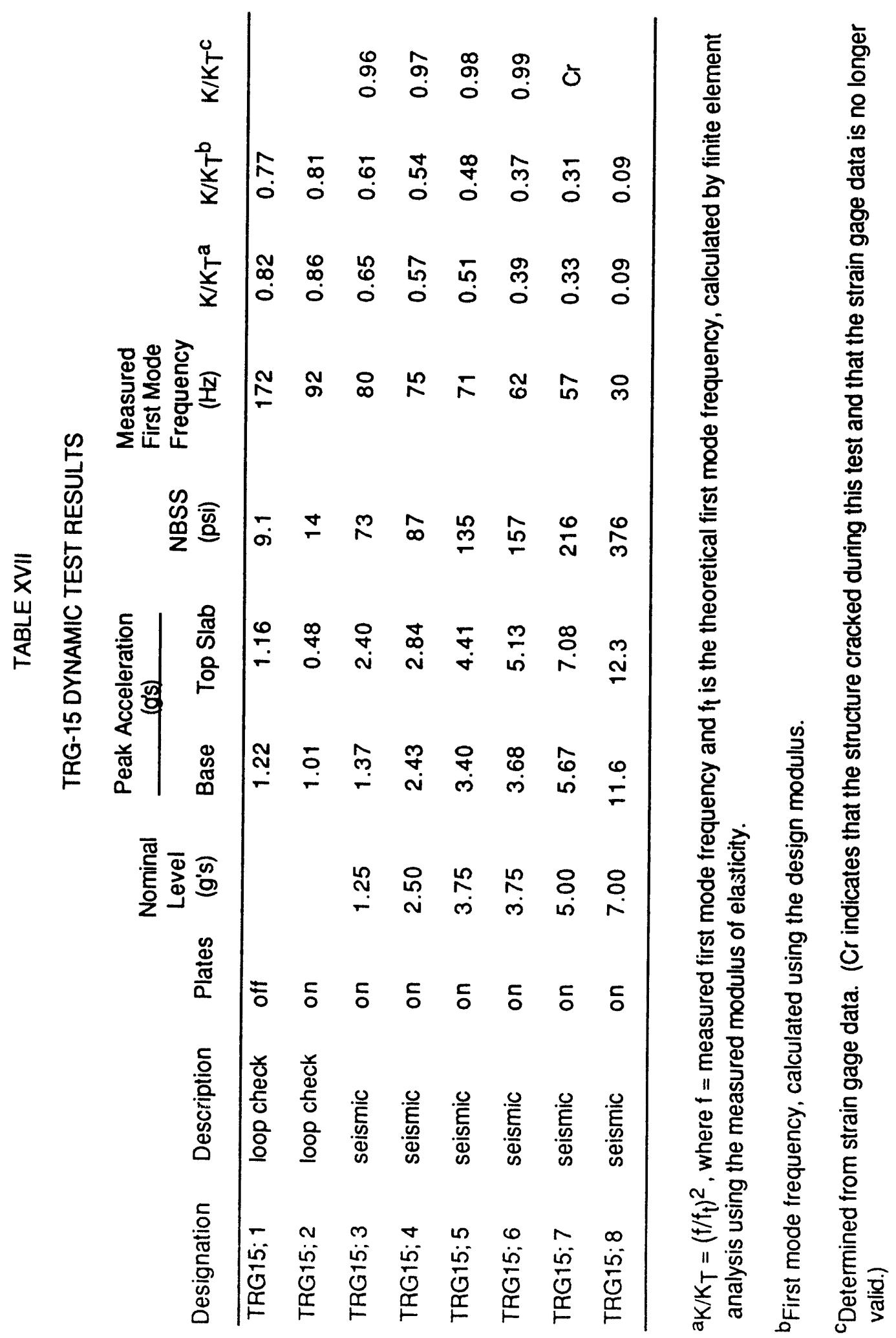




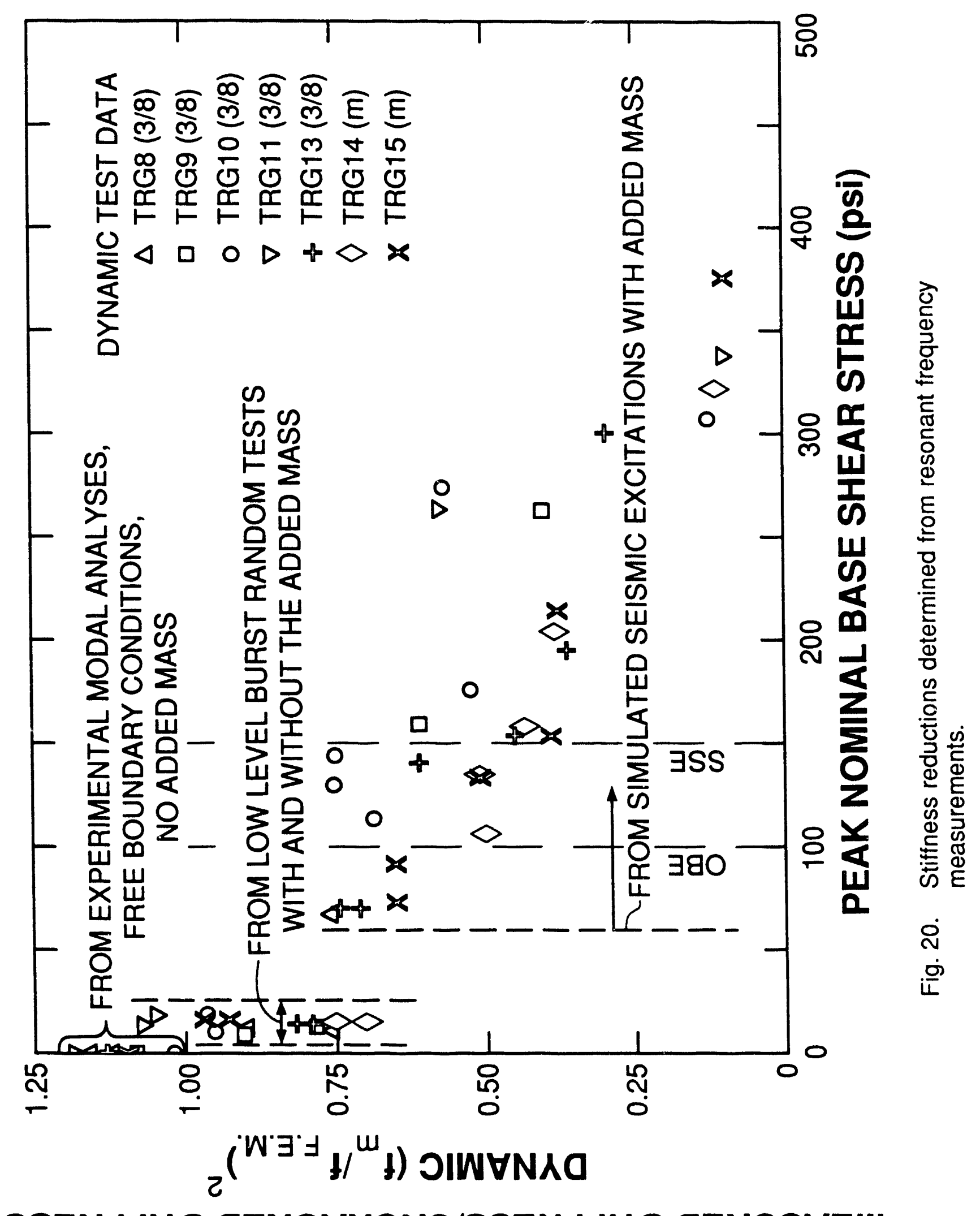

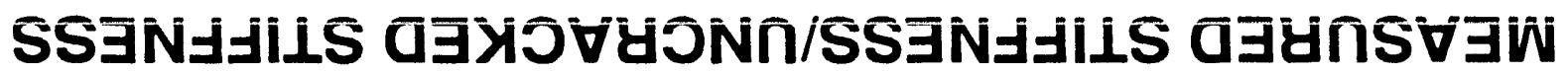




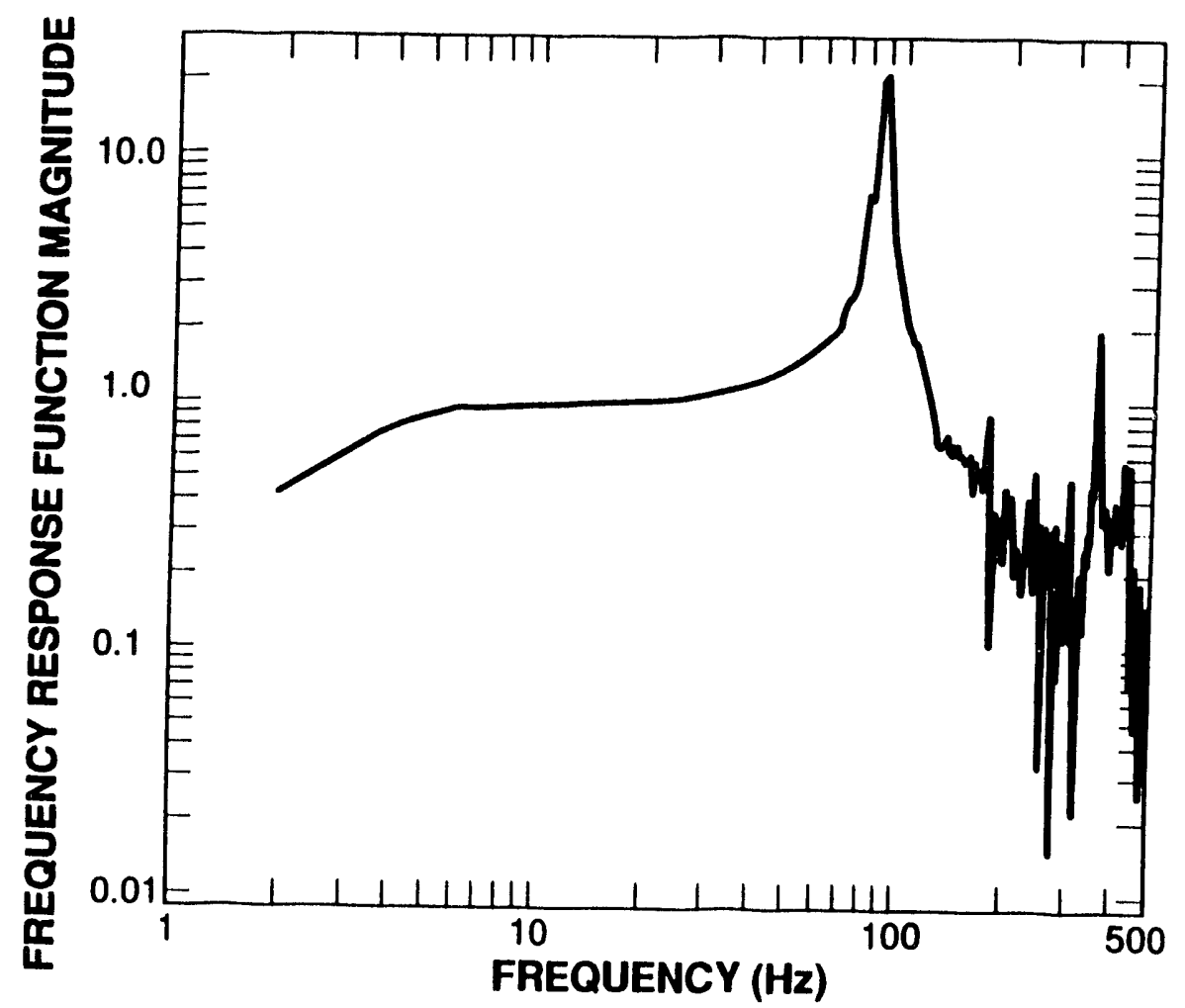

Fig. 21. Frequency response function, TRG-13 first seismic pulse, Ch.3y/Ch.2y.

\section{Test Results (Strain Gage Data)}

Stiffness values can also be determined from the strain gage data. Referring to Fig. 22, the total deformation, $\delta_{T}$, of plane $B C$ relative to plane $A D$ is

$$
\delta_{T}=\left(\beta_{A C}+\delta_{A C}\right) \cos \phi-f
$$

and

$$
\phi=\cos ^{-1}\left[\frac{f^{2}+\left(\beta_{A C}+\delta_{A C}\right)^{2}+\left(h+\beta_{C d}\right)^{2}}{2 f\left(\beta_{A C}+\delta_{A C}\right)}\right],
$$

where $h$ and $f$ are defined in Fig. 18, $\delta_{A C}$ and $\delta_{C D}$ are the readings from gages $A C$ and $C D$, respectively, and $\beta_{A C}$ is the distance between points $A$ and $C$ prior to deformation. With the instrumentation used during these tests, the total deformation was determined from the average of four separate displacement readings. The bending and shear deformations, $\delta_{\mathrm{b}}$ and $\delta_{\mathrm{s}}$, are found with the following equations:

$$
\delta_{b}=\frac{2 h\left(\delta_{C D}-\delta_{A B}\right)}{3 f} \text {, and }
$$




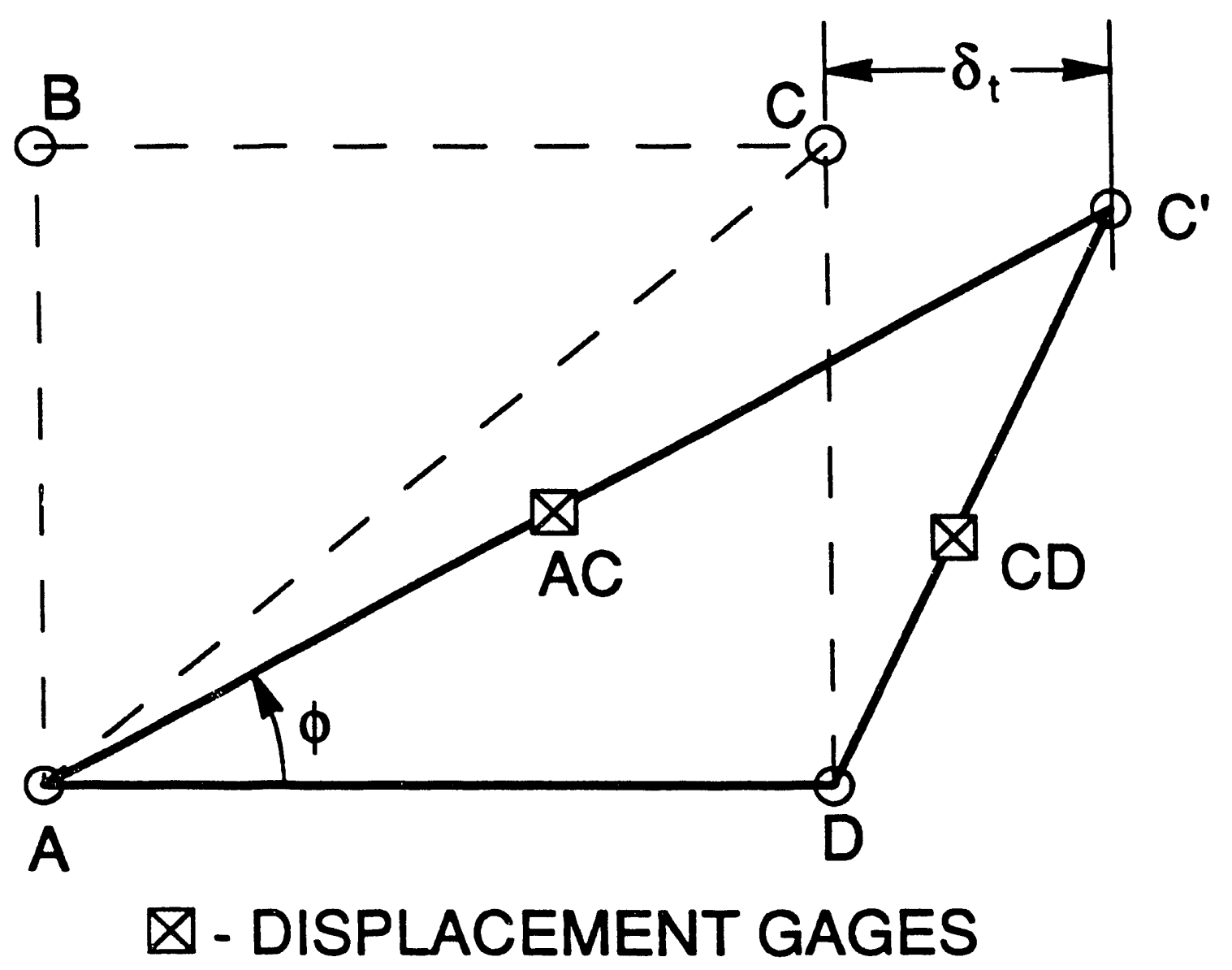

Fig. 22. Method for determining horizontal displacements from internal gage readings.

$$
\delta_{\mathrm{S}}=\delta_{\mathrm{T}}-\delta_{\mathrm{b}} .
$$

A detailed discussion of these equations and the assumptions used in their development is given in [1].

From the free-body diagram in Fig. 23, it is evident that, knowing either the force applied to the steel plate for the static case or the acceleration of the center-of-mass of the top concrete slab, the steel plates, and a portion of the distributed mass of the walls for the dynamic case, will give the force and moment that cause the relative displacement of plane BC to plane AD. With these force and displacement measurements, a stiffness value can be computed and compared with a theoretical stiffness determined by applying Castigliano's theorem to the portion of the structure between plane $A D$ and $B C$, as discussed in [1]. The total, bending and shear stiffness terms $\left(k_{T}, k_{b}\right.$, and $k_{s}$, respectively) are

$$
k_{T}=\frac{1}{\frac{b L^{2}}{2 E_{c} l}+\frac{L^{3}}{3 E_{c} l}+\frac{L}{A G}},
$$




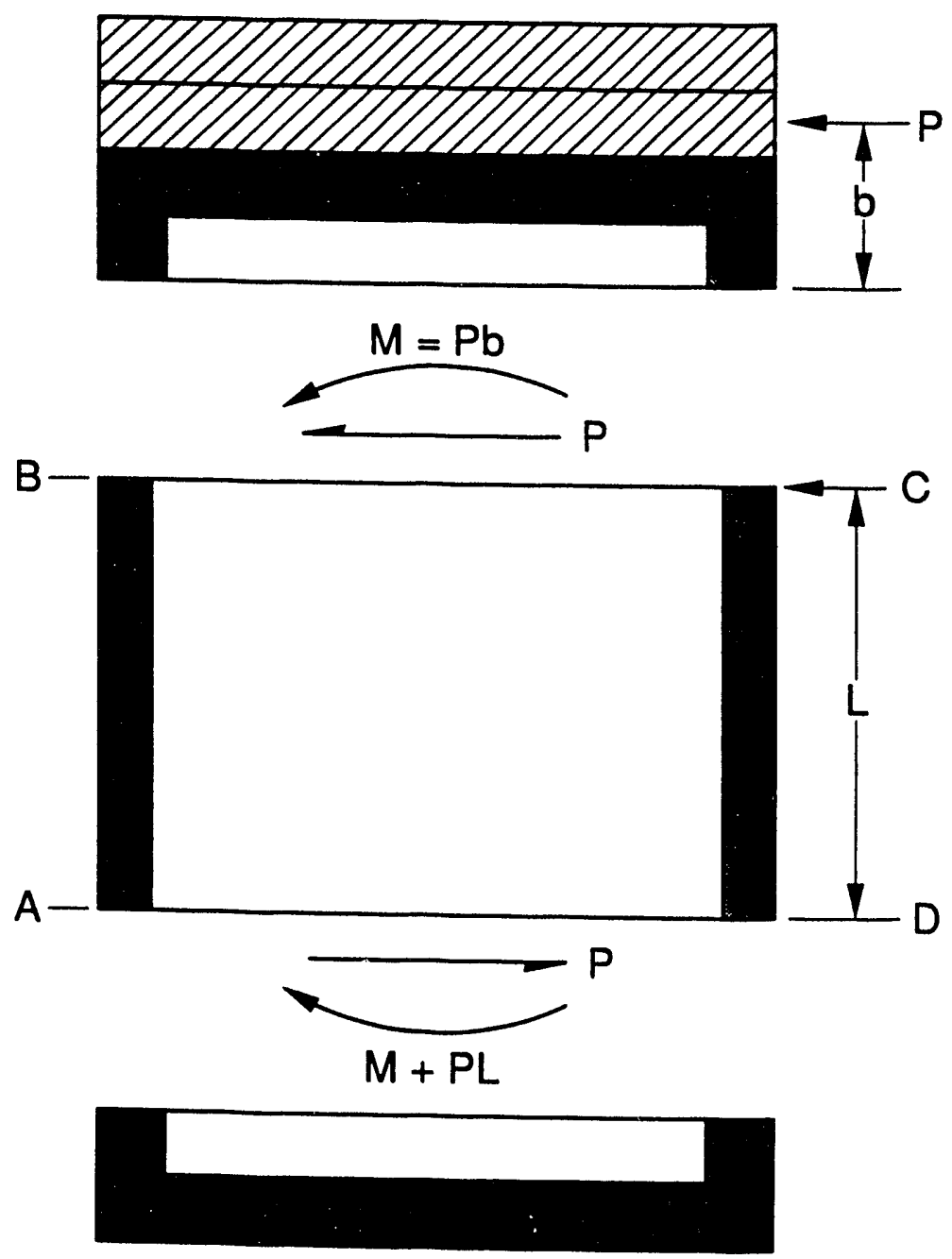

Fig. 23. Free-body diagram of a TRG-type structure.

where $b$ and $L$ are defined in Fig. 23,

I = the cross-sectional moment of inertia, including end walls;

$A=$ the cross-sectional area of the shear wall only;

$G=$ the concrete's shear modulus;

$k_{b}=\frac{6 E I}{2 L^{3}+3 b L^{2}}$

and

$k_{s}=\frac{A G}{L}$. 
The application of this method to stiffness measurements, using dynamic data, requires the assumption that the inertial forces associated with the mass of the walls between planes $A D$ and $B C$ and the corresponding deformations are negligible compared with the forces associated with the acceleration of the top plates and their related deformations.

Peak-to-peak relative displacements from dynamic tests are compared with those displacements predicted by the mechanics-of-materials theory (Eq. 13) for similar force levels. The ratio of measured to predicted relative displacements is equivalent to the ratio of measured to predicted stiffness. Figure 24 shows the acceleration-time history of the center-of-mass of the portion of the structure above the instrumented section of the shear wall. Acceleration values from Fig. 24 that correspond to peaks in the displacement-time history shown in Fig. 25 can be used to obtain the force levels necessary for the application of Eq. 13. This method of comparing measured and predicted relative displacements (or stiffness) can be applied to any successive peaks from the dynamic data allowing for the consistency of the method to be checked.

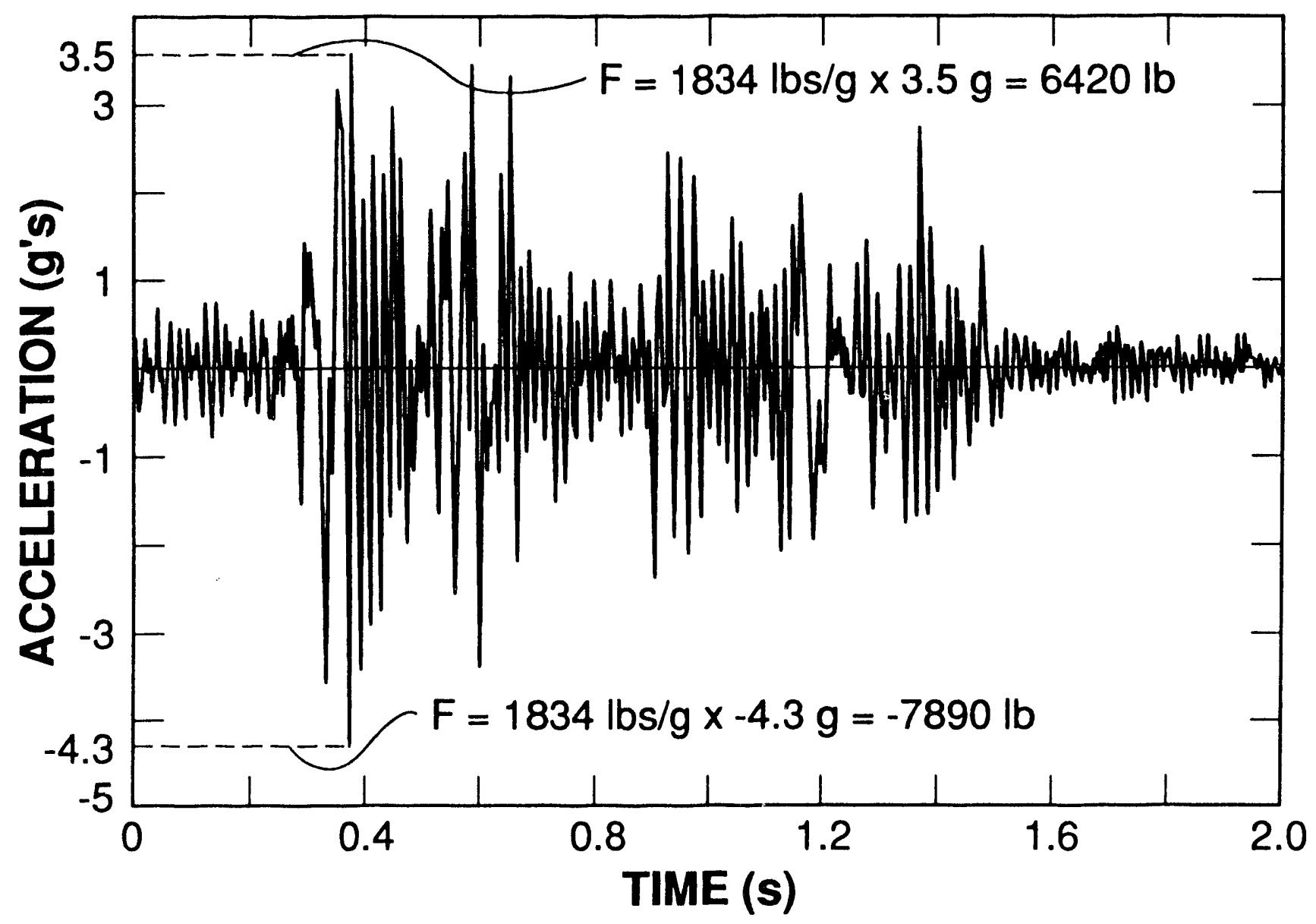

Fig. 24. Acceleration-time history of the top mass during the second seismic pulse on TRG-10. 


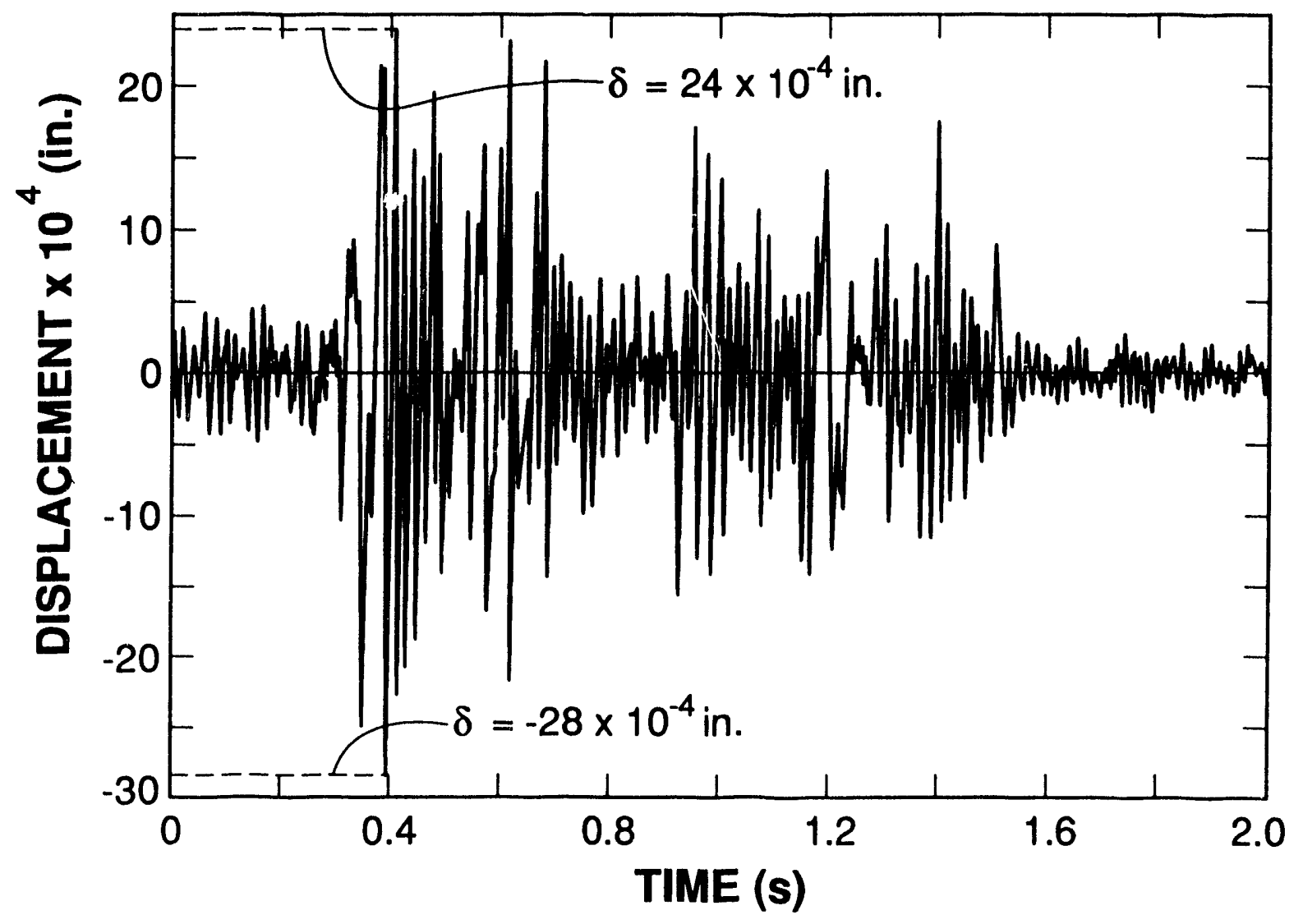

Fig. 25. Relative displacements determined from strain gage readings during the second seismic pulse on TRG-10.

Data from the second seismic pulse on TRG-10 are used as an example. The peak-to-peak relative displacement shown in Fig. 25 is $5.2 \times 10^{-3}$ in. The corresponding peak-to-peak force shown in Fig. 24 is $14,310 \mathrm{lb}$. This structure's theoretical stiffness as determined by Eq. 13 is $2.60 \times 10^{6} \mathrm{lb} / \mathrm{in}$. $\left(E_{c}=3.24 \times 10^{6} \mathrm{psi}, b=6.12 \mathrm{in}\right.$., $L=26$ in., $\mathrm{I}=34,900$ in. $\left.{ }^{4}, \mathrm{G}=1.35 \times 10^{6} \mathrm{psi}, \mathrm{A}=61.1 \mathrm{in.}{ }^{2}\right)$. With this theoretical stiffness the peakto-peak force of $14310 \mathrm{lb}$ would be expected to produce a peak-to-peak displacement of $5.5 \times 10^{-3} \mathrm{in}$. These data imply that the ratio of the measured stiffness to the theoretical stiffness is 1.06. Two other peak-to-peak displacement and corresponding acceleration readings from this test were examined. These other two readings both yielded stiffness ratios of 1.11. The average ratio of the measured to the theoretical stiffness from these three data sets is 1.09 and this value is given in Table XII. All stiffness values determined from the strain gage data tabulated in Tables XI through XVII are the average of three peak-to-peak displacement readings, that were measured at different times during the seismic transient. No strain gage data were obtained during the loop checks.

During a dynamic test, cracking can be identified by a sudden shift in the strain-time history that results from a relief of strain within the instrumented region when cracking occurs outside this region. Figure 26 is an example of this shift from data obtained with Gage AB during the sixth seismic pulse on TRG-10 (Test TRG-10;8). At this point, the strain gages no longer provide an accurate measure of the overall structural deformations. 


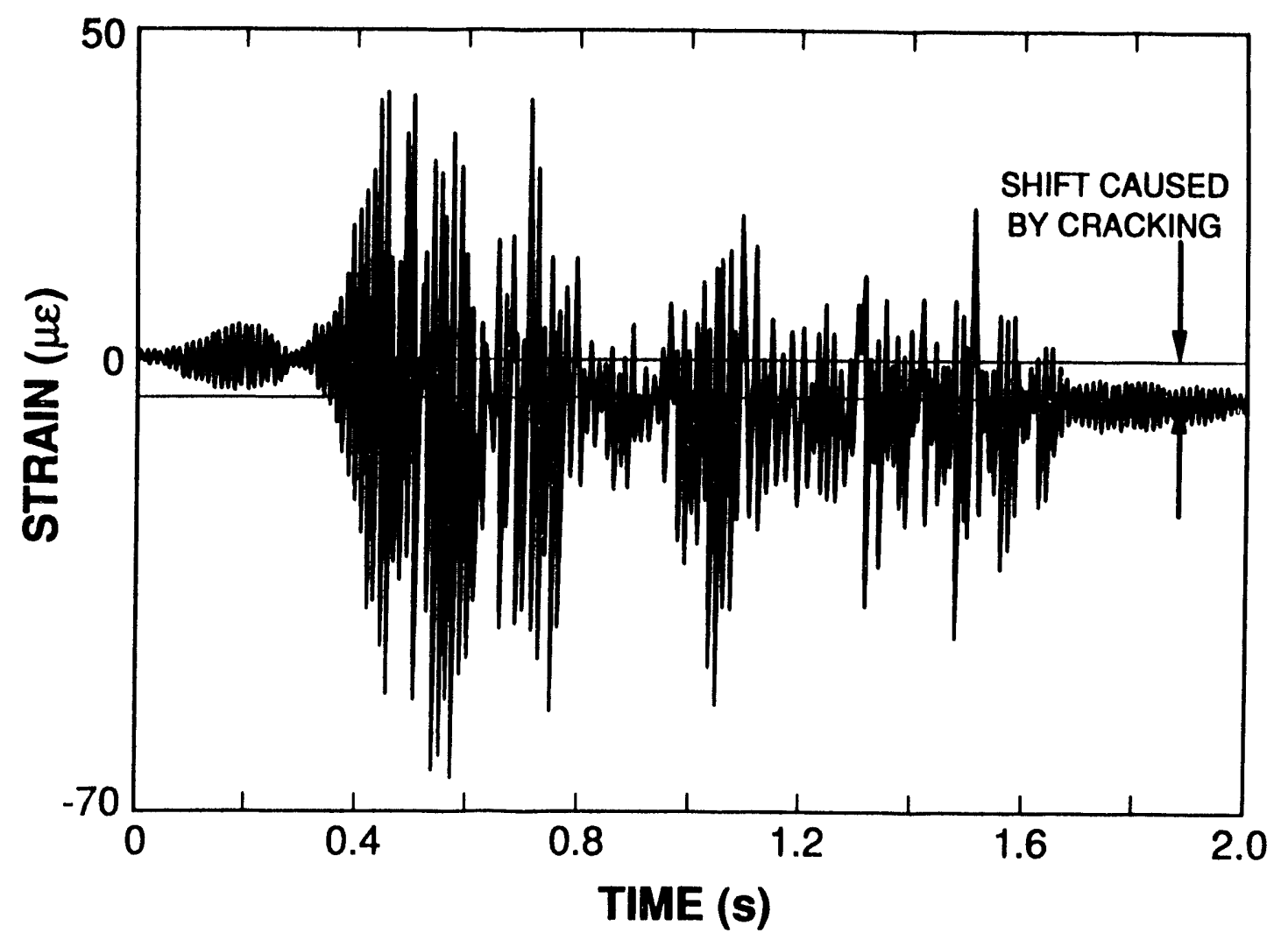

Fig. 26. D. C. shift in the strain gage reading that results from cracking of the structure.

\section{Error Sources}

One difficulty encountered during the testing was control of the shake table during transients that introduced damage. The first seismic pulse on TRG-14 is used for an example. This pulse was supposed to be a nominal 1.25-g test, but the peak input acceleration was $2.76 \mathrm{~g}$ 's. The resonant frequency measured during the test was $70 \mathrm{~Hz}$, as compared with $78 \mathrm{~Hz}$ during the previous pulse, indicating that damage occurred during this pulse. Figure 27 compares the response spectrum computed from the command signal with the response spectrum computed from the measured base acceleration. From this plot one can see the distortion in the input signal that resulted from the control system's inability to handle the change in the dynamic properties of the structure during a damaging transient.

Finally, the issues of base slip, torsional motion about an axis normal to the plane of the table, rigid body rotation about an axis normal to the plane of the shear wall, slip of the steel plates relative to the top concrete slab, and slip of the structure relative to the shake table must be addressed. The FRF shown in Fig. 28 relates the acceleration in the direction of excitation Ch.3Y (see Fig. 17) during test TRG 13;5 to a similar component of acceleration measured at the outer edge of the top concrete slab, Ch.4y. From this plot it is evident that no amplification of motion at Point 4 relative to Point 3 was measured. This implies that torsional motion did not occur. Similar plots from other tests showed that torsional motion did not occur during any test. 


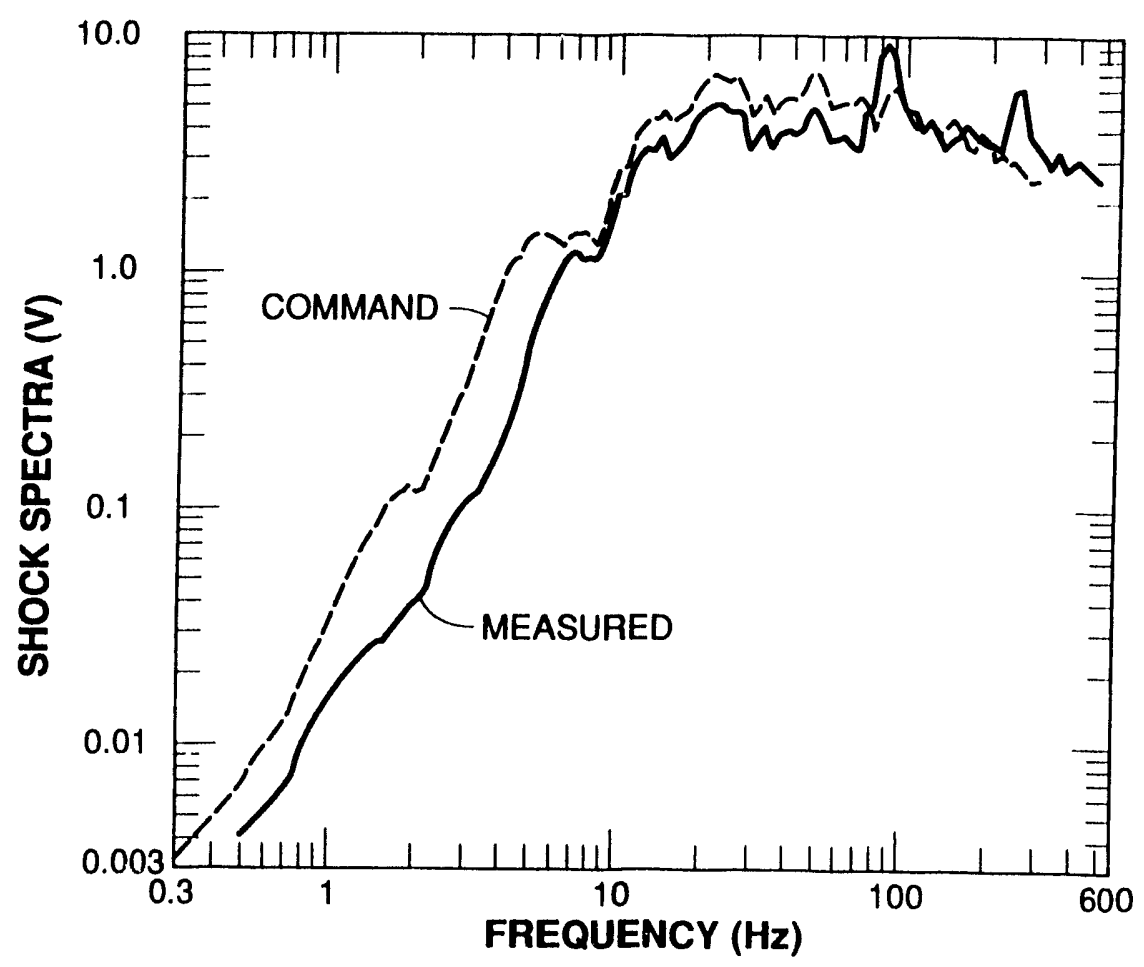

Fig. 27. Comparison of the response spectrum generated from the command signal and the response spectrum generated from the measured base excitation (Ch.2y) of TRG-14 during the first seismic pulse (4\% damping).

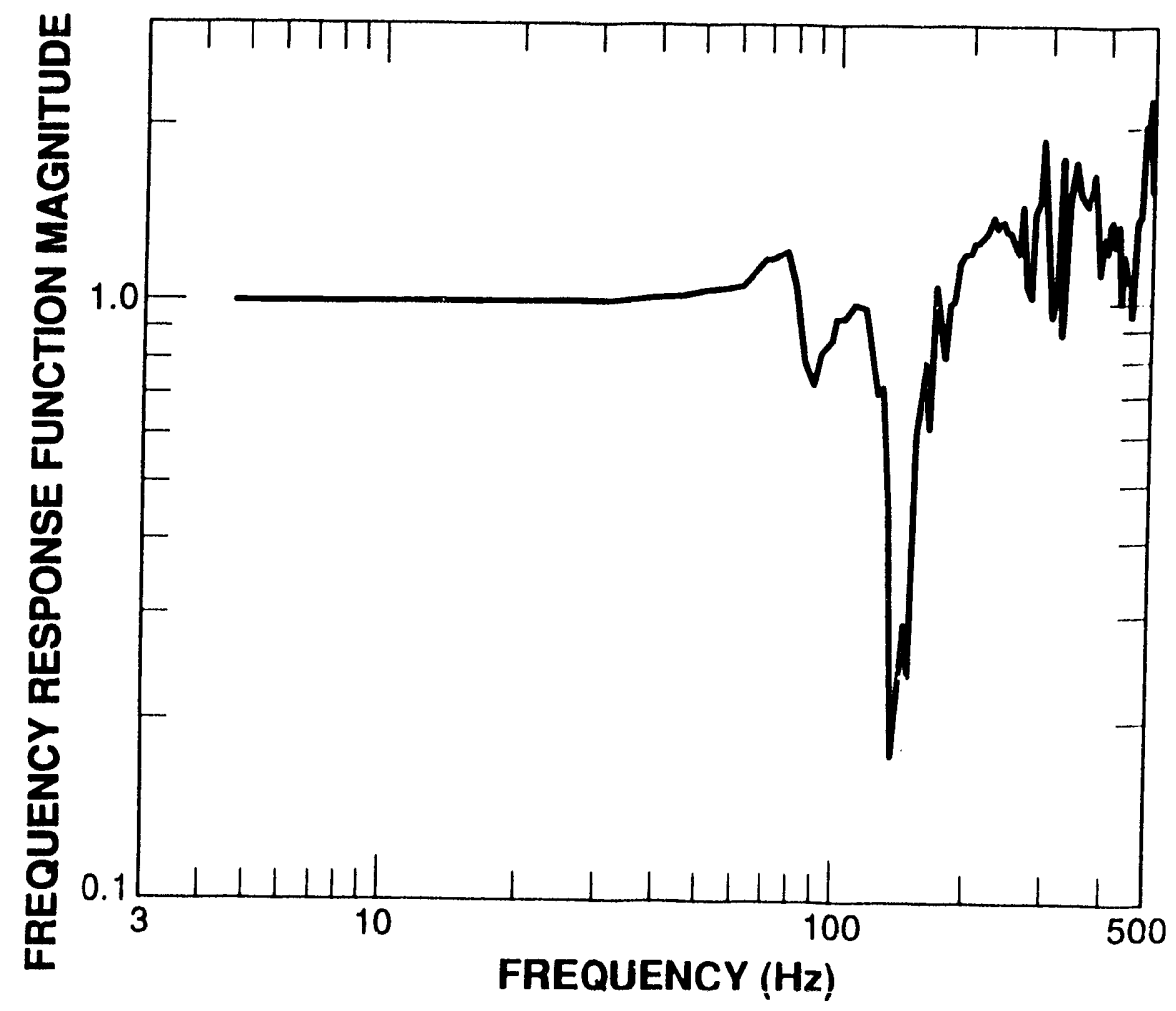

Fig. 28. Frequency response function Ch.4y/Ch.3y, third seismic pulse on TRG-13. 
A comparisc $n$ of the strong motion portion of the acceleration-time histories measured at Points $2 y$ and $1 y$ during test TRG15;7 (shown in Fig. 29) reveals that no slippage between the structure and the shake table occurred during this high-level test. Similarly, Fig. 30 compares Point 9y with Point 3y and shows that no slippage occurred between the structure and the steel plates during the test TRG15;7. Slippage at either location was not observed during any of the tests.

Rigid-body rotation and nonrigid-body base rotation were a problem during all the tests. Figure 31 compares the strong motion portion of the acceleration-time histories measured at Points $2 \mathrm{v}$ and $6 \mathrm{v}$ during test TRG15;1. This plot shows that the motions are 18iv-deg out-of-phase and that they are of almost identical magnitude. These data im ply that the structure was undergoing rigid-body rotation during this lowlevel test. Si nilar response was cbserved during the loop check with the mass added (Trast TRG15;2). Power spectral densities (PSD), Figs. 32 and 33 , calculated for $2 v$ and 'ov show that the' frequency of this rotation during TRG15;1 is approximately $200 \mathrm{~Hz}$. Figures 34 and 35 show similar PSDs from test TRG15;2, where, because of the added mass, the frequency has shifted to 120 riz.

When seismic pulses were applied to the structure, a much more complicated response was observed at Points $2 \mathrm{v}$ and $6 \mathrm{v}$. Thu time histories in Fig. 36 measured during tesi TRG15;3 show that the motion is no longer directly out-of-phase and that it changes from in-phase to out-of-phase during the test. These motions cause the discrepancy between the etiffness values determined from accelerometer readings and the stiffness values deterinined from strain gage data.

\section{E. Comparison of Strain Gage Data With Accelerometer Data}

Figure 37 compares the stiffness reductions determined from accelerometer data with stiffness reductions determined from the strain gage data. Until the structures were cracked by loads that resulted from the applied base excitations, no stiffness reduction was detected by the strain gages. The stiffness results obtained from the strain gage data agree with the stiffness results obtained during static, cyclic testing on TRG-12, -13 and -16 (see Section VII), as well as with the stiffness results obtained during static, cyclic testing of TRG-4. The stiffness reductions shown in Fig. 37, which are determined from accelerometer data, are greater than those determined from the strain gage data. This discrepancy occurs besause the fundamental mode of the structure does not correspond to the fixed-base fundamental mode determined by FEA. From Figs. 31 and 36, it is apparent that the fixed-base condition assumption is violated at very low excitation levels. It is of interest to note that the stiffness reductions that can be determined from accelerometer data measured during the experimental modal analyses (see Fig. 20) correspond to the stiffness reductions determined from the strain gage data. The experimental modal analyses identify the mode shapes that correspond to the resonant frequency measurements. With the mocle shapes identified, one can verify that the resonant frequencies being compared (measured and analytical) correspond to the same mode. 


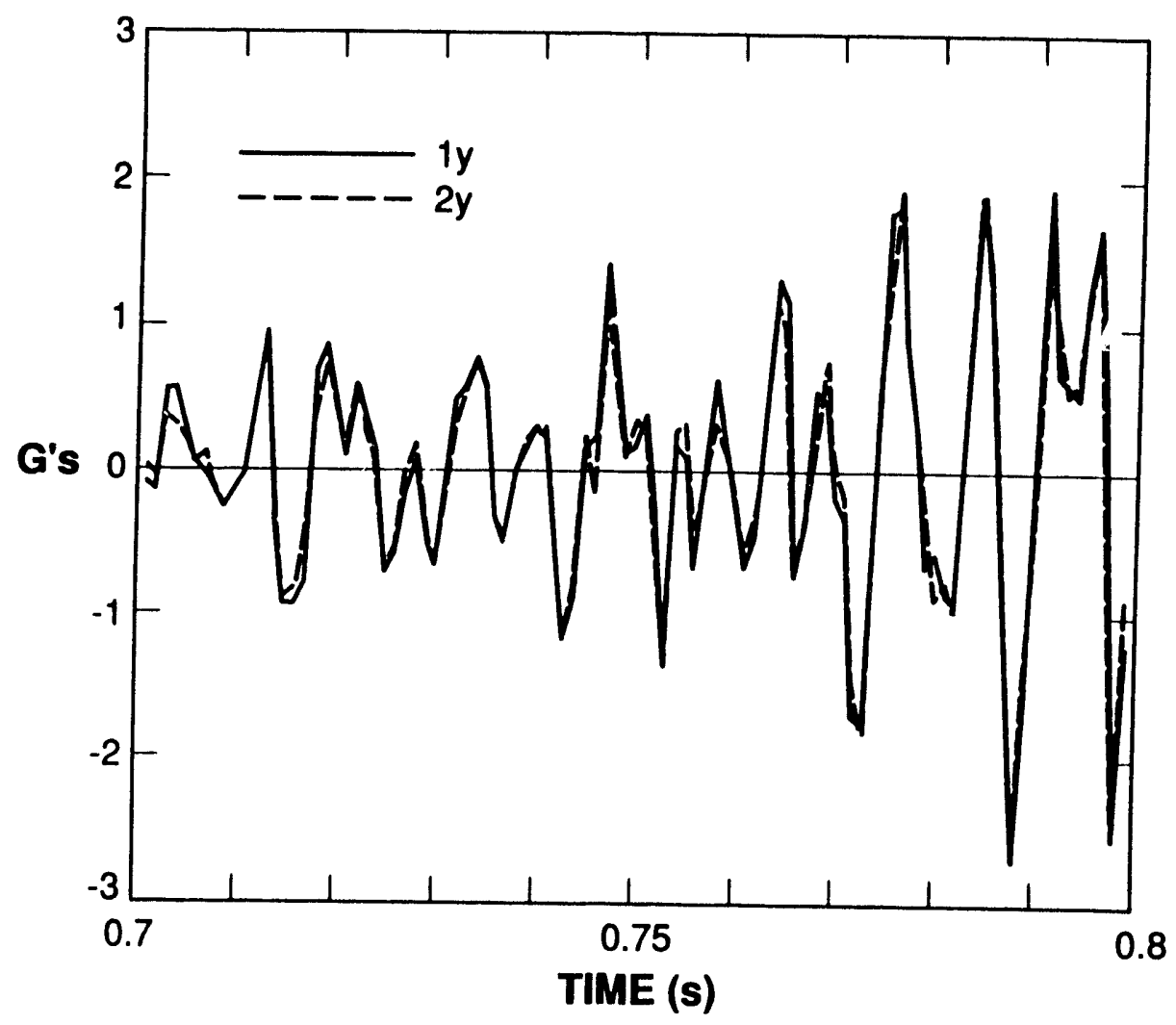

Fig. 29. A comparison of the acceleration-time histories from Ch.1y and Ch.2y during the strong motion portion of test TRG15;7.

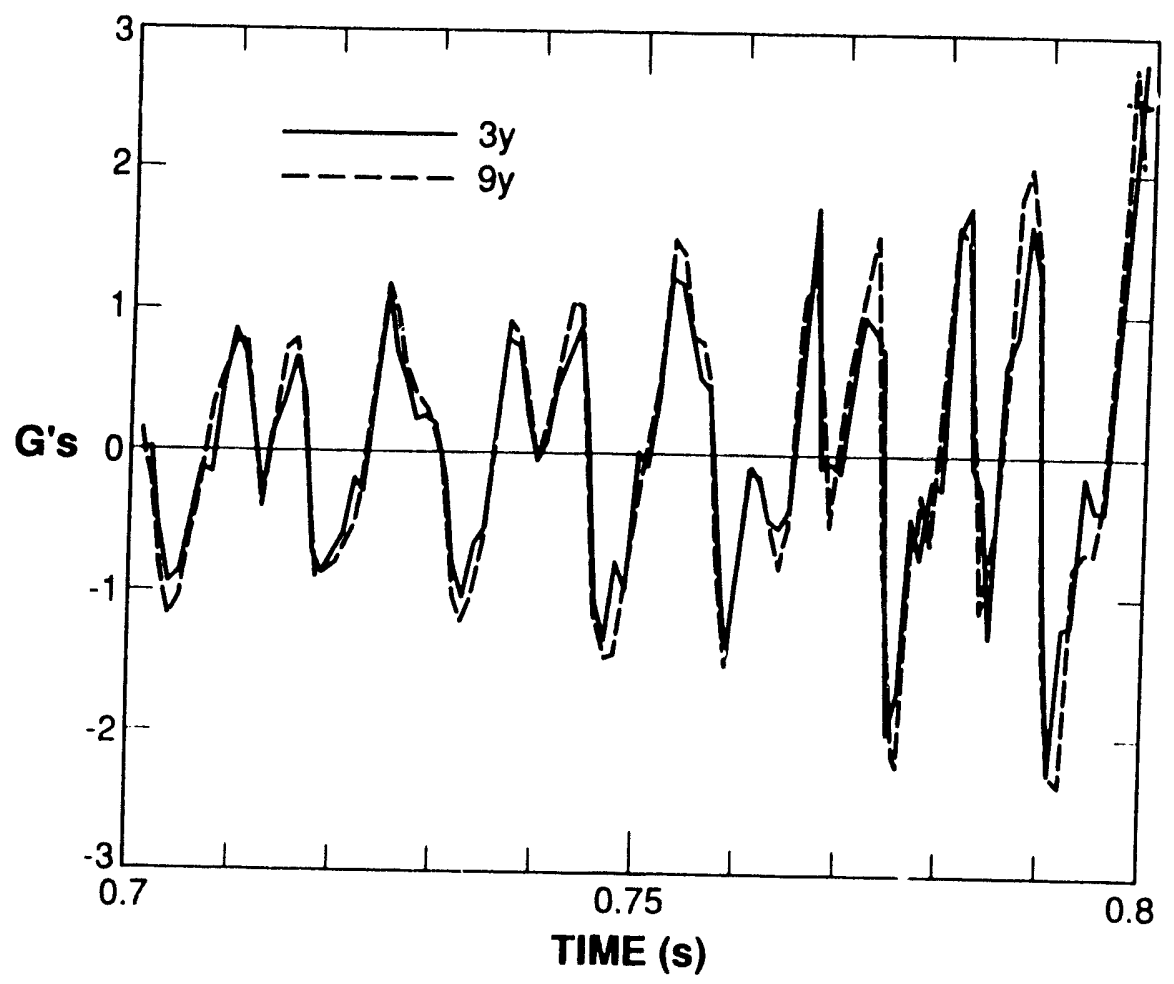

Fig. 30. Â comparison of the acceieratation-time hisionies from Cin.gy and Cin.3y during the strong motion portion of test TRG15;7. 


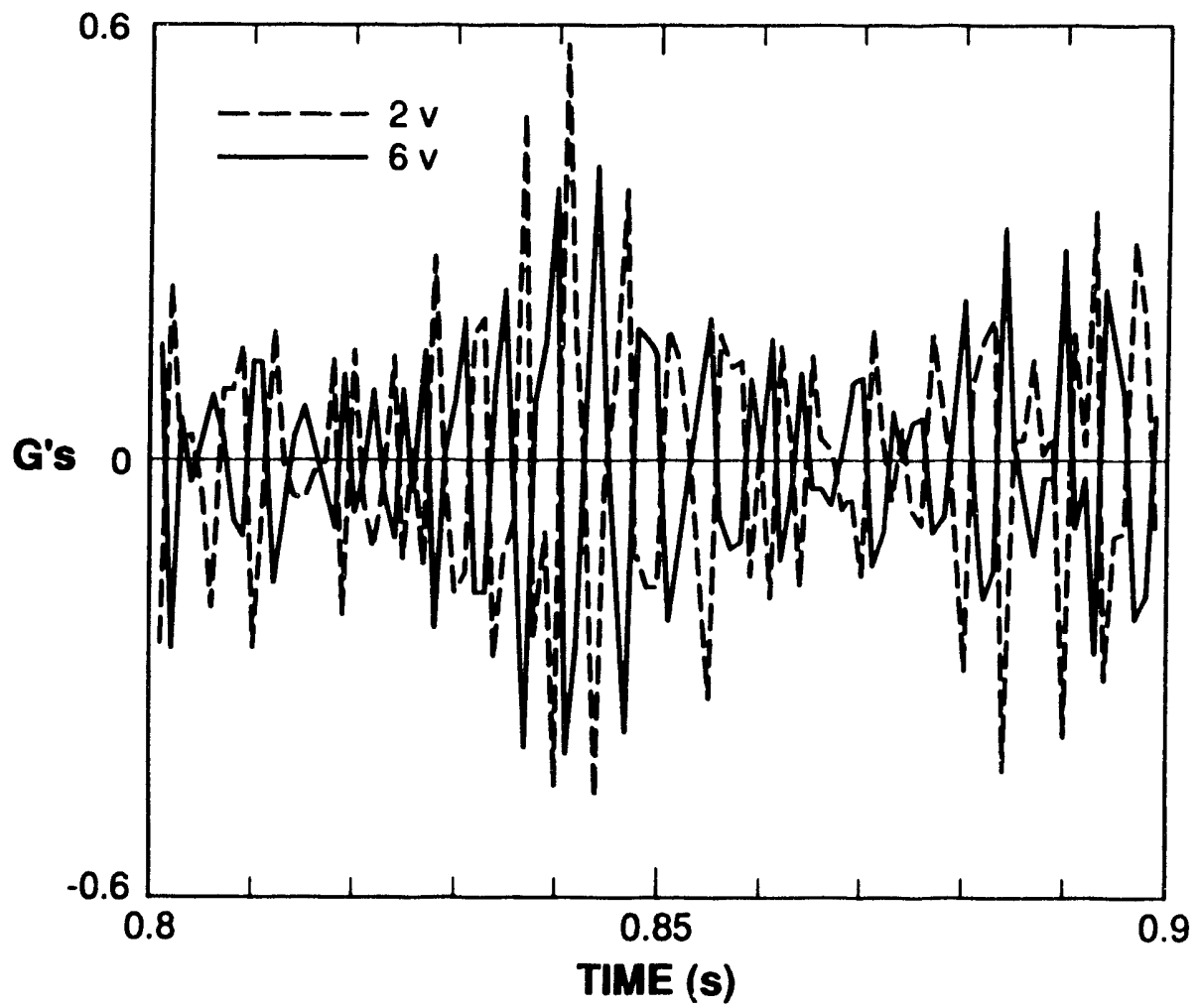

Fig. 31. A comparison of the acceleration-time histories from $\mathrm{Ch} .2 \mathrm{v}$ and $\mathrm{Ch} .6 \mathrm{v}$ during the strong motion portion of test TRG15;1.

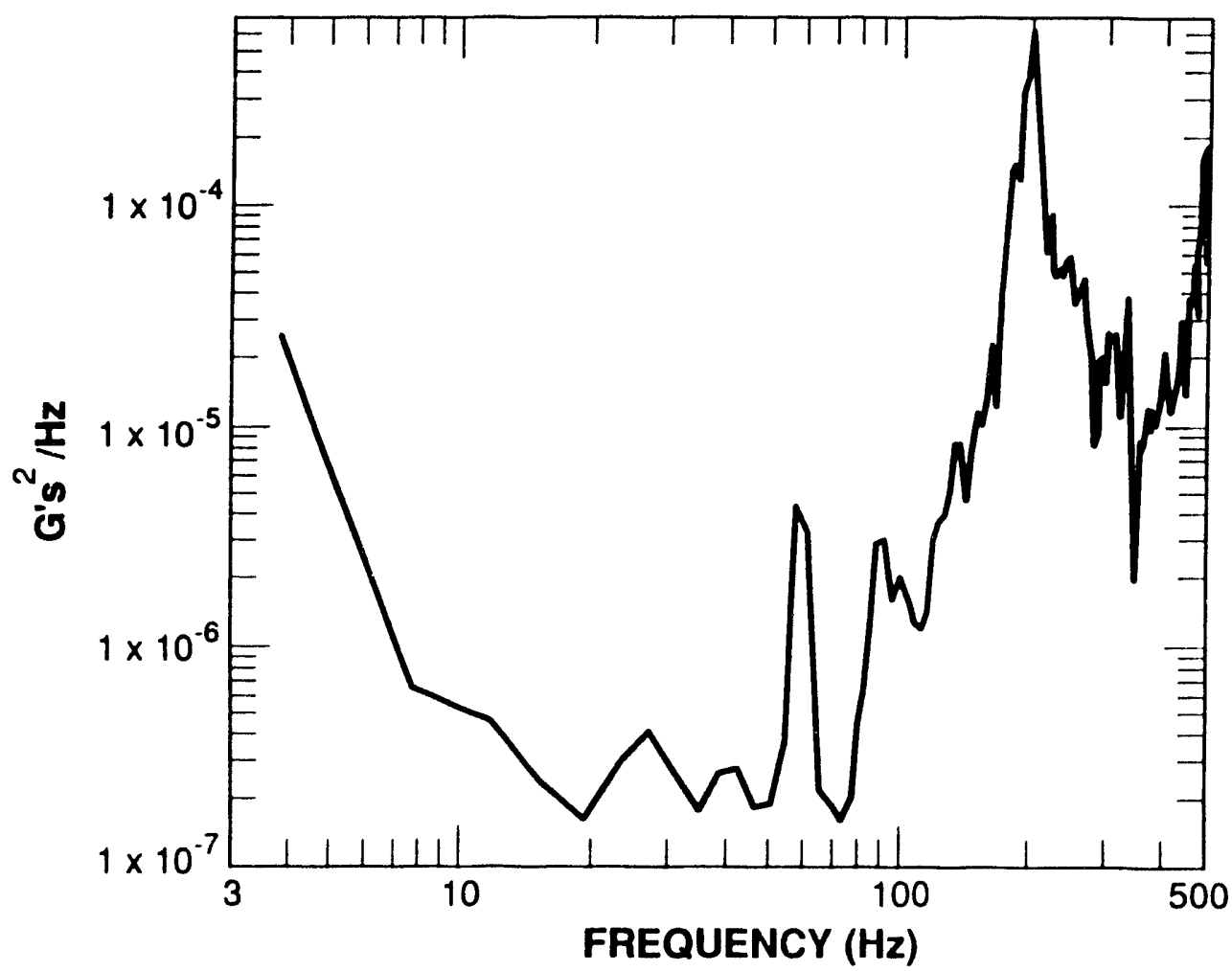

Fig. 32. Power spectral density plot, Ch.2v, test TRG-15;1. 


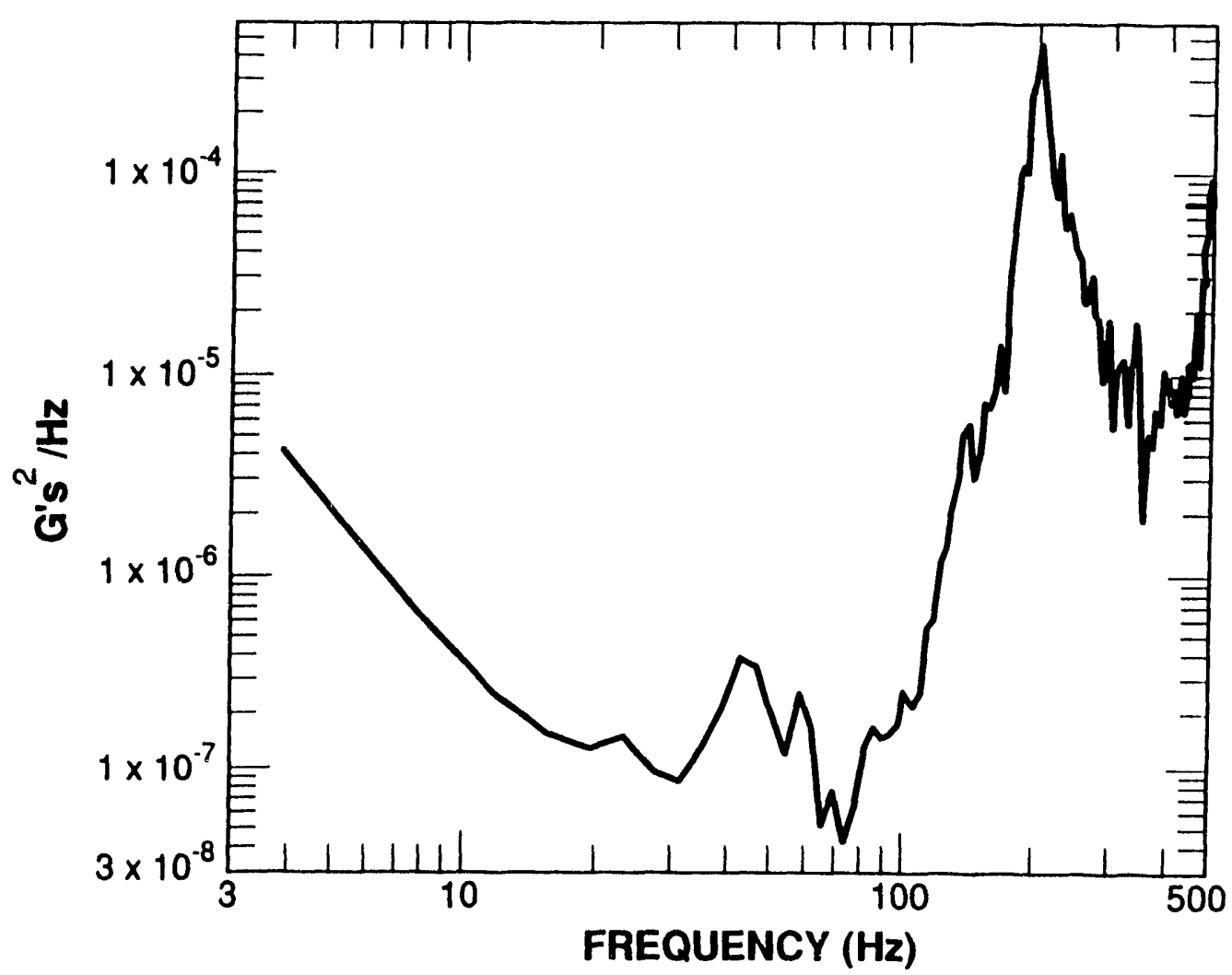

Fig. 33. Power spectral density plot, Ch.6v, test TRG-15;1.

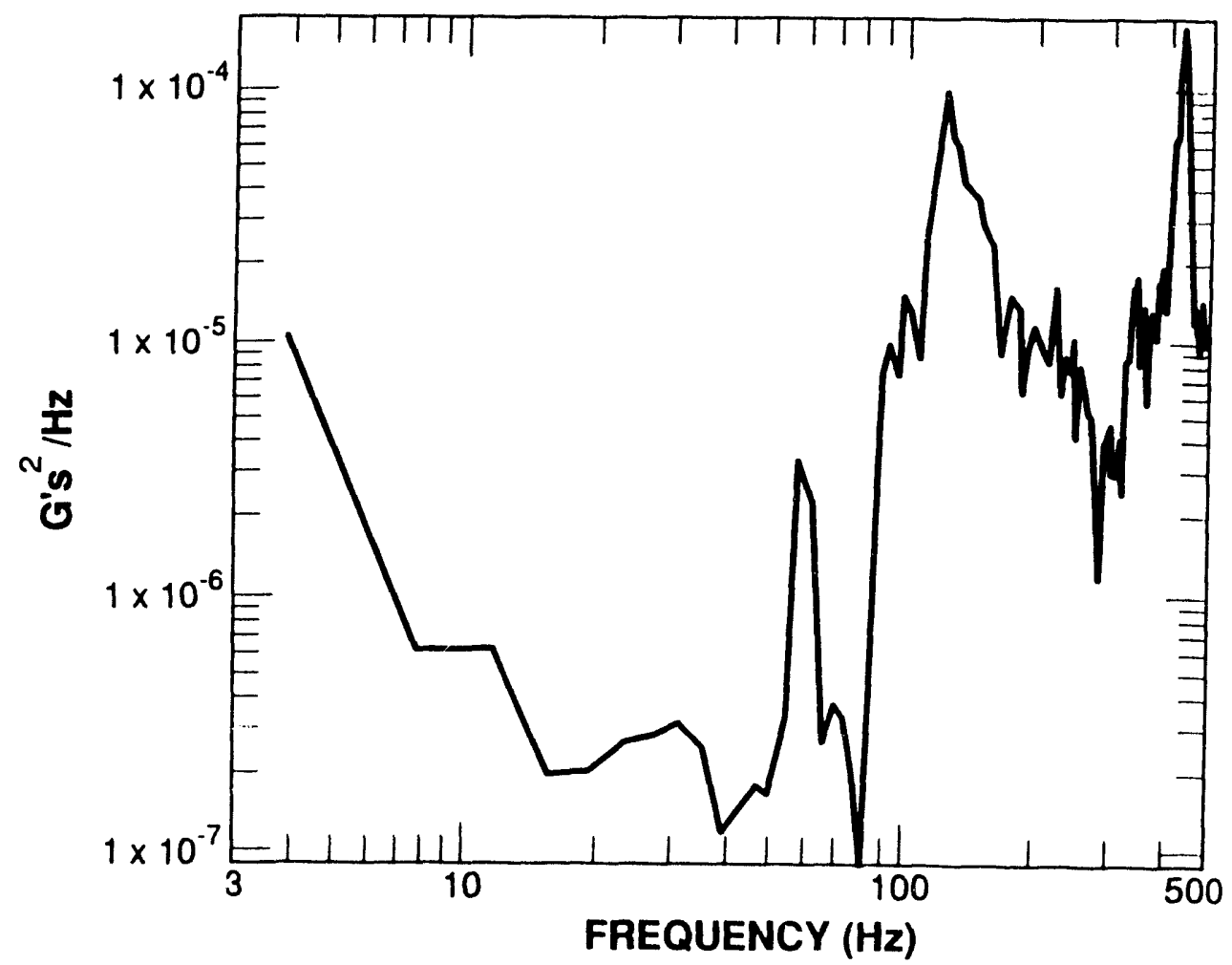

Fig. 34. Power spectral density plot, Ch.2v, test TRG-15;2. 


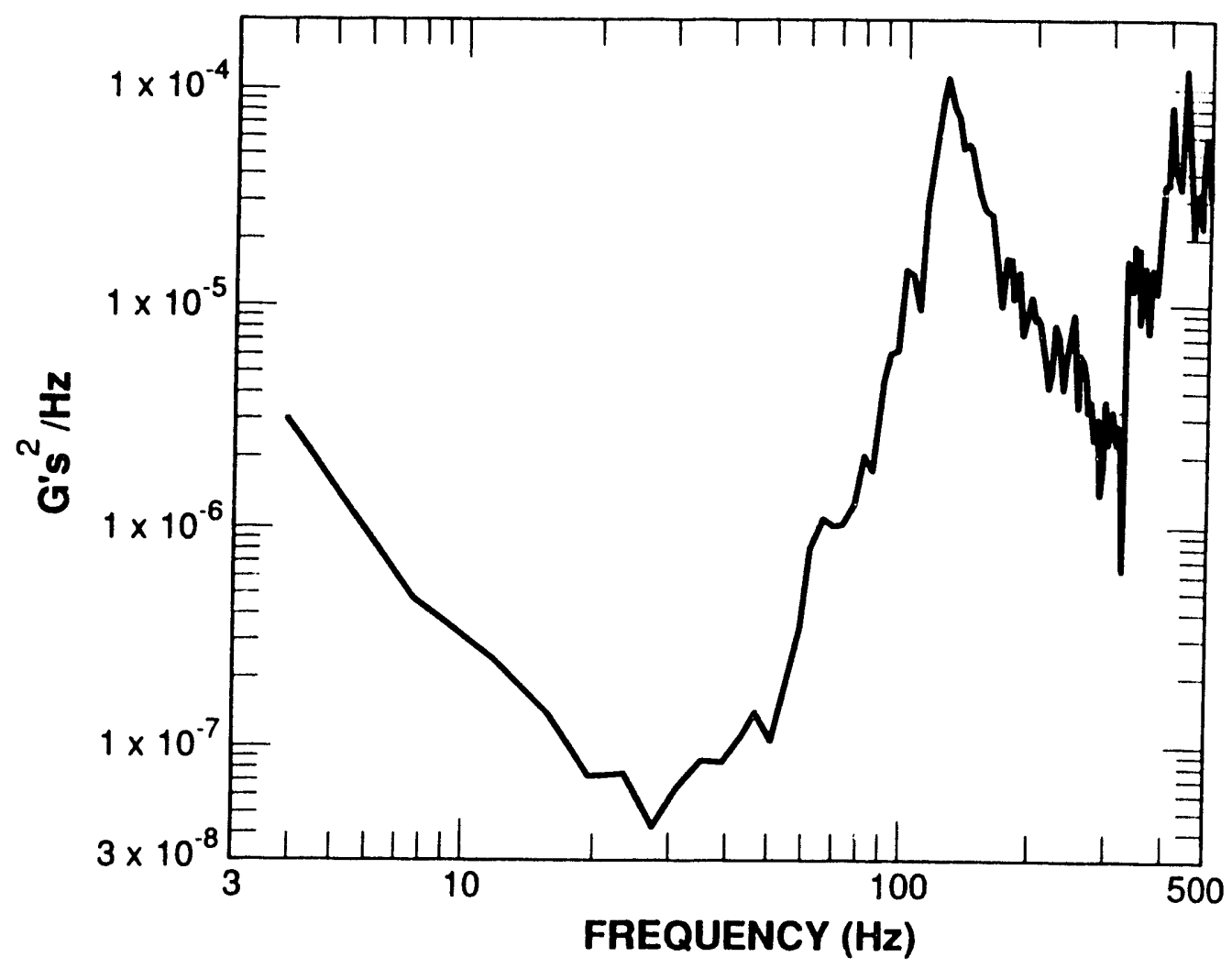

Fig. 35. Power spectral density plot, Ch.6v, test TRG-15;2.

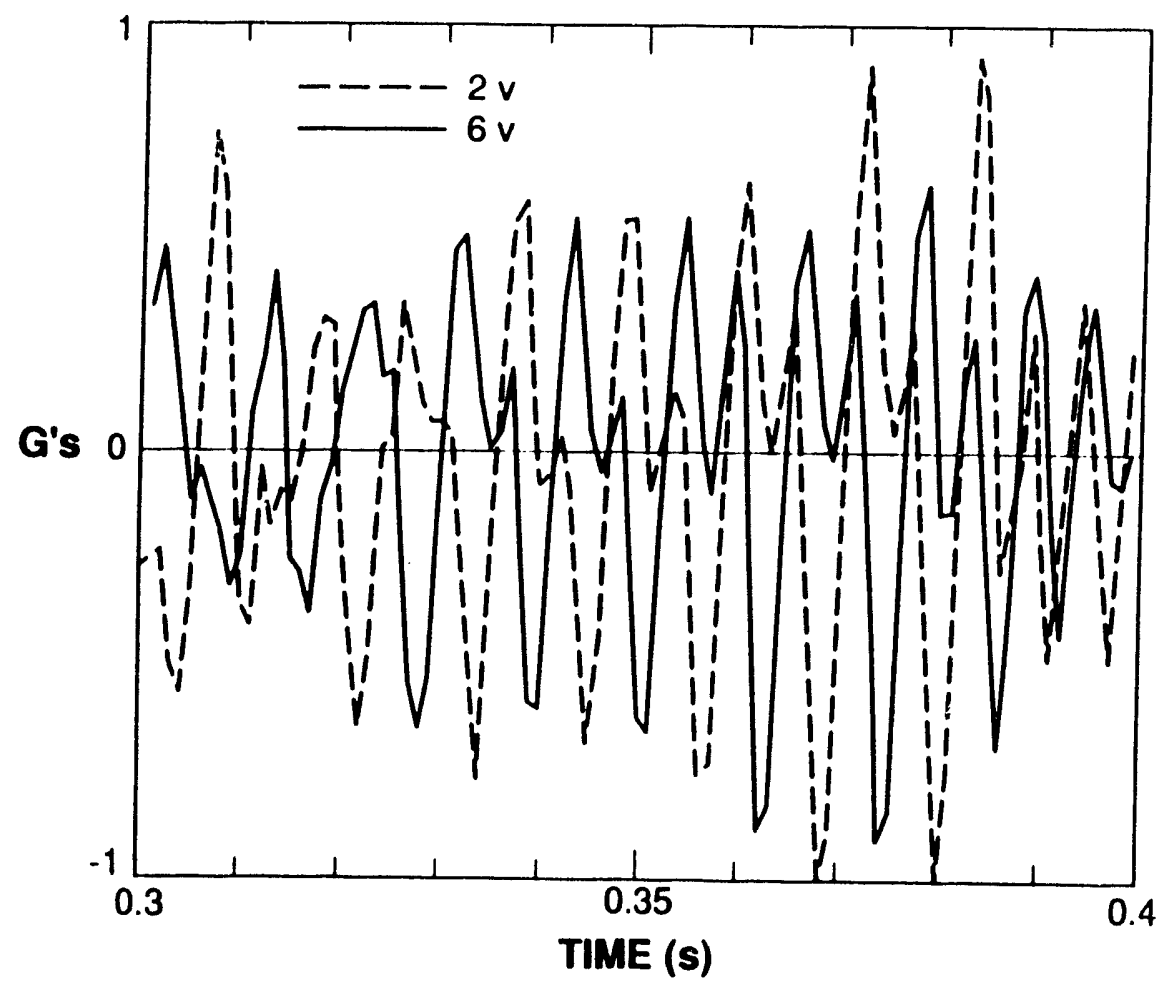

Fig. 36. A comparison of the acceleration-time histories from Ch.2.v and Ch.6v during the strong motion portion of test TRG-15;3. 


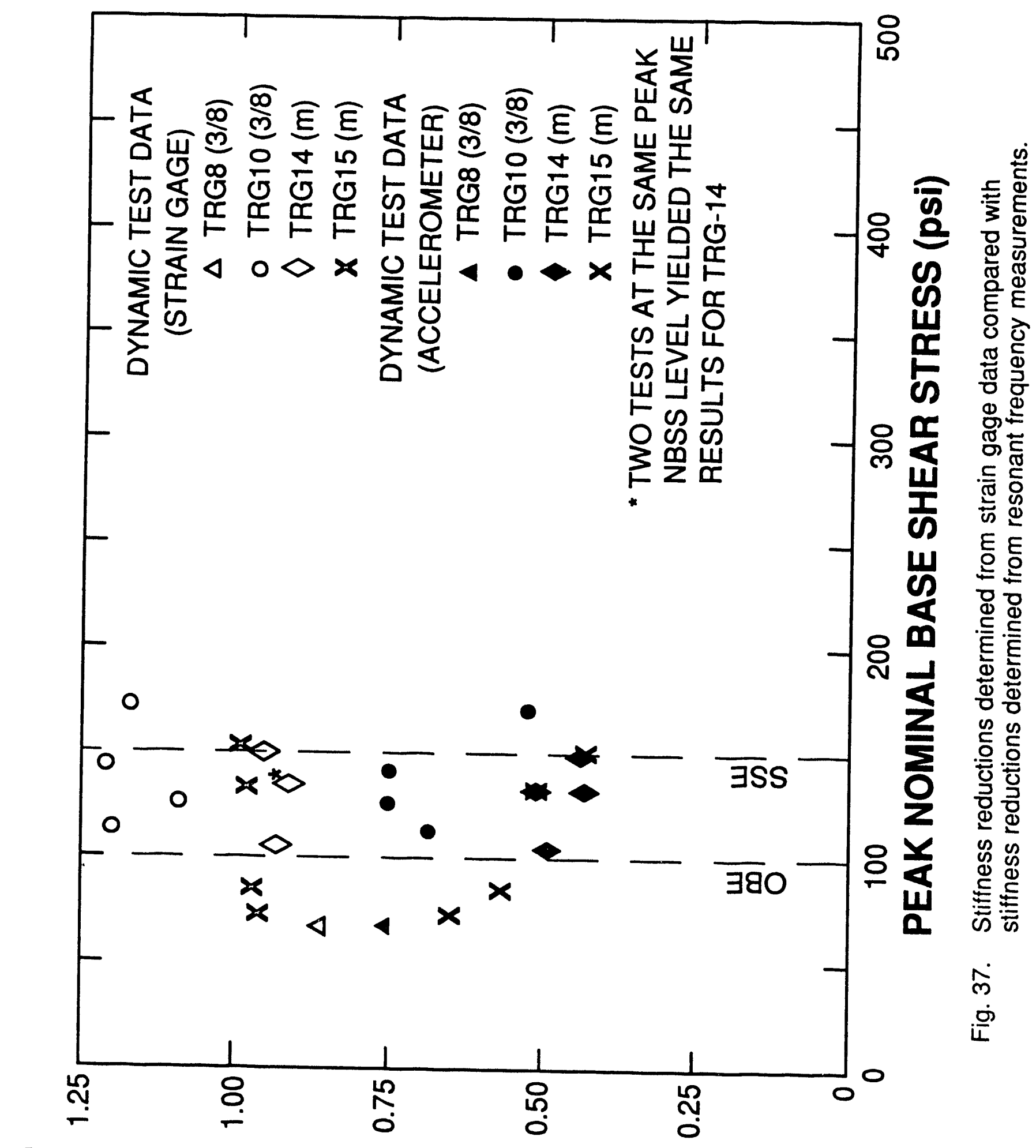

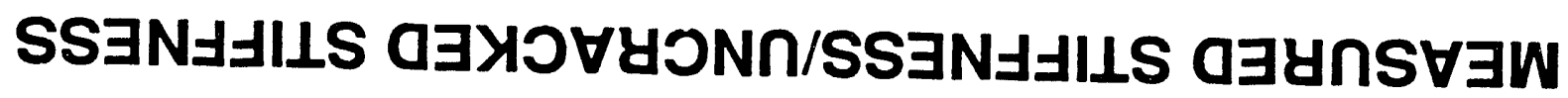




\section{E. Damping Data}

Values for damping in the 1/3-scale shear wall structures for the simulated seismic tests were determined from the measured accelerometer data. Two different methods that estimate an equivalent viscous damping ratio from FRFs were used. When reviewing these results, it must be remembered that certain assumptions have been made about the structures, properties, and test configuration. These assumptions are as follows:

(1) The structures can be adequately represented as a linear, viscously damped, single-degree-of-freedom system.

(2) The base motion input is pure translation in the horizontal direction and in the plane of the shear wall.

(3) The mass of the single-degree-of-freedom model can be estimated as shown in Eq. 8.

It has been observed that the test configuration is not a single degree-of-freedom system even before the structures fracture. This fact is indicated by the significant response of the model base in the vertical direction (see Figs. 31, 36). Sources of compliance that cause other modes of vibration include the airbags that the shake table rests on, the bolted joint between the model and the table, and the attachment of the moving top of the slip table to the fixed base of the table. These differences between the assumed model and the actual test structure and test configuration will affect the observed FRFs and, hence, the calculated damping values. Other differences occur because concrete is not a linear material and because the damping mechanism in concrete is not viscous. Therefore, the calculated values of viscous damping will be only a first approximation to the damping phenomonon in the shear wall structures.

Damping ratios from the FRFs were determined in two different ways. One method is based upon the equation discussed in [13].

$$
\zeta=\frac{1}{2} \frac{\left(\frac{f_{\max }}{f_{\min }}\right)^{2}-1}{\left(\frac{f_{\max }}{f_{\text {min }}}\right)^{2}+1}
$$

where $\zeta=$ viscous damping ratio,

$$
\begin{aligned}
& f_{\max }=\text { the frequency at which the real part of the FRF is a maximum, } \\
& f_{\min }=\text { and }
\end{aligned}
$$

Here, $f_{\max }$ and $f_{\min }$ are at the positive and negative peak of the real part of the FRF on either side of the coordinate axis crossing that indicates a resonant frequency.

The second method uses the FPF magnitude plot and is discussed in [11]. The equation used is 


$$
\zeta=\frac{\omega_{2}-\omega_{1}}{2 \omega_{n}}
$$

where $\quad \omega_{n}=$ the frequency at the peak of the FRF magnitude plot; and

$\omega_{1}, \omega_{2}=$ the half power frequencies associated with $\omega_{n}$.

These methods are applied to the test results for the seismic pulses applied to TRG-8, $-9,-10,-14$, and -15 . The results of these calculations are shown in Table XVIII. Considerable uncertainty exists in these values because of the deviations of the actual structure and the test conditions from the assumed analytical model, as previously discussed.

With these difficulties in mind, the viscous damping ratios that are reported in Table XVIII were recorded only to one decimal place. Table XVIII also shows an average for the damping coefficients that is determined by the two methods. It is appropriate that this average be carried only to one significant figure.

In Table XVIII, a modal frequency is given that was obtained from the FRF. This frequency represents the response of the structure in shear. It is an indicator of the degree of damage the structure has experienced. Frequencies in the range of approximately $75 \mathrm{~Hz}$ or greater are obtained when the structures have little or no damage. Damping ratios obtained in this response range agree with those obtained from the experimental modal analyses. Frequencies in the range of $40 \mathrm{~Hz}$ to approximately $75 \mathrm{~Hz}$ are generally obtained when the structures have been cracked at the end-wall base-slab interface, but not in the shear wall. Frequencies of less than $40 \mathrm{~Hz}$ may indicate cases where the cracking has at least been initiated in the shear wall. It is not certain that the shear wall cracked in any of the structures that were tested.

\section{STATIC TESTING AND RESULTS}

\section{A. Instrumentation and Test Setup}

The static tests on TRG-12, -13 , and -16 were intended to duplicate the static tests performed on TRG-4. After the modal testing had been completed, the structures were bolted to a 6-in.-thick steel base plate. A layer of plaster-of-Paris was placed between the base of the structures and the base plate io provide an even bearing surface that would conform to the base of the structure. Thirty-six 0.5 -in.-diam studs, torqued to $30 \mathrm{ft}-\mathrm{lb}$, fixed the base of the structures to the plate. A layer of plaster-of-Paris was also placed on top of the structures and two 2-in.-thick-steel plates were mounted on top of the structures. These plates were held in place with thirty-six 0.5 -in.-diam bolts also torqued to $30 \mathrm{ft}-\mathrm{lb}$. Load was applied to the bottom steel plate in an anilogous manner to those in the TRG-4 test. 
TABLE XVIII

Viscous Damping Ratio Values Measured on Structures Used in the Seismic Test Series

\begin{tabular}{|c|c|c|c|c|}
\hline \multirow{2}{*}{$\begin{array}{l}\text { Seismic } \\
\text { Pulse No. }\end{array}$} & \multirow{2}{*}{$\begin{array}{r}\text { Resonant } \\
\text { Frequency, } \\
(\mathrm{Hz})\end{array}$} & \multicolumn{2}{|c|}{$\begin{array}{l}\text { Calculated Damping } \\
\text { Coefficent, \% }\end{array}$} & \multirow{2}{*}{$\begin{array}{c}\text { Average Damping } \\
\text { Batio. } \%\end{array}$} \\
\hline & & $\operatorname{Re}(H(i \omega))$ & $\|H(j \omega)\|$ & \\
\hline TRG8;-3 & 84 & $\cdots$ & 0.3 & 1 \\
\hline $\begin{array}{l}\text { TRG9;-3 } \\
\text { TRG9;-4 } \\
\text { TRG9;-5 } \\
\text { TRG9;-6 }\end{array}$ & $\begin{array}{l}74 \\
62 \\
36 \\
16\end{array}$ & $\begin{array}{l}2.0 \\
7.0 \\
3.6 \\
7.8\end{array}$ & $\begin{array}{l}1.7 \\
-- \\
-- \\
--\end{array}$ & $\begin{array}{l}2 \\
7 \\
4 \\
8\end{array}$ \\
\hline $\begin{array}{l}\text { TRG10;-3 } \\
\text { TRG10;-4 } \\
\text { TRG10;-5 } \\
\text { TRG10;-6 } \\
\text { TRG10;-7 } \\
\text { TRG10;-8 }\end{array}$ & $\begin{array}{l}80 \\
84 \\
84 \\
70 \\
73 \\
33\end{array}$ & $\begin{array}{r}2.0 \\
1.2 \\
1.6 \\
1.0 \\
9.0 \\
12.0\end{array}$ & $\begin{array}{l}1.2 \\
1.2 \\
1.2 \\
2.0 \\
-- \\
9.4\end{array}$ & $\begin{array}{r}2 \\
1 \\
1 \\
2 \\
9 \\
10\end{array}$ \\
\hline $\begin{array}{l}\text { TRG14;-4 } \\
\text { TRG14;-5 } \\
\text { TRG14;-6 } \\
\text { TRG14;-7 } \\
\text { TRG14;-8 } \\
\text { TRG14;-9 }\end{array}$ & $\begin{array}{l}70 \\
71 \\
62 \\
63 \\
59 \\
31\end{array}$ & $\begin{array}{c}5.6 \\
-- \\
3.8 \\
4.2 \\
4.4 \\
11\end{array}$ & $\begin{array}{l}3.5 \\
-- \\
4.3 \\
3.3 \\
6.2 \\
--\end{array}$ & $\begin{array}{r}5 \\
- \\
4 \\
4 \\
5 \\
10\end{array}$ \\
\hline $\begin{array}{l}\text { TRG15;-3 } \\
\text { TRG15;-4 } \\
\text { TRG15;-5 } \\
\text { TRG15;-6 } \\
\text { TRG15;-7 } \\
\text { TRG15;-8 }\end{array}$ & $\begin{array}{l}80 \\
75 \\
71 \\
62 \\
57 \\
30\end{array}$ & $\begin{array}{l}0.6 \\
2.0 \\
-. \\
3.7 \\
-- \\
6.6\end{array}$ & $\begin{array}{l}0.4 \\
0.8 \\
0.8 \\
4.7 \\
4.1 \\
7.4\end{array}$ & $\begin{array}{l}1 \\
1 \\
1 \\
4 \\
4 \\
7\end{array}$ \\
\hline
\end{tabular}

An instrumentation frame was assembled around the structures independent of the base plate. Twenty Ono-Sokki EG-233 displacement transducers (resolution of $4 \times 10^{-5} \mathrm{in}$.) were placed on the structures and on the instrumentation frame at locations shown schematically in Fig. 38. Ten gages were mounted on the model itself, providing relative displacement readings that were independent of any rigid-body rotation and translation. Of these ten, eight were located on the shear wall and were used to obtain the readings necessary to separate the shear and bending components of displacement. Overall structural deformations, including rigid-body motion, were monitored with the remaining 10 gages attached to the instrumentation frame. These external gages were also used to measure torsional motion of the structure. Figure 39 shows the TRG-12 structure mounted on the base plate with the instrumentation frame in place. 

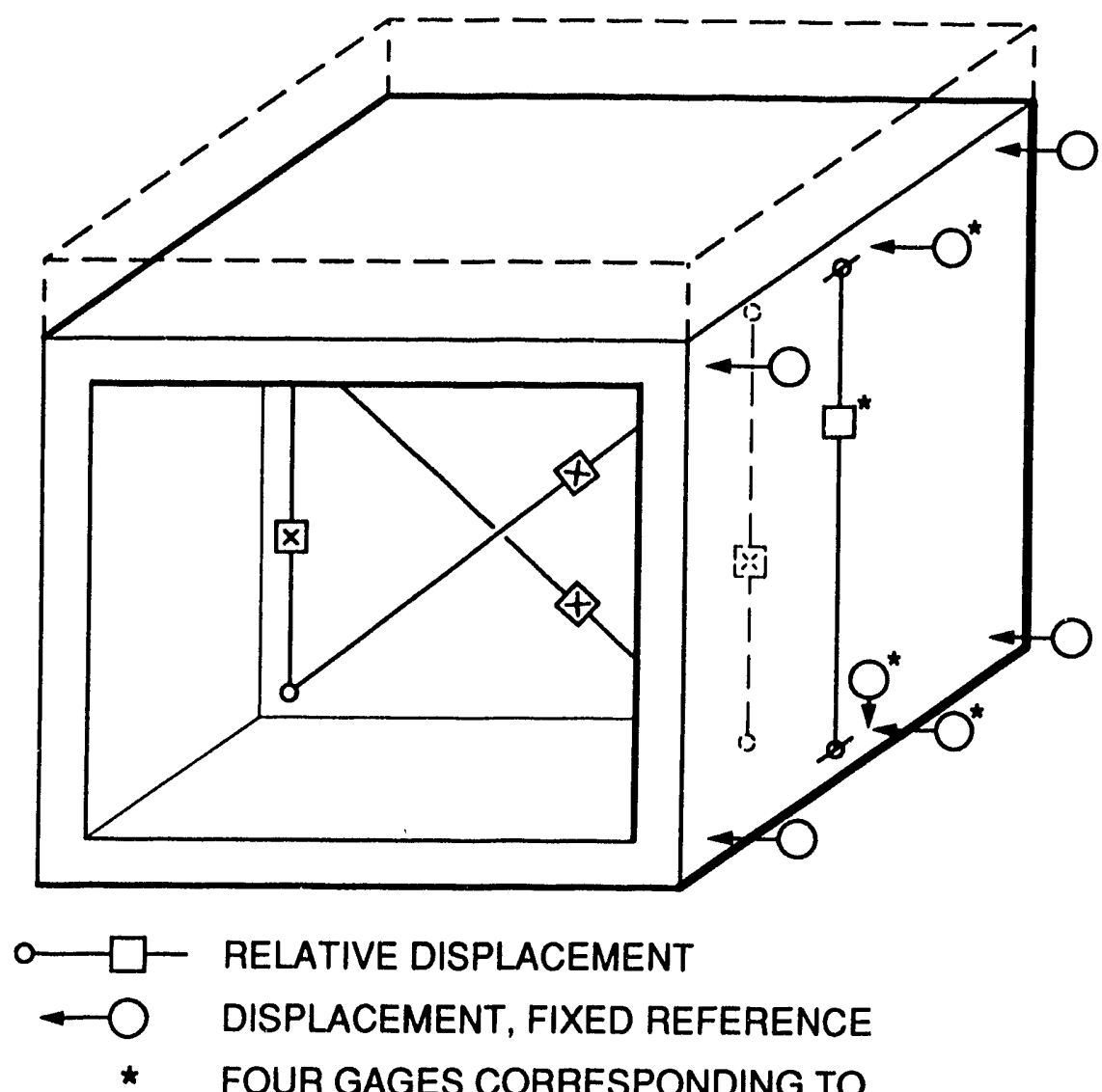

RELATIVE DISPLACEMENT

DISPLACEMENT, FIXED REFERENCE

FOUR GAGES CORRESPONDING TO

THESE ARE ON THE OTHER END WALL

$\times \quad$ FOUR GAGES CORRESPONDING TO

THESE ARE ON THE OTHER SIDE

OF THE SHEAR WALL

Fig. 38. Displacement transducer locations.

In addition to the displacement transducers used to measure displacements during the tests on TRG-12 and -16, long-gage-length $(120-\mathrm{mm})$ strain gages were mounted end-to-end on both sides of the shear wall at locations that corresponded to the relative displacement gages. The strain gages were wired in series so that each group of gages, either along the diagonal or vertical, would act as one continuous gage over their entire combined lengths. Similar strain gages were mounted on TRG-8, $-9,-10,-14$ and -15 during simulated seismic tests so that relative displacements could be measured directly during dynamic tests (see Figs. 18 and 19). A direct comparison of the displacements, determined by integrating the strain readings and those measured with the displacement gages, provided a quantitative assessment of how accurately the strain gages can measure displacement during the simulated seismic tests.

Because the static tests were performed outdoors, the strain gage readings were susceptible to thermal effects. To mininize the thermal effects, undamaged strain gages, which were still mounted on one of the structures previously tested to failure dynamicaily, were used as temperature-compensating gages in the measuring bridge circuits. 


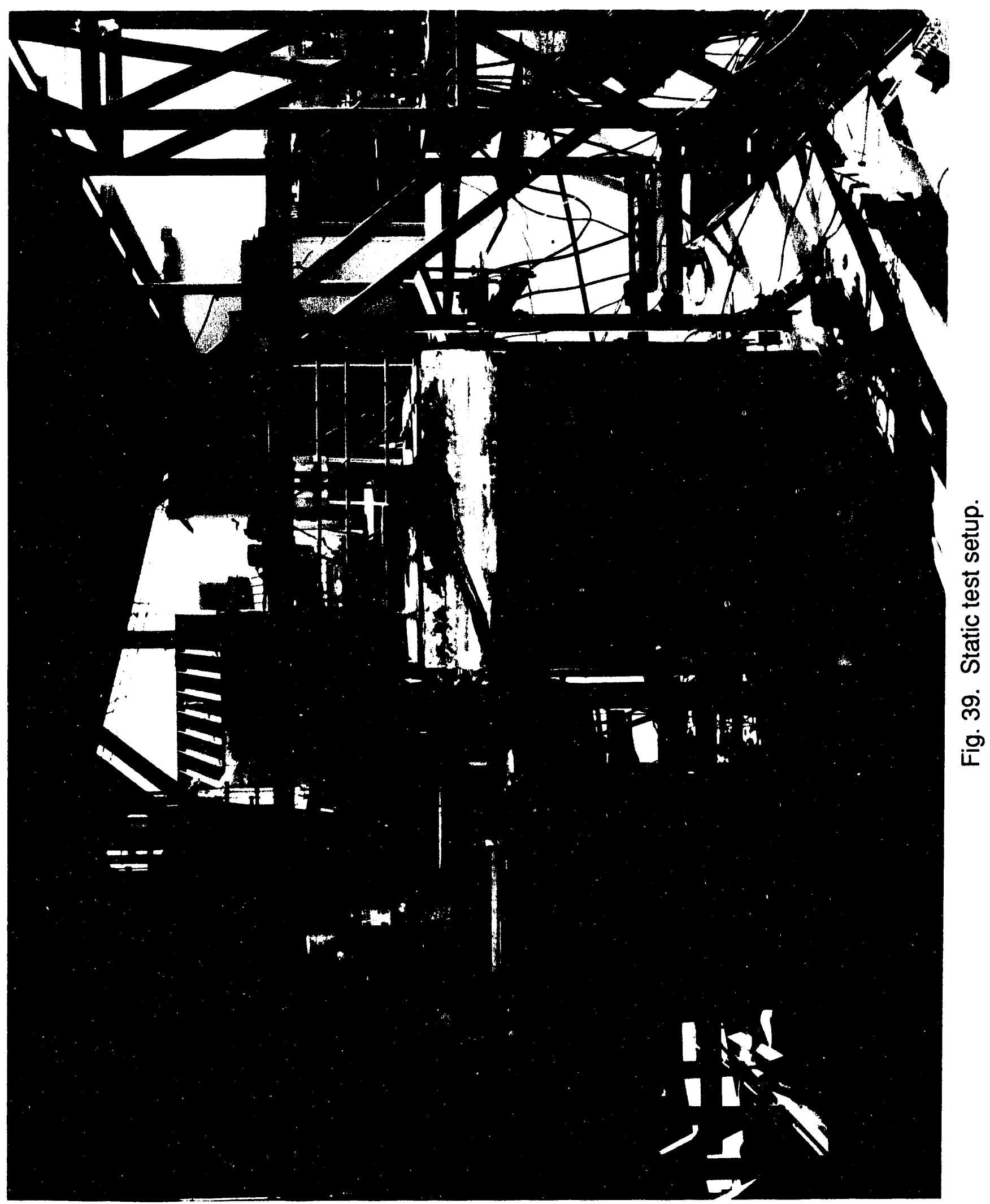


An MTS hydraulic actuator was used to load the structure, and force input was monitored with a load cell located between the actuator and the bottom steel plate. At specified load increments, thie output of the strain gage bridges, displacement transducers, and load cell were recorded using a data acquisition system based on an HP 3497A scanner and an HP 1000 computer. After some low-level tests to check the instrumentation, the load histories shown in Figs. 40-42 were followed. In these figures, each integer on the horizontel axis represents a point at which the data were scanned. The complete load reversals shown in these load histories were intended to represent the forces induced in a Seismic Category I structure during seismic excitation. The breaks in the load histories at the end of a cycle were the result of zeroing the gages and load cell before the start of the next cycle. This discontinuity was accounted for in the final data reduction.

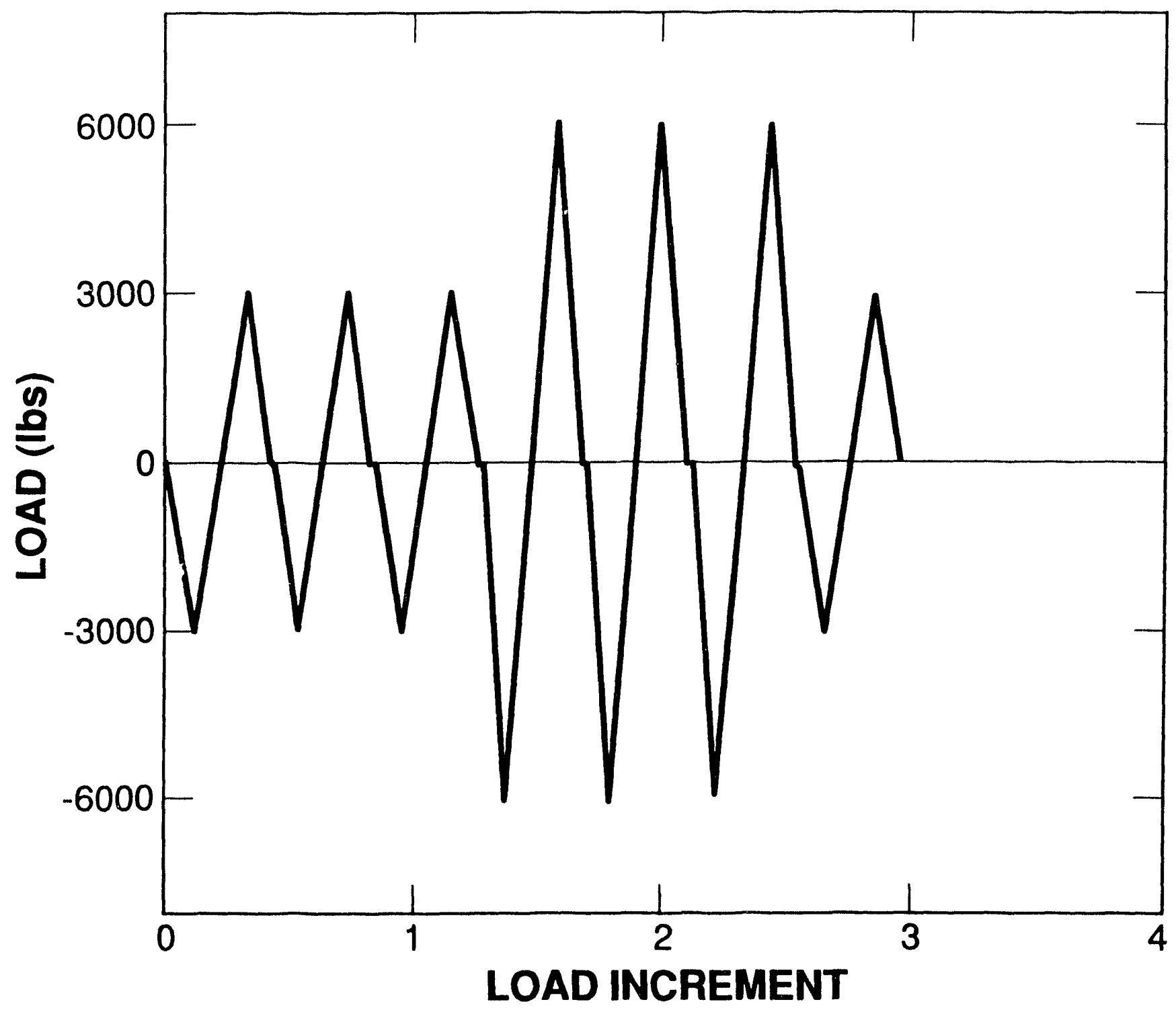

Fig. 40. TRG-13 load history. 


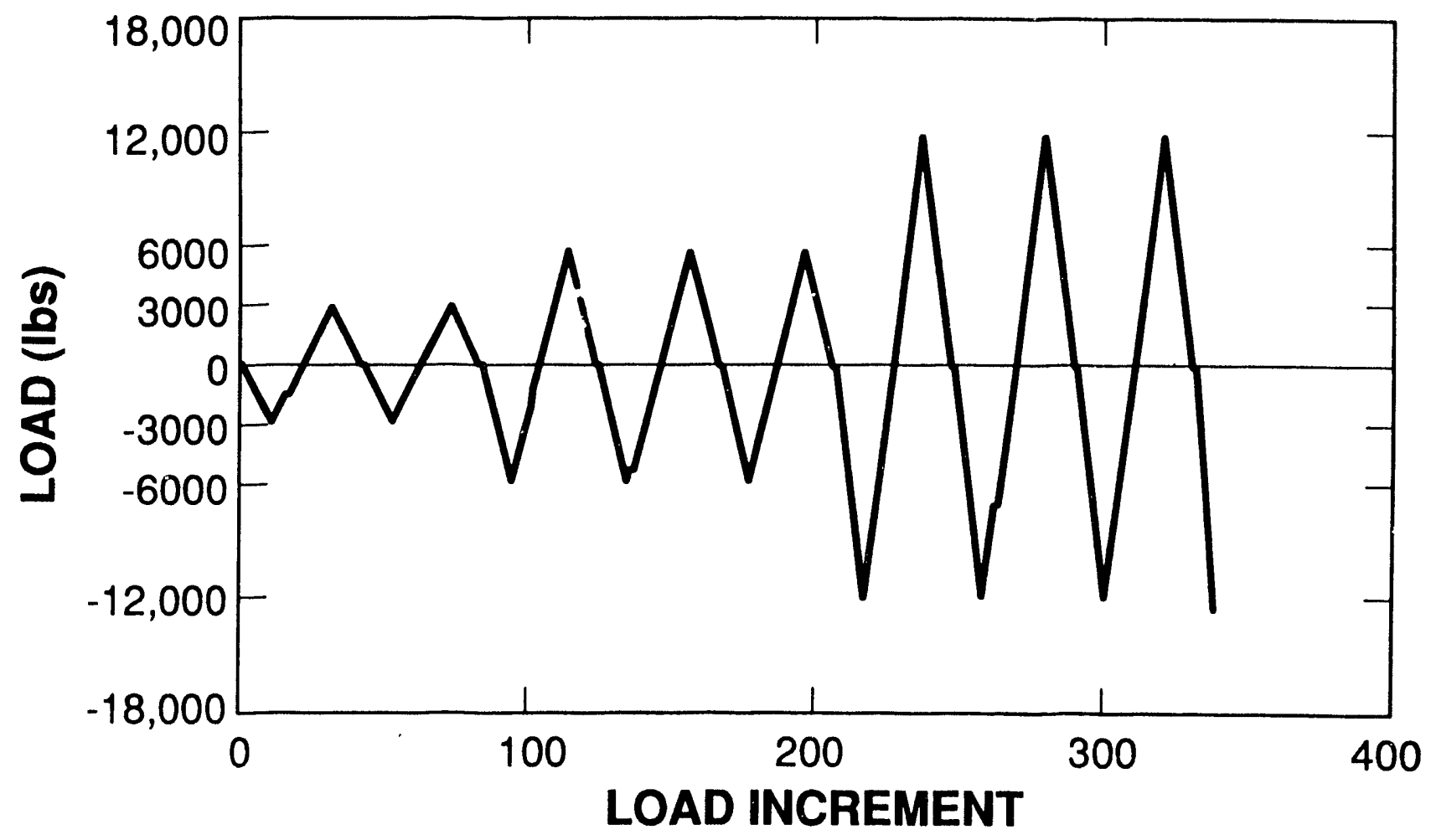

Fig. 41. TRG-12 load history.

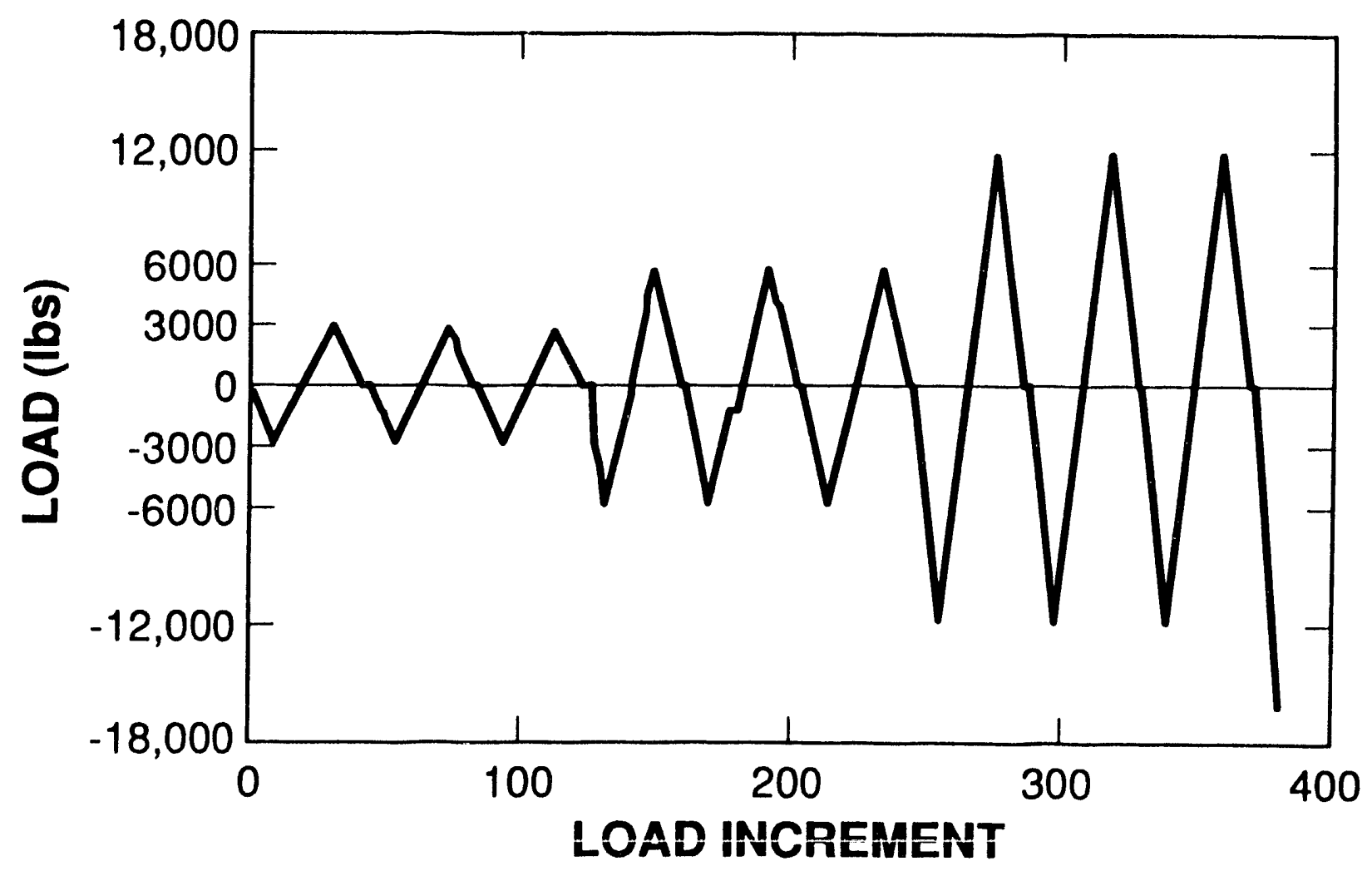

Fig. 42. TRG-16 load history. 


\section{B. Test Results (Displacement Transducers)}

TRG-13 exhibited repeatable linear response during all of the load cycles it experienced, as shown in Fig. 43. This structure was not taken to failure because it was, subsequently, to be used for simulated seismic tests. Stiffness and hysteretic energy losses for TRG-12, -13 and -16 were calculated from the internal relative displacement gages and from the strain gages in an identical manner as on TRG-4. The previous section on seismic testing provides a review of the internal gage data reduction used to obtain displacements and Appendix B recaps the method used to obtain damping properties from static, cyclic load-deformation data. Results obtained from the TRG-13 data concerning stiffness and damping are summarized in Table XIX. The theoretical stiffness values listed in Table XIX were calculated in a manner identical to the theoretical stiffness values reported in [1] and discussed in the seismic testing section. It should be noted that after the static tests were complete and the base studs had been removed, a 50-psi NBSS had to be applied to the structure to break the plaster-of-Paris loose from the base plate. This load gives an estimate of the bond that the plaster-ofParis provides at the base of the structure. Strain gages were not mounted on this structure.

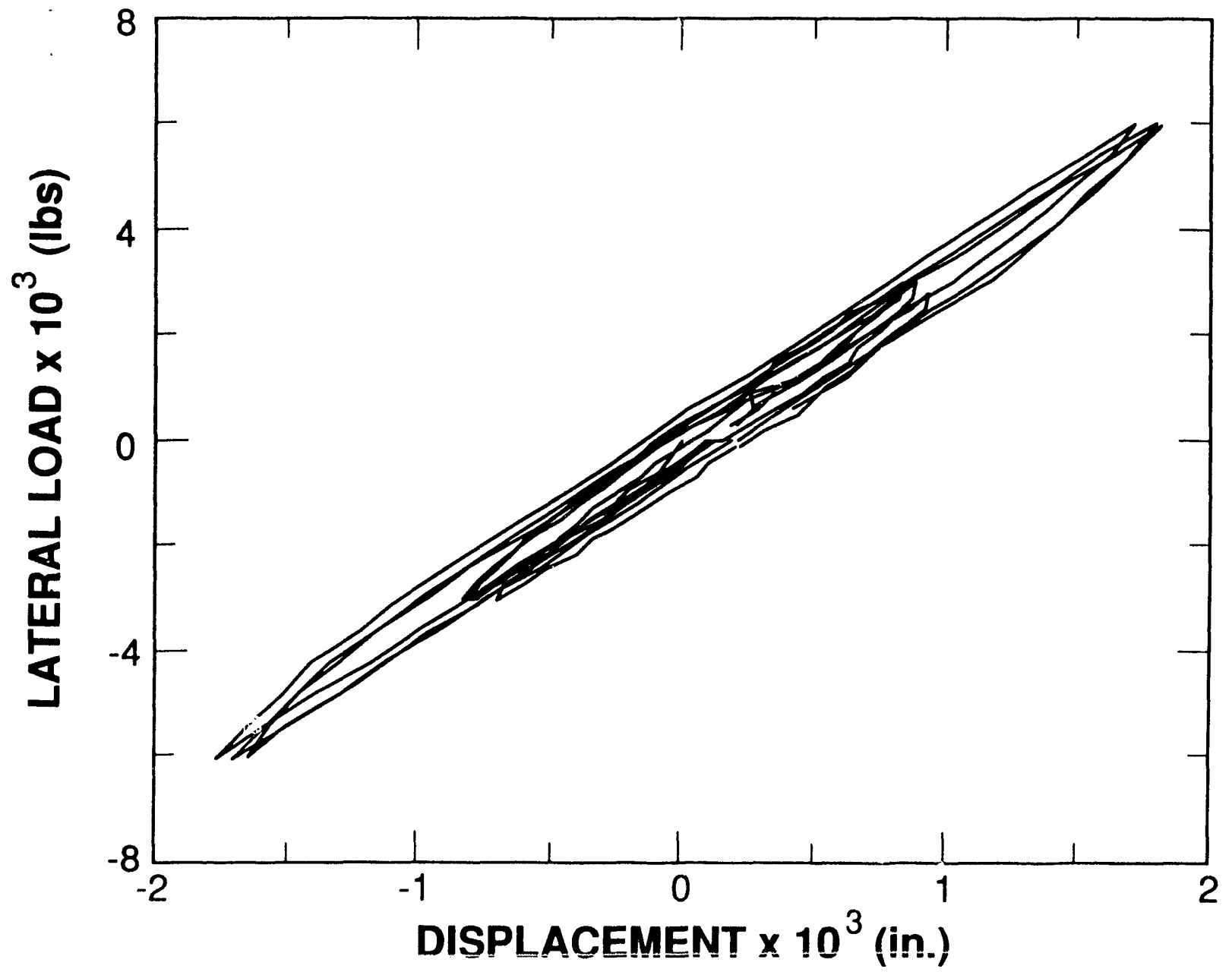

Fig. 43. Force versus displacement from the average of the internal relative displacement gage readings on TRG-13. 


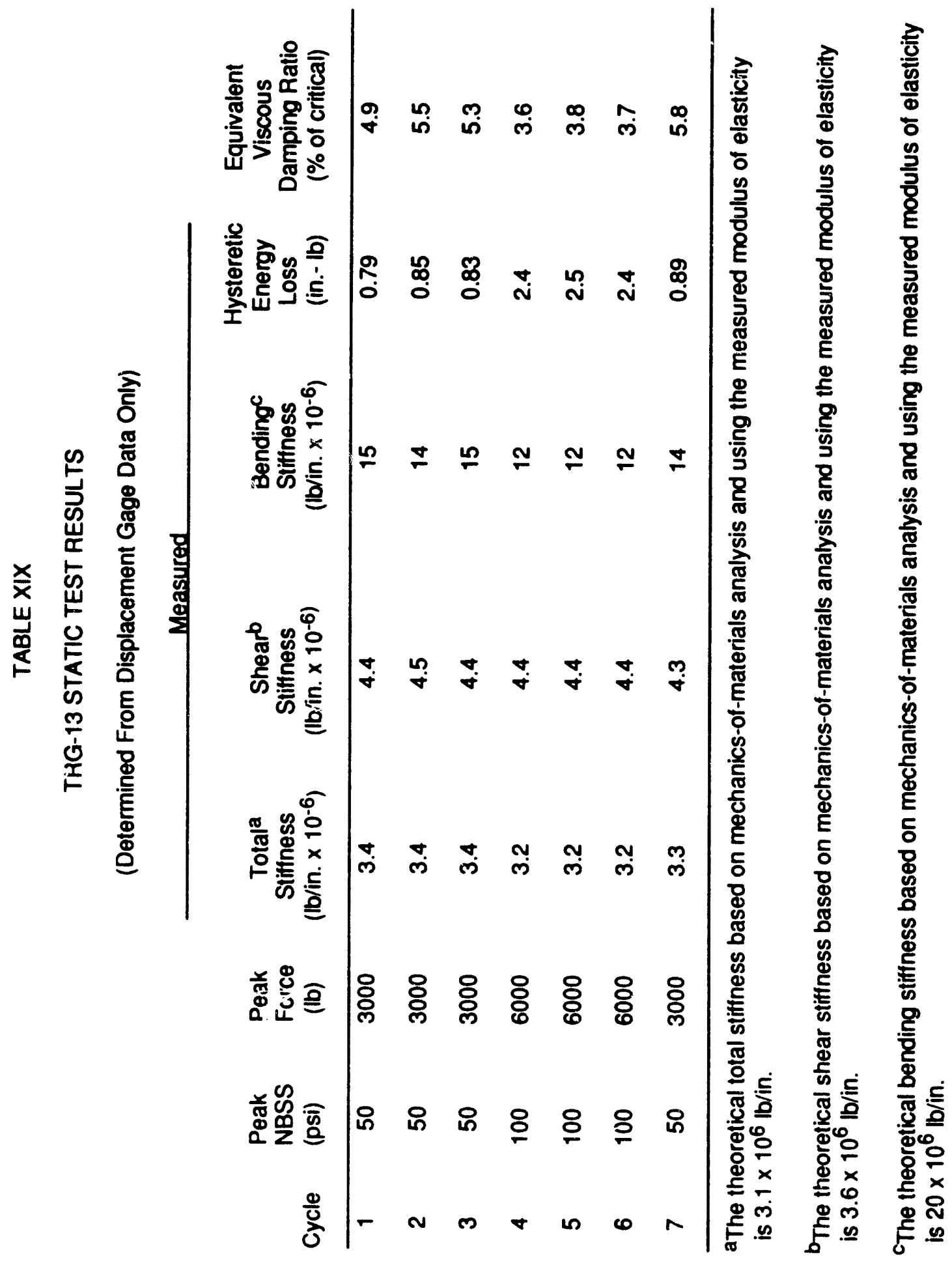


The total stiffnesses measured on TRG-13 were slightly higher than the theoretical stiffness. During placement of this structure and the TRG-12 structure, the forms for the end walls bent outwaid from the end wall in the vicinity of the shear wall. This deformation resulted in the shear wall and end walls having slightly larger dimensions than those shown in Fig. 2 and contributed to the slightly higher measured stiffness values. Bending deformations were small relative to the resolution of the displacement transducers and, hence, the corresponding component of stiffness did not agree well with theory.

Results from TFIG-12 and -16 are summarized in Tables $X X$ and $X X I$, respectively. Both structures exhibited total stiffnesses that agreed well with the ry prior to cracking. Again, the bending displacements were difficult to measure and accurate assessment of this component of stiffness proved difficult. The initial cracking induced by the applied load (as opposer, to cracking that existed prior to testing that results from shrinkage during the curing process) on TRG-12 occurred between 12,000 and 13,400 lb. An exact figure was not obtained because the structure failed abnuptly during the same load increment in which cracking was initiated. TRG-16 firs' cracked at a load of $11,000 \mathrm{lb}$ during the first 200-psi NBSS cycie. When the differences between the tensile strengths of these structures and the TRG-4 structure are accounted for, the first cracking loads measured on TRG-16 accurately predict the first cracking load measured on TRG-4 as summarized in Table XXII. Note that after cracking occurred on TRG-16, the subsequent cycles showed an increased stiffness. This increase results from the cracking occurring outside the field that was being monitored with the relative displacement gages and the associated redistribution of the stress field within the gaged area.

Both TRG-12 and TRG-16 failed in an abrupt manner with a large flexure crack opening through the base of the tensile end wall, as shown in Fig. 44. The lack of ductility after cracking in these structures, as compared with that in the TRG-4 structure is attributed to the difference in ductility of the conventional rebar used in TRG-4 as compared with the ductility of the wire mesh rebar used in TRG-12 and -16 . Tensile tests were done on these two types of rebar to quantify this difference. Figure 45 compares the stress-strain curves from a typical specimen of both types of rebar. This figure illustrates the difference in ductility of the two types of rebar.

\section{Test Results (Strain Gages)}

Finally, the deformations determined from the strain gage readings are compared with the deformations measured with the displacement transducers. Figure $46 \mathrm{com}$-pares displacements measured on TRG-16 by the two instrumentation methods during a 50-psi NBSS cycle. From these data it is evident that the displacements from the strain gage readings agree well with those from the digital gages; hence, it is concluded that displacement may be measured accurately with the strain gages during dynamic tests. Table XXI compar ss the stiffness and hysteretic energy loss results that were obtained from strain gage data with similar results obtained with displacement transducers. It appears that the strain gages give more consistent readings than the displacement transducers. Discrepancies in the measured hysteretic energy loss, obtained from the displacement trañsucucers and the strain gages, is the result of lost motion in the 


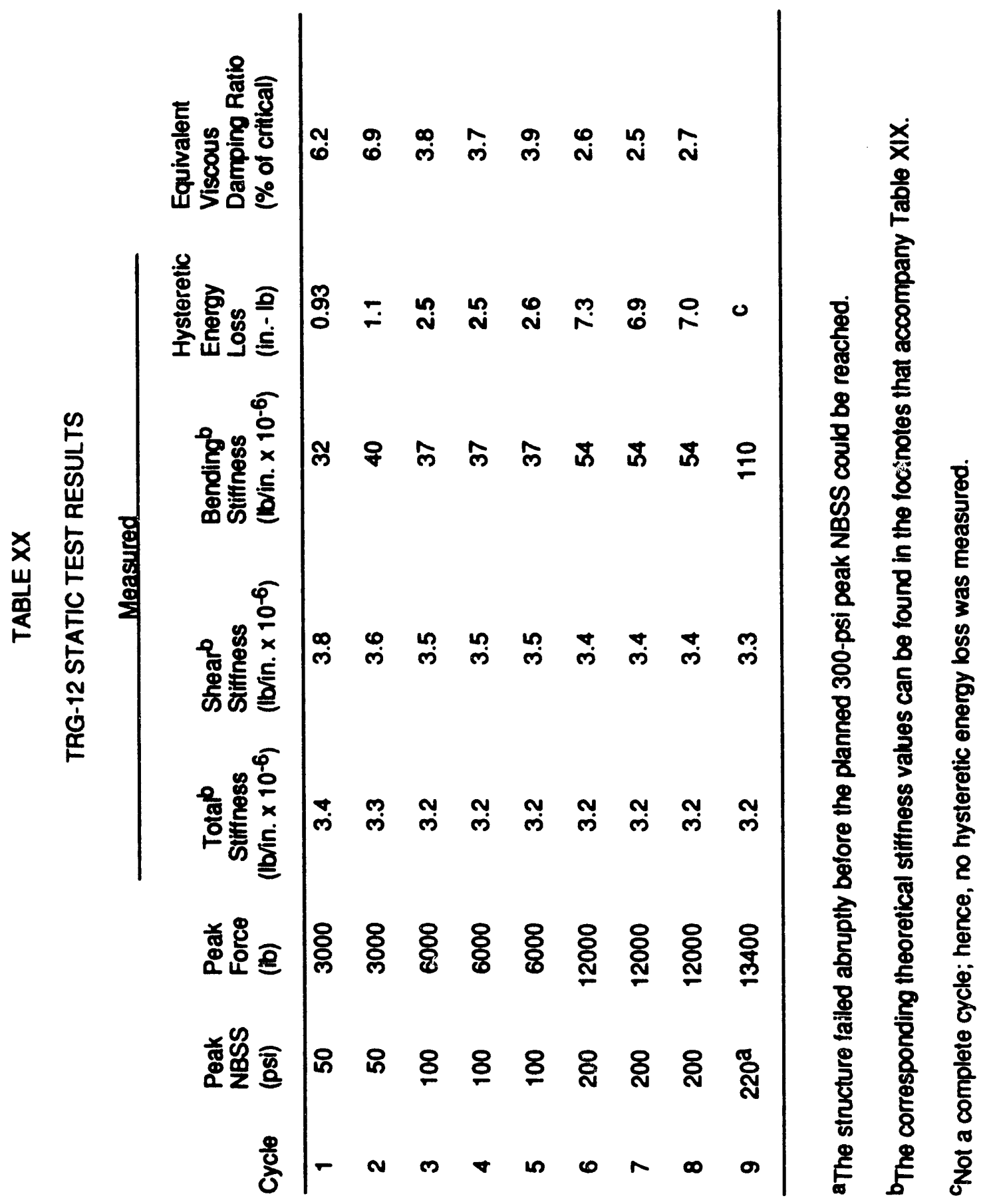




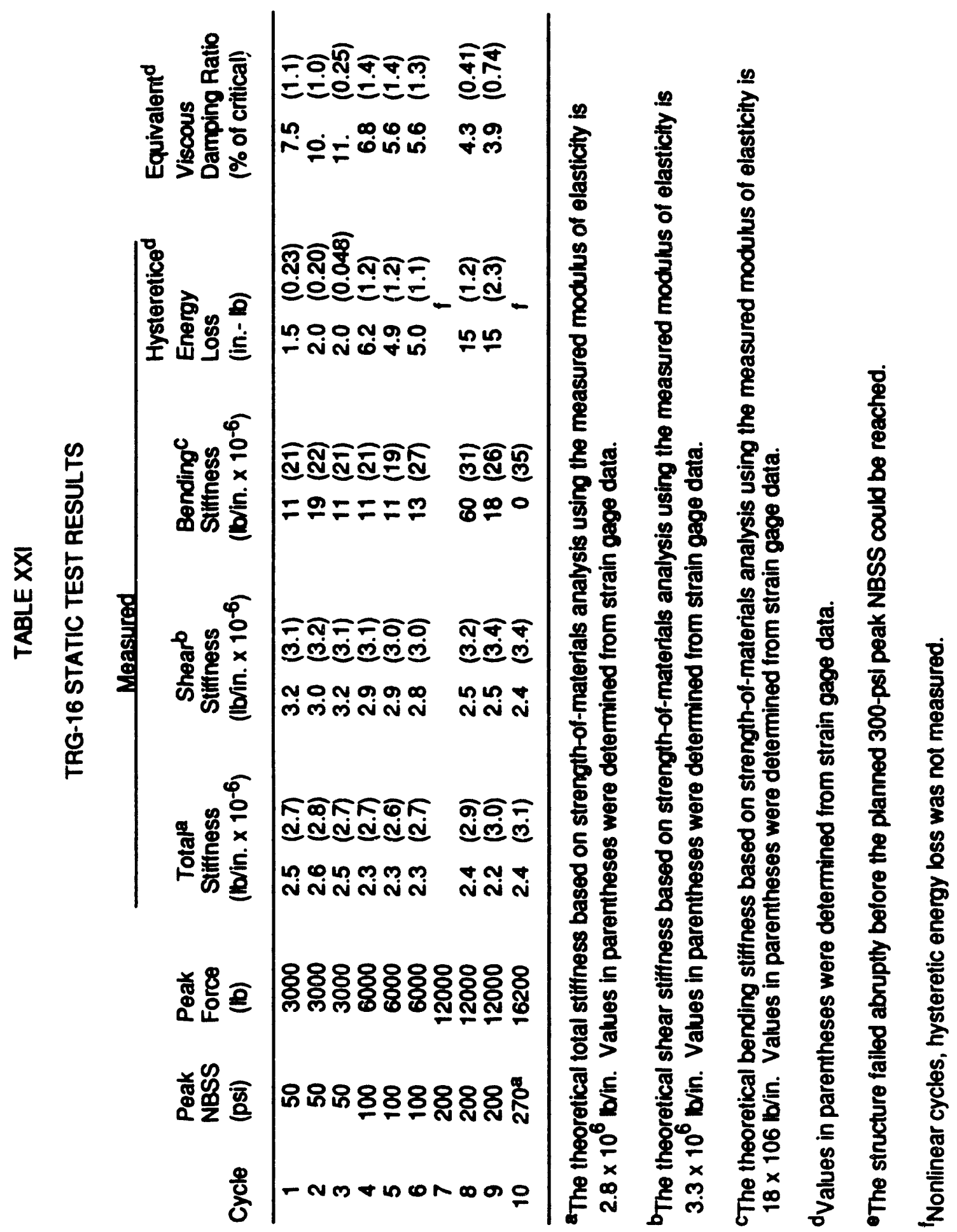


TABLE XXII

COMPARISON OF FIRST-CRACK LOADS MEASURED ON TRG-12 and -16

WITH THE FIRST-CRACK LOAD MEASURED ON TRG-4

\begin{tabular}{lcccc} 
Structure & $\begin{array}{l}\text { Crack } \\
\text { Load } \\
\text { (lb) }\end{array}$ & $\begin{array}{c}\text { NBSS at } \\
\text { Cracking } \\
\text { (psi) }\end{array}$ & $\begin{array}{c}\text { Split } \\
\text { Cylinder } \\
\text { Tensile } \\
\text { Strength } \\
\text { (psi) }\end{array}$ & $\begin{array}{c}\text { Normalize } \\
\text { NBSS } \\
\text { at } \\
\text { Crackinga }\end{array}$ \\
\hline TRG-4 & 71,000 & 131 & 360 & 131 \\
TRG-12b & $12,000-13,400$ & $200-220$ & 450 & $160-176$ \\
TRG-16 & 11,000 & 183 & 480 & 137
\end{tabular}

a These values have been normalized to the TRG-4 tensile strength.

b Crack load can only be bonded because the first cracking and failure occurred during the same load increment.

displacement gage mounting system. The strain gages provide a more accurate estimate of the hysteretic energy loss, and viscous damping ratios determined from these data agree with the precracking viscous damping ratios measured during simulated seismic tests and during experimental modal analyses (see Tables VIII and XVIII). On TRG-12 one strain gage circuit failed. Without these readings to average, the data were found to be inconsistent because of the asymetric loading.

\section{SUMMARY AND CONCLUSIONS}

These final tests in the Seismic Category I structures program were io provide additional data concerning the scalability of the seismic response of small-scale con-crete structures to the seismic response of conventional concrete prototypes. Results of experimental modal analyses show that when the structures were subjected to low-level random excitations, the dynamic properties (mode shapes, resonant frequencies) of the prototype TRG-4 structure were accurately predicted by both the $3 / 8$-in. aggregate and the microconcrete $1 / 3$-scale models. The distortion of the normal forces that result from geometric scaling [12] appears to have no adverse effect on the similitude of the dynamic properties as identified by these methods. Because the frequency resolution of the frequency response functions was not properly scaled, similitude of the modal damping values can not be addressed.

No appreciable difference was observed between the stiffness measured with strain gages and the stiffness measured with displacement transducers during static tests. Both measurement methods show that the structures respond with a stiffness accurately predicted by mecitantics-oi-maieriais theory until cracking is induced from the externally applied load. The load at which first cracking occurs was about 150-psi NBSS, and the actual values were a function of the individual test specimen's concrete 


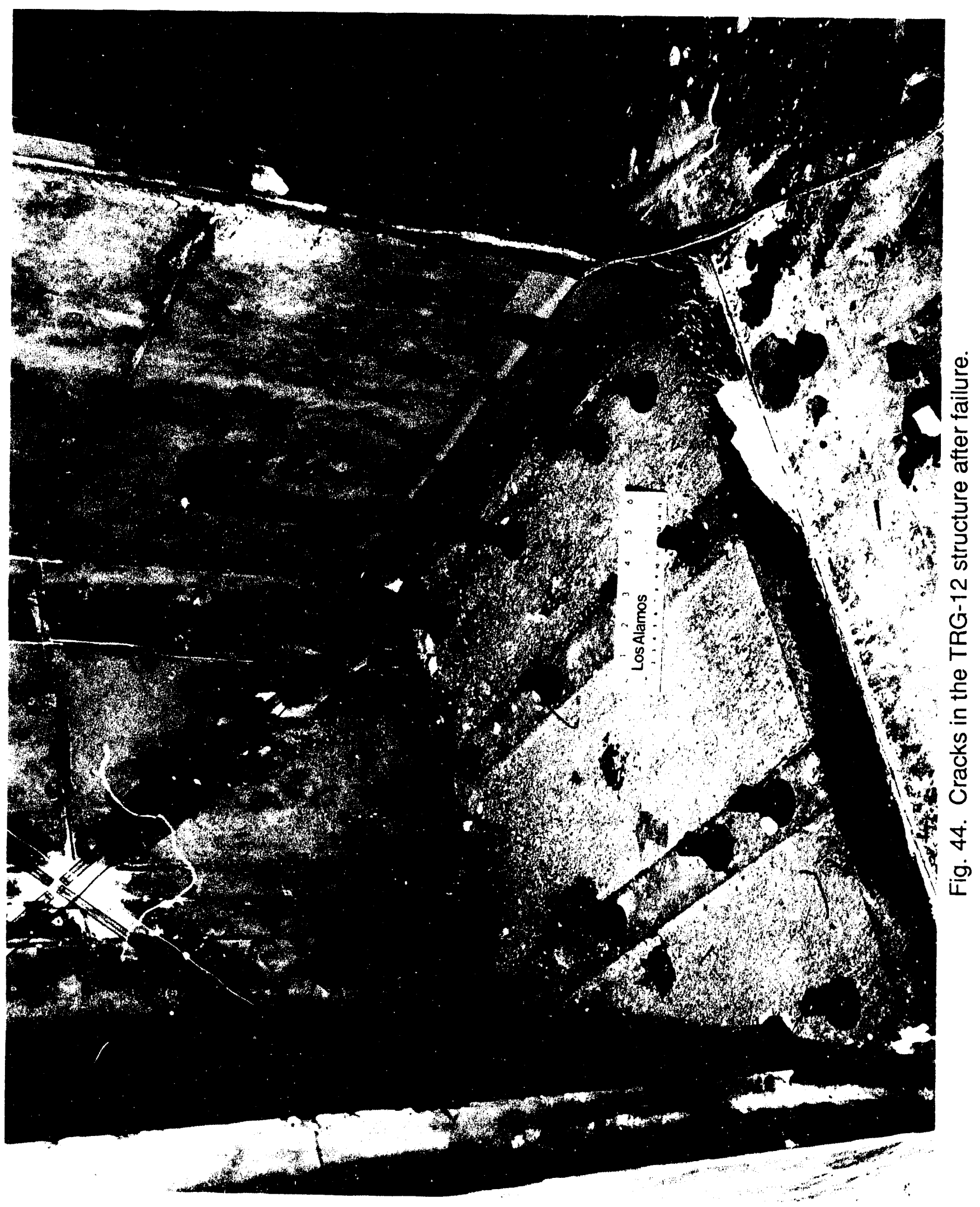




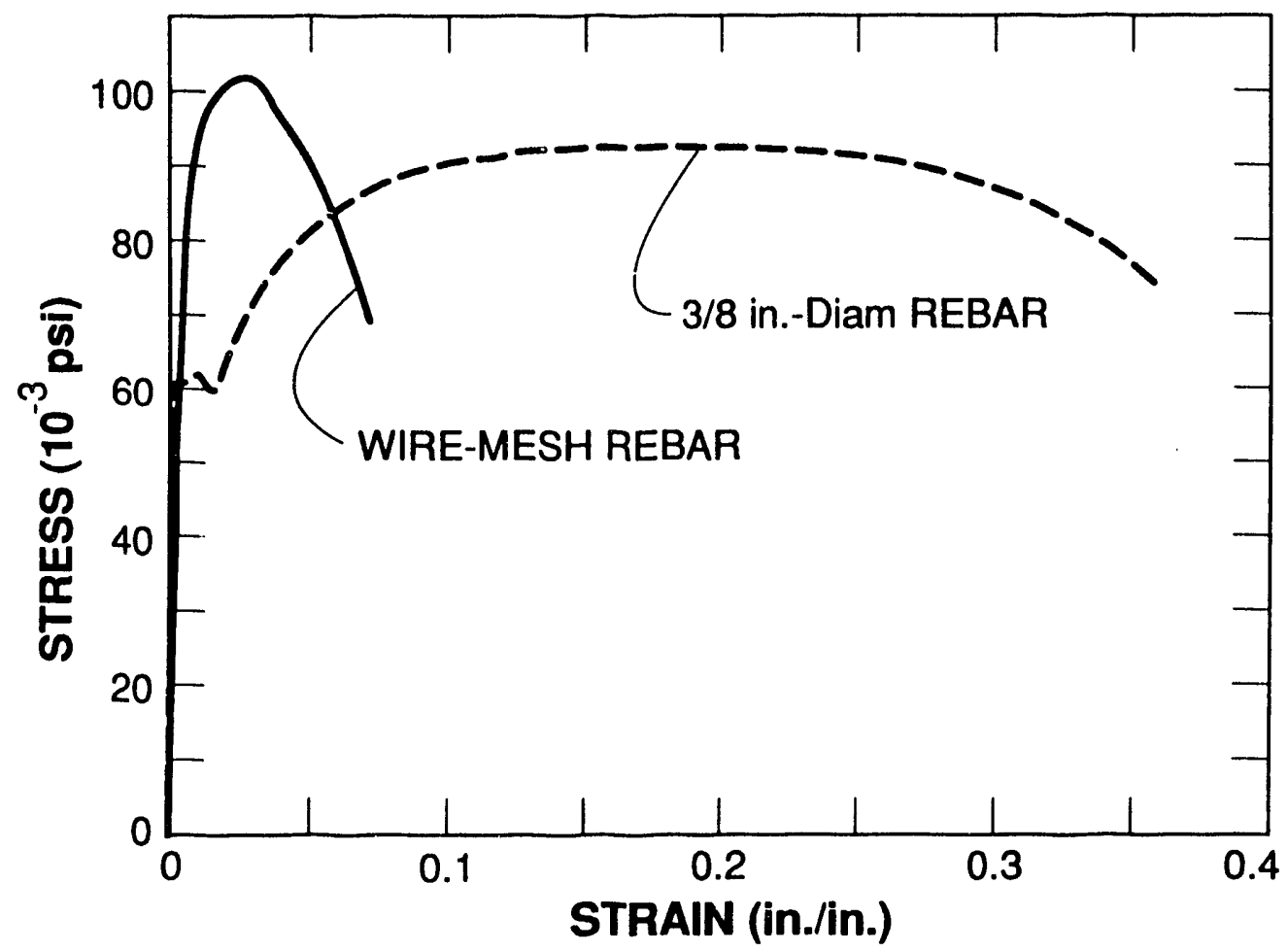

Fig. 45. A comparison of the stress-strain curve from conventional rebar to the stress-strain curve of the wire mesh rebar used in TRG-7 through -16 .

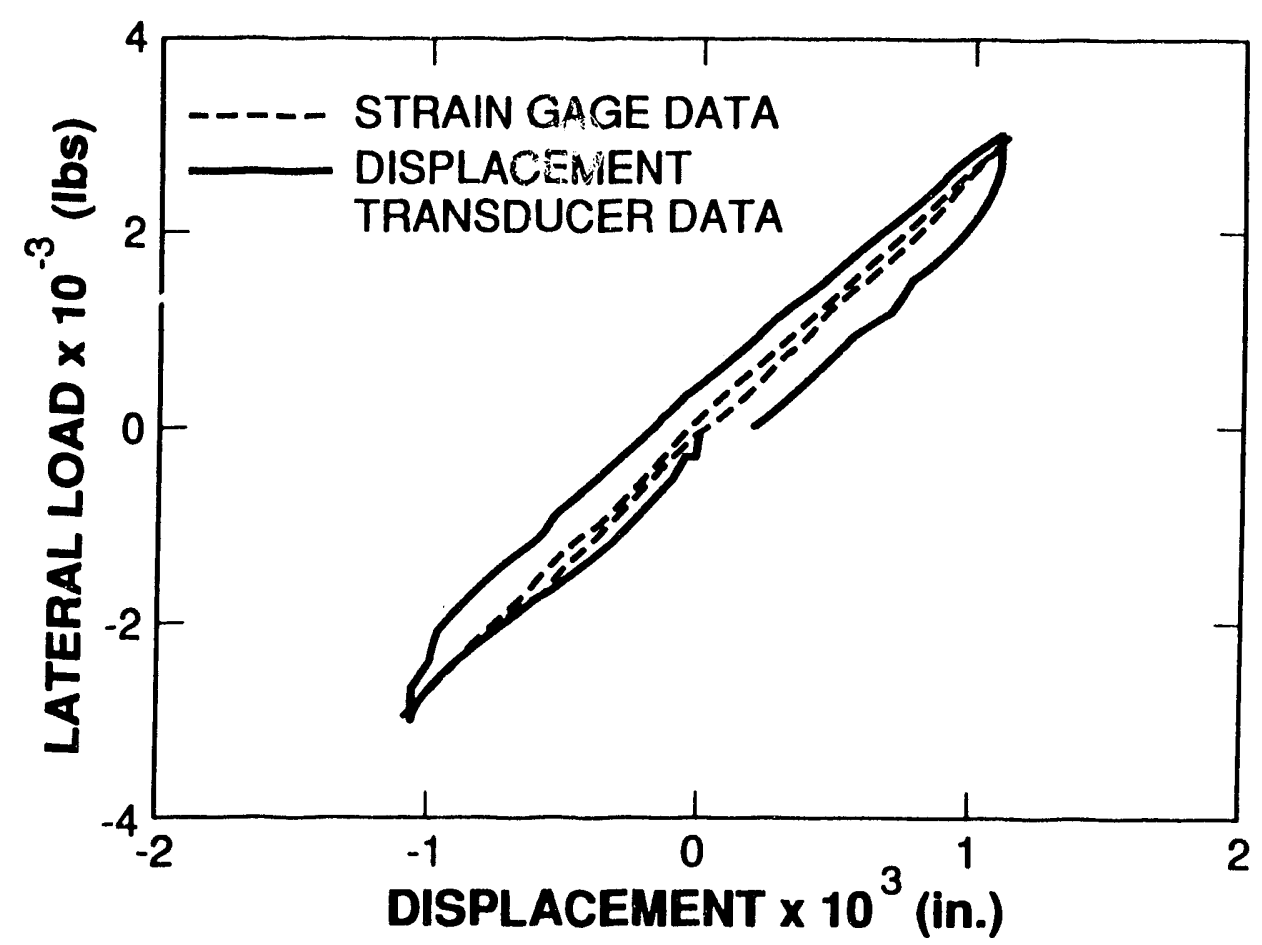

Fig. 46. A comparison of the internal relative displacement measurements determined by integrating strain gage readings with similar measurements made with displacement transducers during a 50-psi NBSS cycle. 
tensile strength. To put this into perspective, OBE seismic events for west coast plants would produce NBSS levels in the range of 50 to 100 psi and Safe-Shutdown Earthquake (SSE) seismic events for similar plants would produce NBSS levels of 150 psi. Static stiffness results from both the 1/3-scale, 3/8-in. aggregate structures and the $1 / 3$-scale microconcrete structures could be scaled to predict the stiffness results on TRG-4 (3/4-in. aggregate) prior to cracking. After cracking, the scale models failed abruptly as a result of the lack of ductility in their rebar. The test setups for the static testing on TRG-4, $-5,-6,-12,-13$, and -16 were such that initial stresses introduced by bolting the structures to the load frames were minimized.

Stiffness measured during dynamic tests have previously been inferred from resonant frequency measurements. Damage caused by transportation, stresses introduced by bolting the structures to the shake table, responses of other modes associated with the shake table, and the test specimens' connections to the table have yielded excessively low initial stiffness measurements on structures tested in the early part of this program (TRG-3 and before). The other modes associated with the shake table invariably occur when structures with a high center-of-mass are tested. With the strain gages mounted on TRG-8, $-9,-10,-14$, and -15 , a direct measurement of stiffness could be obtained during dynamic tests, and the onset of cracking could be identified by sudden jumps in the strain readings. Strain gage stiffness data from the dynamic tests agree with the static stiffness data. However, when cracking occurs at the end wall-floor slab interface, the response observed on TRG-8 through -16 was substantially different compared with the postcracking response observed on TRG-4 and -5. Failure in TRG-8 through -16 occurred at the end-wall/base-slab interface because of a tensile failure in the reinforcement. This failure occurred prior to fracture of the shear walls from shear loading. A mismatch in the ductility of the reinforcement used in the TRG-4 and -5 structures and the rebar used in the TRG-8 through -16 structures was the probable cause of the different failure modes. Figure 47 summarizes the credible stiffness data that has been obtained statically and dynamically in this program. This figure can be compared with Fig. 20, which gives the dynamic stiffness values determined from previous accelerometer data reported in this program.

The strain gage data obtained during these tests show that, before the base excitation levels that produced cracking in the end walls, the structures responded with repeatable theoretical stiffness values, implying elastic response and no cumulative damage effects. After cracking, the response of the shear wall structures appears to be a function of the peak load level experienced by the structure during its lifetime.

Viscous damping ratios, prior to cracking of the structures, as determined from either static or dynamic test data, are about $1 \%$ of critical. Previous values reported at around 3 to $5 \%$ were determined from accelerometer data. These data are influenced by the response of other modes associated with the shake table and the test speciman's connection to the shake table. Therefore, the damping measured with accelerometers is that of the entire shake table/test specimen system, not that of the shear wall element. Previously, damping values of 3 to $5 \%$ were also obtained from hysteretic energy losses measured with displacement transducers during static tests. This range is believed to be larger than the true value because of the inherent hysteresis in the displacement gages and mounting hardware that were used. Figure 46 shows the difference between the 


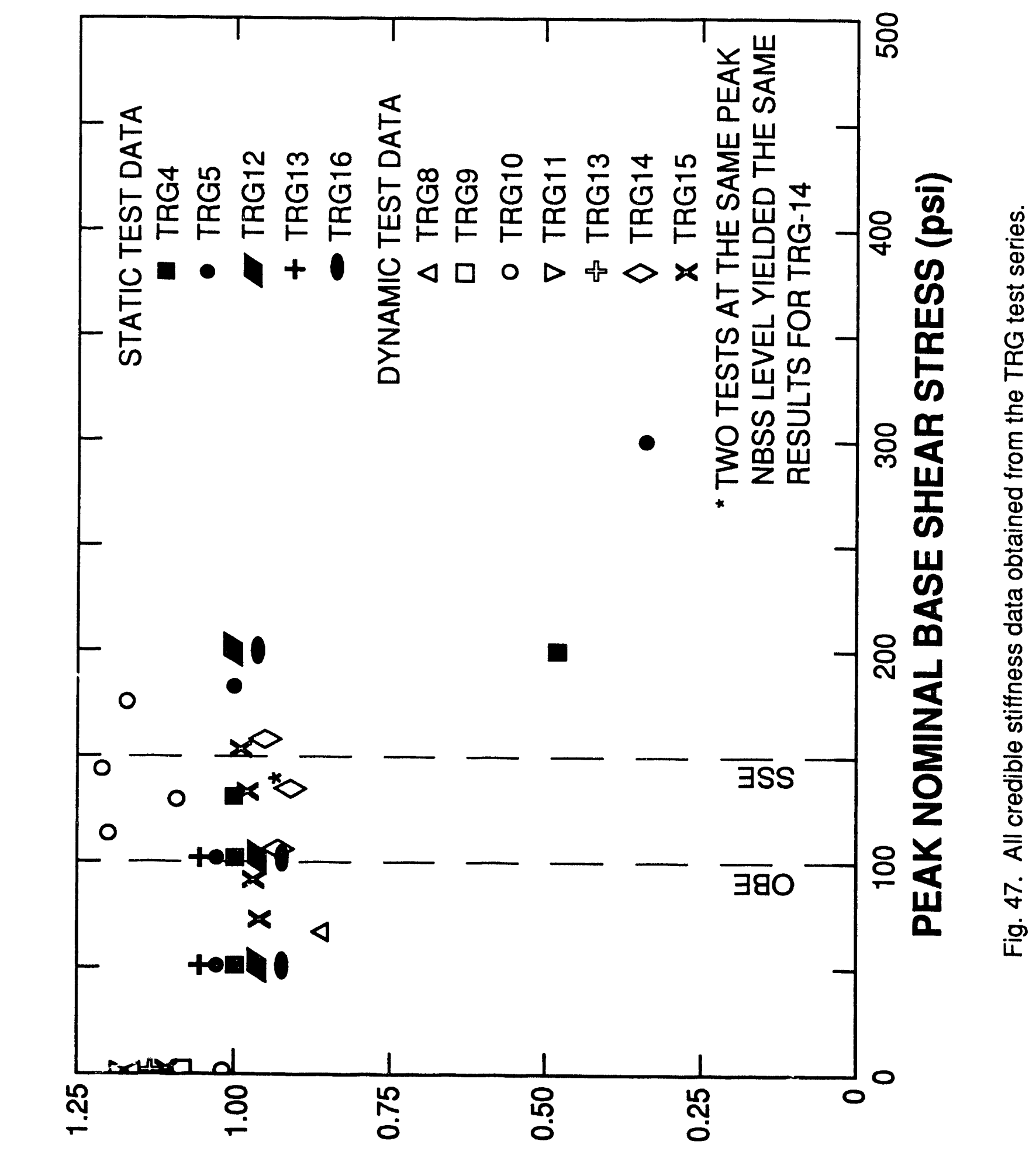

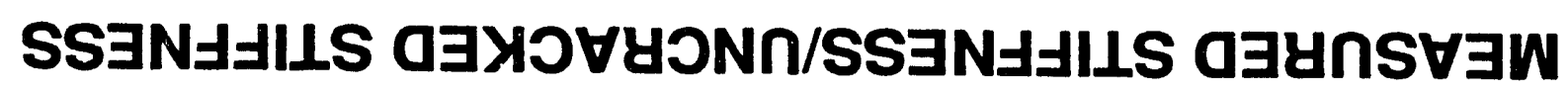


hysteretic energy loss measured with the displacement transducers and the energy loss determined from integrated strain gage data. The $1 \%$ equivalent viscous damping ratio value has been found by several methods, including equating hysteretic energy losses measured statically and dynamically to the energy losses from a viscous damper, curvefitting frequency response function measurements made during experimental modal analyses, and other standard frequency domain analysis techniques.

The damping values determined from the strain gage data agree with those suggested in [14], that is, 0.5 to $1.0 \%$ for concrete below $25 \%$ of yield. However, these values are considerably lower than those specified in Reg. Guide 1.61 [15] (4\% for OBE level seismic events). Reg. Guide 1.61 specifies system damping values that would take into account factors such as construction joints that increase the damping. The dampings we have reported are for monolithic concrete shear wall elements that have not been cracked by the applied loads. The data available in the open literature give damping values similar to those specified in Reg. Guide 1.61. These data are influenced by base connection effects.

The values of damping for shear walls, as determined from experiments performed in this program, may be summarized as follows:

1. In a structure that is undamaged initially, then subjected to a seismic pulse of a level that leaves the structure essentially undamaged at the end of the test, the equivalent viscous damping ratio will be $1 \%$ percent or less.

2. Structures that have cracked at the end-wall/base-slab interface as a result of the seismic excitation will have an equivalent viscous damping ratio in the range of 2 to $10 \%$. The actual value that the structure exhibits during the seismic pulse depends on the degree of damage sustained during the transient.

3. At simulated seismic excitations levels in which the structure cracks in the shear wall and at the end-wall/base-slab interface, the equivalent viscous damping ratio will exceed $10 \%$.

The two areas in which scalability has not been demonstrated are those that occur during simulated seismic excitations (because no reliable data have been obtained on a conventional concrete prototype) and during the postcracking static cyclic response (because of dissimilar postyield properties of the rebar).

Although actual in situ Category 1 structures may be cracked and their response may be bound by the responses observed with different structures tested during this program, no data are available from an actual structure and, hence, any such statement would be purely speculation. 


\section{REFERENCES}

1. C. R. Farrar, J. G. Bennett, W. E. Dunwoody, and W. E. Baker, "Static Load Cycle Testing of a Low-Aspect Ratio Six-Inch Wall, TRG-Type Structure TRG-4-6 (1.0, $0.25), "$ Los Alamos National Laboratory report LA-11422-MS, NUREG/CR-5222 (June 1989).

2. "Standard Specification for Steel Welded Wire, Fabric, Plain, for Concrete Reinforcement," in Annual Book of ASTM Standards, Roberta A. Prieman-Storer, Ed. (American Society for Testing and Materials, Philadelphia, Pennsylvania, 1985), Vol. 1.04, A185-85, pp. 130-134.

3. ACl Committee 349, Code Requirements for Nuclear Safety Related Concrete Structures and Commentary, American Concrete Institute, Detroit, Michigan, 1985.

4. ACl Committee 318, Building Code Requirements for Reinforced Concrete, American Concrete Institute, Detroit, Michigan, 1983.

5. Standard Test Method for Compressive Strength of Cylindrical Concrete Specimen," in Annual Book of ASTM Standards, Roberta A. Prieman-Storer, Ed. (American Society for Testing and Materials, Philadelphia, Pennsylvania, 1985), Vol. 4.02, C39-84, pp. 24-29.

6. "Standard Test Method for Static Modulus of Elasticity and Poisson's Ratio of Concrete in Compression," in Annual Book of ASTM Standards, Roberta A. Prieman-Storer, Ed. (American Society for Testing and Materials, Philadelphia, Pennsylvania, 1985), Vol. 4.02, C469-83, pp. 303-307.

7. "Standard Test Method for Slump of Portland Cement Concrete," in Annual Book of ASTM Standards, Roberta A. Prieman-Storer, Ed. (American Society for Testing and Materials, Philadelphia, Pennsylvania, 1985), Vol. 4.02, C143-78, pp. 109-112.

8. "Method of Sampling Freshly Mixed Concrete," in Annual Book of ASTM Standards, Roberta A. Prieman-Storer, Ed. (American Society for Testing and Materials, Philadelphia, Pennsylvania, 1985), Vol. 4.02, C172-82, pp. 133-135.

9. "Standard Method of Making and Curing Concrete Specimens in the Filed," in Annual Book of ASTM Standards, Roberta A. Prieman-Storer, Ed. (American Society for Testing and Materials, Philadelphia, Pennsylvania, 1985), Vol. 4.02, C31-84, pp. 5-10. 
10. "Standard Test Method for Splitting Tensile Strength of Cylindrical Concrete Specimens," in Annual Book of ASTM Standards, Roberta A. Prieman-storer, Ed. (American Society for Testing and Materials, Philadelphia, Pennsylvania, 1985), Vol. 4.02, C496-85, pp. 335-339.

11. D. Ewins, Modal Testing: Theory and Practice, (John Wiley \& Sons, Inc., New York, 1984).

12. R. C. Dove and J. G. Bennett, "Scale Modeling of Reinforced Concrete Category I Structures Subjected to Seismic Loading," Los Alamos National Laboratory report LA-10624-MS, NUREG/CR-4474 (January 1986).

13. C. R. Farrar and J. G. Bennett, "Experimental Assessment of Damping in Low Aspect Ratio, Reinforced Concrete Shear Wall Structures," Los Alamos National Laboratory report LA-11325-MS, NUREG/CR-5154 (August 1988).

14. H. Newmark and W. Hall, "Seismic Design Criteria for Nuclear Reactor Facilities," in Proc. 4th World Conference on Earthquake Engineering, B4, pp. 37-50. (Santiago, Chile, 1969).

15. Division of Nuclear Regulatory Standards, "Damping Values for Seismic Design of Nuclear Power Plants, Regulatory Guide 1.61," (United States Nuclear Regulatory Commission, Washington, DC, 1973).

16. E. G. Endebrock, R. C. Dove, and C. A. Anderson, "Margins to Failure - Category I Structures Program: Background and Experimental Plan," Los Alamos National Laboratory report LA-9030-MS, NUREG/CR-2347 (December 1981).

17. E. G. Endebrock, R. C. Dove, and W. E. Dunwoody, "Analysis and Tests on SmallScale Shear Walls--FY 82 Final Report," Los Alamos National Laboratory report LA-10443, NUREG/CR-4274 (September 1985).

18. R. C. Dove, J. G. Bennett, C. Farrar, and C. A. Anderson, "Seismic Category I Structures Program Final Report, FY 1983-1984," Los Alamos National Laboratory report LA-11013-MS, NUREG/CR-4924 (September 1987).

19. J. G. Bennett, R. C. Dove, W. E. Dunwoody, E. G. Endebrock, C. R. Farrar, and P. Goldman, "Simulated Seismic Tests on 1/42- and 1/14-Scale Category I, Auxiliary Buildings," Los Alamos National Laboratory report LA-11093-MS, NUREG/CR-4987 (October 1987).

20. J. G. Bennett, R. C. Dove, W. E. Dunwoody, C. R. Farrar, and P. Goldman, "The Seismic Category I Structures Program: Results for FY 1985," Los Alamos National Laboratory report LA-11117-MS, NUREG/CR-4998 (December 1987).

21. J. G. Bennett, R. C. Dove, W. E. Dunwoody, C. R. Farrar, and P. Goldman, "The Seismic Category I Structure Program: Results for FY 1986," Los Alamos National Laboratory report LA-11377-MS, NUREG/CR-5182 (September 1988). 
22. C. R. Farrar, J. G. Bennett, W. D. Dunwoody, W. E. Baker, "Static Load Cycle Testing of a Low-Aspect-Ratio Four-Inch Wall, TRG-Type Structure TRG-5-4 (1.0, 0.56)," Los Alamos National Laboratory report LA-11739-MS, NUREG/CR-5487 (November 1990).

23. C. R. Farrar, J. G. Bennett, W. E. Baker, W. E. Dunwoody, "Static Load Cycle Testing of a Very Low-Aspect-Ratio Six-Inch Wall TRG-Type Structure TRG-6-6 $(0.27,0.50)$, "Los Alamos National Laboratory report LA-11796-MS, NUREG/CR5533 (November 1990). 


\section{APPENDIX A}

SEISMIC CATEGORY I STRUCTURES PROGRAM BACKGROUND AND SUMMARY

$$
\text { A }-1
$$




\section{A-I. BACKGIROUND}

The purpose of this report is to provide the NRC and the PRA investigators with a summary of the principal results and conclusions from the series of tests on structures of identical geometry designated TRG-7-2 $(1.0,0.25)$ through TRG-16-2 $(1.0,0.25)$. The nomenclature used here is as follows:

TRG-No.-Wt (AR,\%R)

where,

TRG = the designation for the series of structures designed and tested using guidance from the program's Techniral Review Group, a group of nationally recognized experts on nuclear structures,

No. = the model number in the test series,

$W_{t}=$ the shear wall thickness, in inches,

$A P_{1}=$ the height-to-length aspect ratio of the shear wall, and

$\% P=$ total percentage by area of steel reinforcing in both directions.

This nomenclature is often abbreviated as TRG-No. For the reader who may be unfamiliar with this program or who wishes to review the program objectives and history, a summary to date is provided.

The Seismic Category I Structure Program is being carried out at I_ANL under the sponsorship of the NRC's Office of Nuclear Regulatory Research and has the objective of investigating the dynamic response of Seismic Category I reinforced concrete structures iexclusive of containment) that are subjected to seismic loads beyond their design basis.

A number of meetings and interactions with the NRC staff have led to a set of specific piogram objectives, which are as follows:

1. to address the seismic response of reinforced concrete Category I structures other than containment;

2. to develop experimenta' data for determining the sensitivity of structural behavior in the elastic and inelastic response range of Category I structures to variations in configuration, design practices, and earthquake loading;

3. to develop experimental data to enable validation of computer programs used to predict the behavior of Category I structures during earthquake motions that cause elastic and inelastic response;

4. to identify floor response spectra charyes that occur during earthquake motions that cause elastic ind inelastic structural response;

5. to develop a method for representing damping in the inelastic range and to demoristrate how this damping changes when structural response goes from the elastic to the inelastic ranges; and

6. to assess how shifts in structural trequency affect plant risk. 
A principal characteristic of the typical structure under investigation is that shear, rather than flexure, is dominant; that is, the ratio of displacement values calculated from terms identified with shear deformation to the values contributed from bending deformation is one or greater; thus, these buildings are called "shear wall" structures.

The Seismic Category I Structures Program began in FY 1980 with an investigation that identified the typical shear wall structure of a nuclear facility and its characteristics (stiffnesses, frequencies, etc.) as areas where designers of facilities (Bechtel Corporation, Sargent \& Lundy, and Tennessee Valley Authority) felt that additional experimental data were needed. A combined experimental/analytical plan for investigation of the dynamic behavior of these structures was laid out as described in [16].* During the first phase, the program concentrated on investigating isolated shear wall behavior using small models (1/30-scale, 1 -in-thick walls) that could be economically constructed and tested both statically and dynamically [17]. Also, during this phase of the program, a technical review group (TRG), consisting of nationally recognized seis mic and concrete experts on nuclear civil structures, was established both to review the progiess and to make recommendations regarding the technical directions of the program. The recommendations of this group have been evaluated in light of the needs of the NRC and, where possible, have been carefully integrated into the proyram.

Following the isolated shear wall phase, the program began testing and evaluating three-dimensional box-like model structures. It was recognized from the outset that scale model testing of concrete structures is a controversial issue in the U.S. civil engineering community. Thus, along with the testing of small-scale structures, a task of demonstrating scalability of the results to prototype structures was initiated. The details and results of these investigations are reported in $[12,18,19]$.

To give a brief synopsis of the situation at the end of FY 1984, the program had tested (in addition to the isolated shear walls), either statically or seismically, 23 different modeis, representing two types of structures--a diesel generator building and an auxiliary building. Two different scales $[(1 / 30,1 / 10)$ and $(1 / 42,1 / 14)]$ of these buildings were used (1-in. and 3-in. walls). In addition, stories varied from one to three. Although a number of results on items such as aging (cure time) and the effect of increasing seismic magnitude have been reported, two important and consistent conclusions came out of the data from these tests. First, the scalability of the results was illustrated both in the elastic and the inelastic range. Second, the so-called "working load' secant stiffness of the models was lower than the computed uncracked cross-sectional values by a factor of about 4 .

During their review, the TRG pointed out the following:

1. Design of prototyce nuclear plant structures is normally based on an uncracked cross-section strength-oi-materials approach that may or may not use a "stiffness reduction factor" for the concrete. But, if such a factor is used, it is never as large as 4.

\footnotetext{
"Reference numbers in this appendix refer to the reference list at the end of the main body of this report.
} 
2. Although the structures themselves appear to have adequate reserve margin (even if the stiffness is only $25 \%$ of the theoretical), any piping and attached equipment will have been designed using inappropriate floor response spectra.

3. Given that a nuclear structure designed to have a natural response of about $15 \mathrm{~Hz}$ really has a natural frequency of $7.5 \mathrm{~Hz}$ (corresponding to a reduction in stiffness of 4), and furthei, given that the natural frequency will decrease because of degrading stiffness, the response of the structure will shift well down into the frequency range for which the energy content of most earthquakes, recorded to date is the largest. This will result in increased amplification in the floor response spectra at lower frequencies, and will, potentially, have a significant impact on the equipment and on the piping design response spectra and their margins of safety.

These three points are related to the differences between the measured and calculated stiffnesses of these structures.

Having made these observations, several questions arose. Did our previous experimental data taken on microconcrete models represent behavior that would be observed in prototype structures? What is the appropriate value of stiffness that should be used in a design and for component response spectra computations in these structures? Should this value be a function of load level? Have the equipment and piping in existing buildings been designed to inappropriate response spectra?

Thus, the primary program emphasis at that time was to ensure the credibility of previous experimental work by beginning to resolve the "stiffness difference" issue. The TRG for this program believed that this important issue had to be addressed before the program objectives could be accomplished.

To address these stiffiness-related concerns, it was agreed that a series of credibility experimenis should be carried out using both large- and small-scale structures. For the large-scale structure, the TRG set limitations on the design parameters. The recommended "ideal" structure characteristics, in order of decreasing priority, were as follows:

1. maximum predicted bending and shear mode natural frequency $\leq 30 \mathrm{~Hz}$,

2. minimum wall thickness $=4$ in.,

3. height-to-depth ratio of shear wall $\leq 1$,

4. USE of actual No. 3 rebar for reinforcing,

5. use of realistic material for aggregate,

6. use of $0.1-1 \%$ steel $(0.3 \%$ each face, each direction, i.e., $0.6 \%$ total each direction), and

7. use of water-blasted construction joints to ensure good aggregate interlock.

A prototype "TRG" structure designed to comply with these specifications (TRG-3 in Fig. A-1) was constructed using actual batch plant concrete and No. 3 rebar. In addition, a 1/4-scale model of the TRG sinucture was constructed with microconcrete and wire mesh rebar, then tested before the prototype was constructed. Botin structures were 


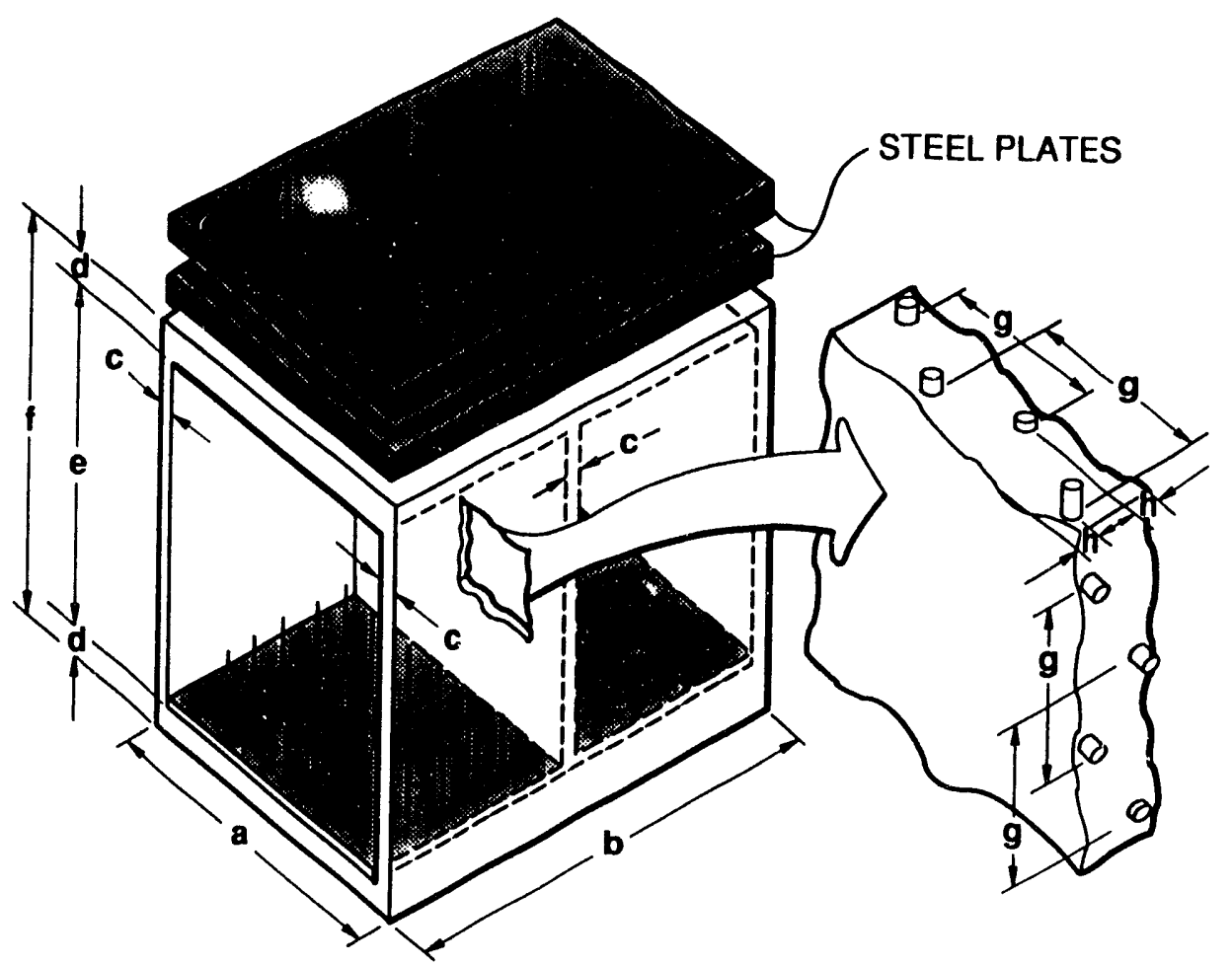

\begin{tabular}{|c|c|c|c|c|c|c|c|c|c|c|}
\hline \multirow[b]{2}{*}{ STRUCTURE } & \multirow[b]{2}{*}{ a } & \multicolumn{7}{|c|}{ DIMENSIONS (in.) } & \multirow{2}{*}{$\begin{array}{c}\text { ADDED } \\
\text { WEIGHT (Ibs) }\end{array}$} & \multirow{2}{*}{$\begin{array}{c}\text { REBAR } \\
\text { diam (in.) }\end{array}$} \\
\hline & & b & c & d & $\theta$ & $f$ & g & h & & \\
\hline $\begin{array}{l}\text { TRG } 1,2 \\
\text { TRG } 3,5 \\
\text { TRG } 4 \\
\text { TRG } 6\end{array}$ & $\begin{array}{l}30 \\
90 \\
90 \\
90\end{array}$ & $\begin{array}{c}40 \\
120 \\
120 \\
120\end{array}$ & $\begin{array}{l}1 \\
4 \\
6 \\
6\end{array}$ & $\begin{array}{l}2 \\
8 \\
8 \\
8\end{array}$ & $\begin{array}{l}30 \\
90 \\
90 \\
24\end{array}$ & $\begin{array}{c}34 \\
106 \\
106 \\
40\end{array}$ & $\begin{array}{c}0.25^{*} \\
4.5^{*} \\
14.5 \\
7.25\end{array}$ & $\begin{array}{l}0.5^{*} \\
1.5^{*} \\
1 \\
1\end{array}$ & $\begin{array}{c}575 \\
37,000 \\
37,000 \\
37,000\end{array}$ & $\begin{array}{l}0.042 \\
0.375 \\
0.375 \\
0.375\end{array}$ \\
\hline
\end{tabular}

Fig. A-1. TRG-1 through TRG-6 geometry.

tested statically and then seismically to failure or, in the case of the prototype, to machine limits. A second 1/4-scale model, TRG-2-1 $(1.0,0.6)$, was also constructed. That model had obvious flaws (cracked sections) that were discovered upon form removal, so it was never fully tested or reported.

These tests were intended to show that the previously observed reductions in stiffness were not related to the use of microconcrete and that the static and dynamic test results of the models could be scaled to conventional concrete structures.

During the static tests, the 1/4-scale model, TRG-1-1 $(1.0,0.6)$, showed stiffness results similar to those of the prototype, TRG-3-4 $(1.0,0.56)$, and suggested that, for lowlevel static response, the microconcrete model did an adequate job of predicting the response of the conventional concrete prototype. A low-force-level experimental rinodal analysis performed before seismic excitation showed stiffness and scalability resilts similar to those obtained from the static test. 
When the structures were tested dynamically on a shake table, both models showed reductions in stiffness consistent with results from previous test data; however, questions concerning curing and handling of TRG-3 made it difficult to obtain conclusions about the reduced stiffness. The prototype TRG structure with its added mass was too large to make reproduction of the input signal possible. This input signal was a scaled version of the one used on the 1/4-scale model, and, because it could not be accurately reproduced (frequency content of the signal was distorted), conclusions concerning the scalability of seismic response between the conventional concrete prototype and the microconcrete model could not be made. The results of these tests appear in detail in Refs. 20 and 21.

Upon completion of the TRG-1 and - 3 tests, the TRG suggested that a statistical plan be carried out to investigate the reduced stiffness as a function of aspect ratio and percent reinforcement (see Appendix A of Ref. 11). At the TRG meeting on December 19,1986 , the group suggested that a reduced statistical plan be carried out. The TRG was not concerned with the technical merit of the original plan, but rather with the time and cost required to successfully complete the test matrix. The TRG was also concerned with deviation from the original program objectives. The TRG suggested that models with an aspect ratio of 1.0 and 0.25 , as well as a model identical to TRG-3, be statically tested, and this plan was adopted. These structures, TRG-4-6 $(1.0,0.25)$, TRG-5-4 $(1.0,0.56)$ and TRG-6-6 $(0.5,0.50)$ exhibited repeatable stiffness values, which, until the structures cracked, were almost identical with the theory. The stiffness components related to shear and bending were separated and were also found to agree almost exactly with the theory. After cracking, the stiffness degraded during load cycling, with the degradation being a function primarily of the load history and the amount of reinforcement. Results from tests on TRG-4 are reported in [1] and results from the tests on TRG-5 and -6 are reported in [22] and [23], respectively.

\section{A-II. REVIEW OF PREVIOUS DYNAMIC TEST RESULTS OBTAINED IN THE SEISMIC CATEGORY 1 STRUCTURES PROGRAM}

Table A-I is a summary of the measured material properties for all the dynamic test spersimens.

1. Isolated Shear Walls. Four single-story, isolated shear wall structures were subjected to sine-sweep vibration tests. During these tests, the strurtures had added mass attached, as shown in Fig. A-2. The results from these tests are summarized in Table A-II. For all dynamic testing, the equivalent stiffness was determined indirectly from the resonant frequency measurements. Initially, these stiffness values were from a factor of 3.6 to 14.3 below the thecretical values, using the measured modulus, and from a factor of 5.0 to 18.1 below the theoretical values, using the $\mathrm{ACl}$ empirical modulus.

Two additional tests were performed on single-str.y is..lated shear walls using simulated seismic inputs and random inputs. The results from these tests are summarized in Tables A-III and A-IV. Initially, stiffnesses were down by factors ranging from 4.2 to 5.7 when the measured modulus was used in the theoretical stiffness calculation; the stift?nesses were down by a factor ranging from 5.7 to 7.1 when the American Concrete Institute (ACI) empirical modulus was used. 
TABLE A-I

MEASURED PROPERTIES FOR DYNAMIC TEST SPECIMENS

\begin{tabular}{|c|c|c|c|}
\hline $\begin{array}{l}\text { Isolated } \\
\text { Shear Walls }\end{array}$ & $\underset{\text { (ksi) }}{{ }^{f} \mathrm{c}}$ & $\begin{array}{c}E_{c} \\
m \\
(D s i)\end{array}$ & $\begin{array}{c}57,000 \sqrt{f} \\
c \\
\text { (osi) }\end{array}$ \\
\hline 10 & 7.48 & $3.5 \times 10^{6}$ & $4.93 \times 10^{6}$ \\
\hline 11 & 6.27 & $3.4 \times 10^{6}$ & $4.51 \times 10^{6}$ \\
\hline 12 & 5.74 & $3.0 \times 10^{6}$ & $4.32 \times 10^{6}$ \\
\hline 13 & 6.85 & $3.4 \times 10^{6}$ & $4.72 \times 10^{6}$ \\
\hline 21 & 7.18 & $3.9 \times 10^{6}$ & $4.83 \times 10^{6}$ \\
\hline 23 & 5.32 & $3.1 \times 10^{6}$ & $4.16 \times 10^{6}$ \\
\hline $2-2$ & 7.45 & $3.1 \times 10^{6}$ & $4.92 \times 10^{6}$ \\
\hline \multirow{2}{*}{\multicolumn{4}{|c|}{$\begin{array}{c}\text { 1/30-Scale, } \\
\text { Single-Story } \\
\text { Diesel Generator } \\
\text { Building }\end{array}$}} \\
\hline & & & \\
\hline $3 D-5$ & 2.62 & $2.4 \times 10^{6}$ & $2.92 \times 10^{6}$ \\
\hline $3 D-6$ & 2.50 & $2.4 \times 10^{6}$ & $2.85 \times 10^{6}$ \\
\hline \multicolumn{4}{|l|}{$\begin{array}{l}\text { Two-Story Diesel } \\
\text { Generator Buildina }\end{array}$} \\
\hline 3D-10-2 (1/30 scale) & 2.60 & $2.5 \times 10^{6}$ & $2.91 \times 10^{6}$ \\
\hline 3D-11-2 (1/30 scale) & 2.89 & - & $3.06 \times 10^{6}$ \\
\hline 3D-12-2 (1/30 scale) & 2.78 & $2.8 \times 10^{6}$ & $3.01 \times 10^{6}$ \\
\hline CERL 1 (1/10 scale) & 3.18 & $2.8 \times 10^{6}$ & $3.21 \times 10^{6}$ \\
\hline CERL 2 ( $1 / 10$ scale $)$ & 3.33 & $2.6 \times 10^{6}$ & $3.29 \times 10^{6}$ \\
\hline \multirow{2}{*}{\multicolumn{4}{|c|}{$\begin{array}{l}\text { Three-Story } \\
\text { Auxiliary } \\
\text { Building }\end{array}$}} \\
\hline & & & \\
\hline 1/42-Scale & 2.90 & $2.6 \times 10^{6}$ & $3.07 \times 10^{6}$ \\
\hline 1/14-Scale & 3.32 & $2.8 \times 10^{6}$ & $3.28 \times 10^{6}$ \\
\hline \multicolumn{4}{|l|}{ TRG Type } \\
\hline \multicolumn{4}{|l|}{ Structures } \\
\hline TRG-1 & 3.77 & $3.2 \times 10^{6}$ & $3.49 \times 10^{6}$ \\
\hline TRG-3 & 3.81 & $2.0 \times 10^{6}$ & $3.52 \times 10^{6}$ \\
\hline TRG-4 & 4.15 & $3.2 \times 10^{6}$ & $3.67 \times 10^{6}$ \\
\hline TRG-5 & 5.03 & $3.9 \times 10^{6}$ & $4.04 \times 10^{6}$ \\
\hline TRG-6 & 4.69 & $3.4 \times 10^{6}$ & $3.90 \times 10^{6}$ \\
\hline
\end{tabular}




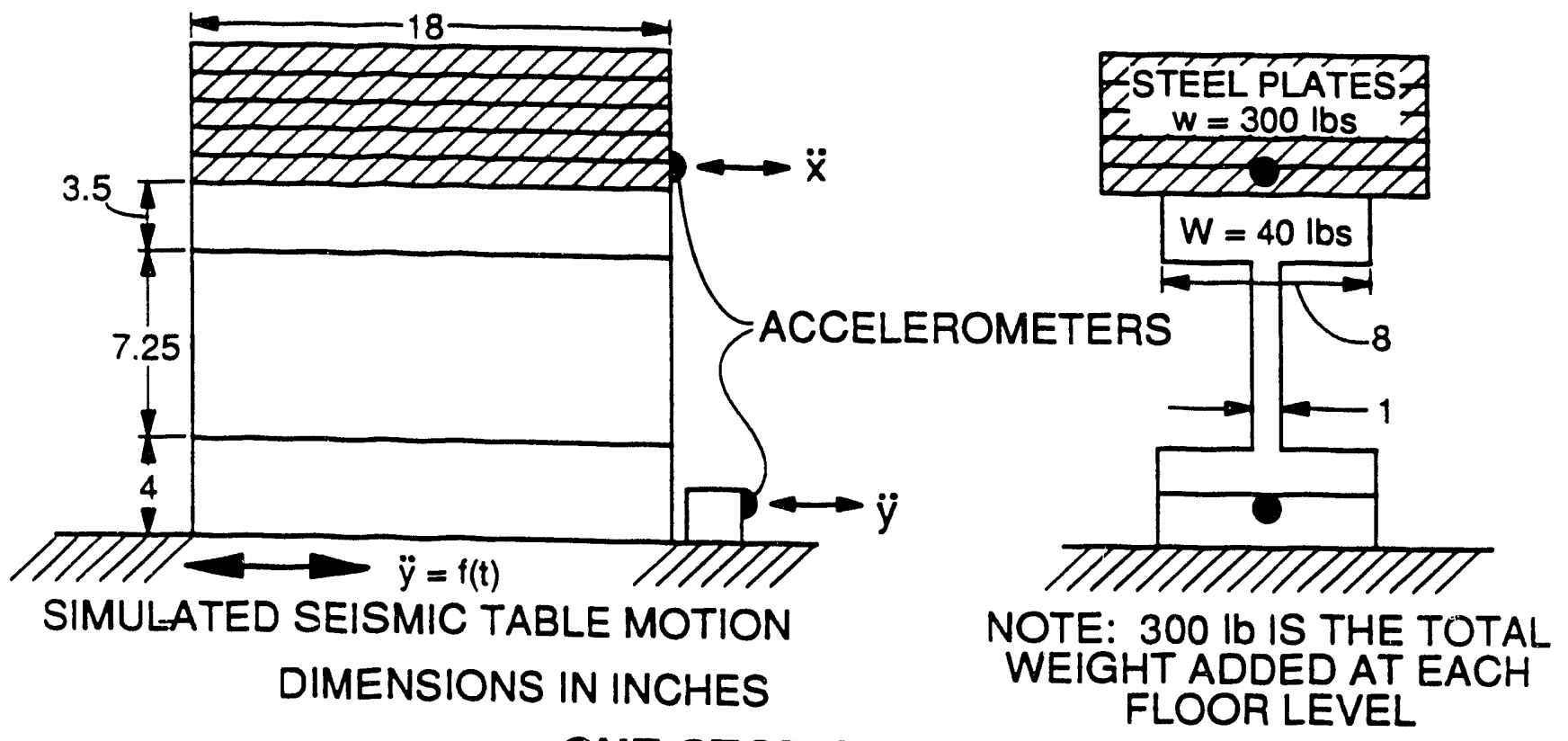

\section{a. ONE-STORY STRUCTURE}

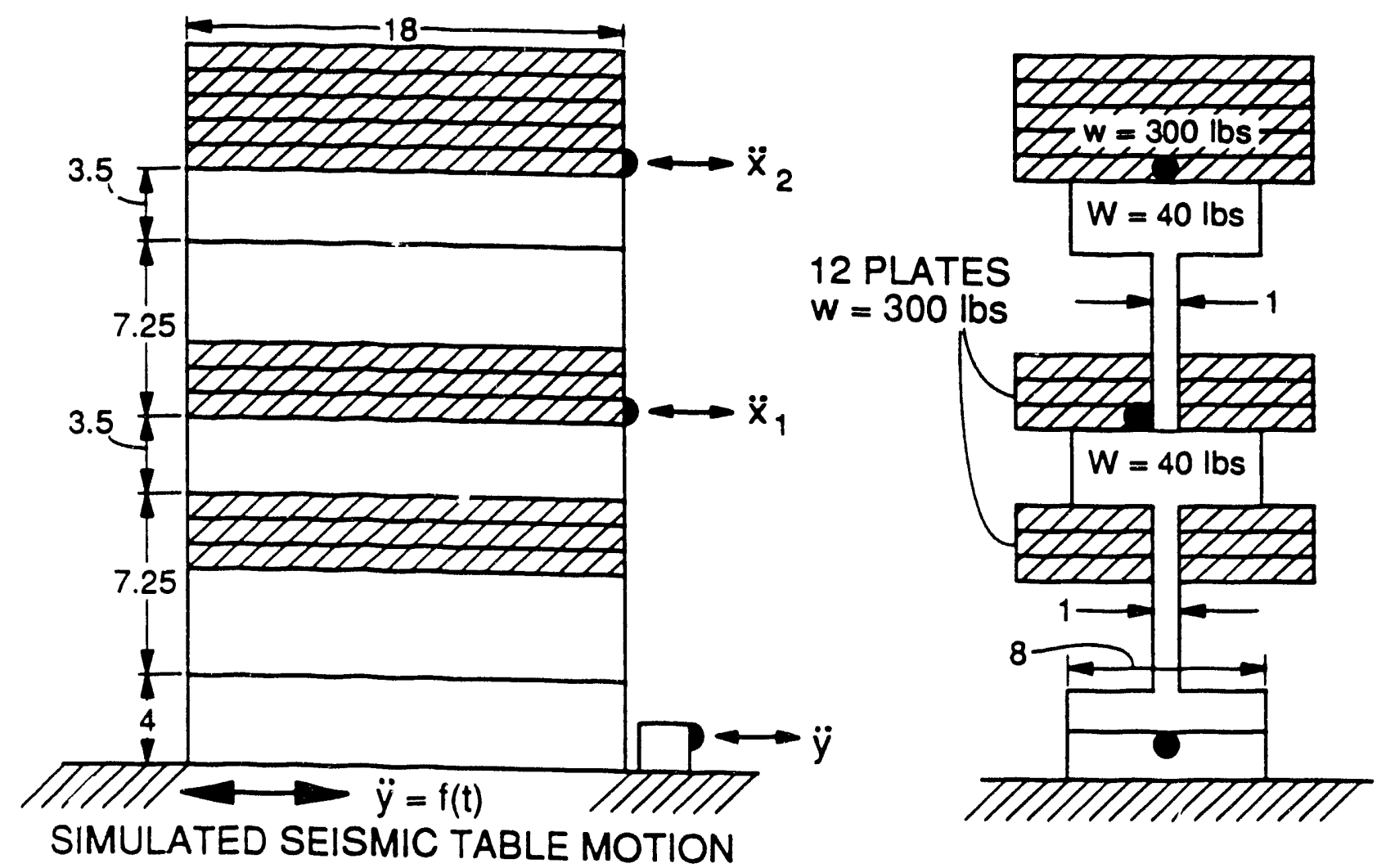

\section{b. TWO-STORY STRUCTURE}

Fig. A-2. Isolated shear wall structures with added mass. 


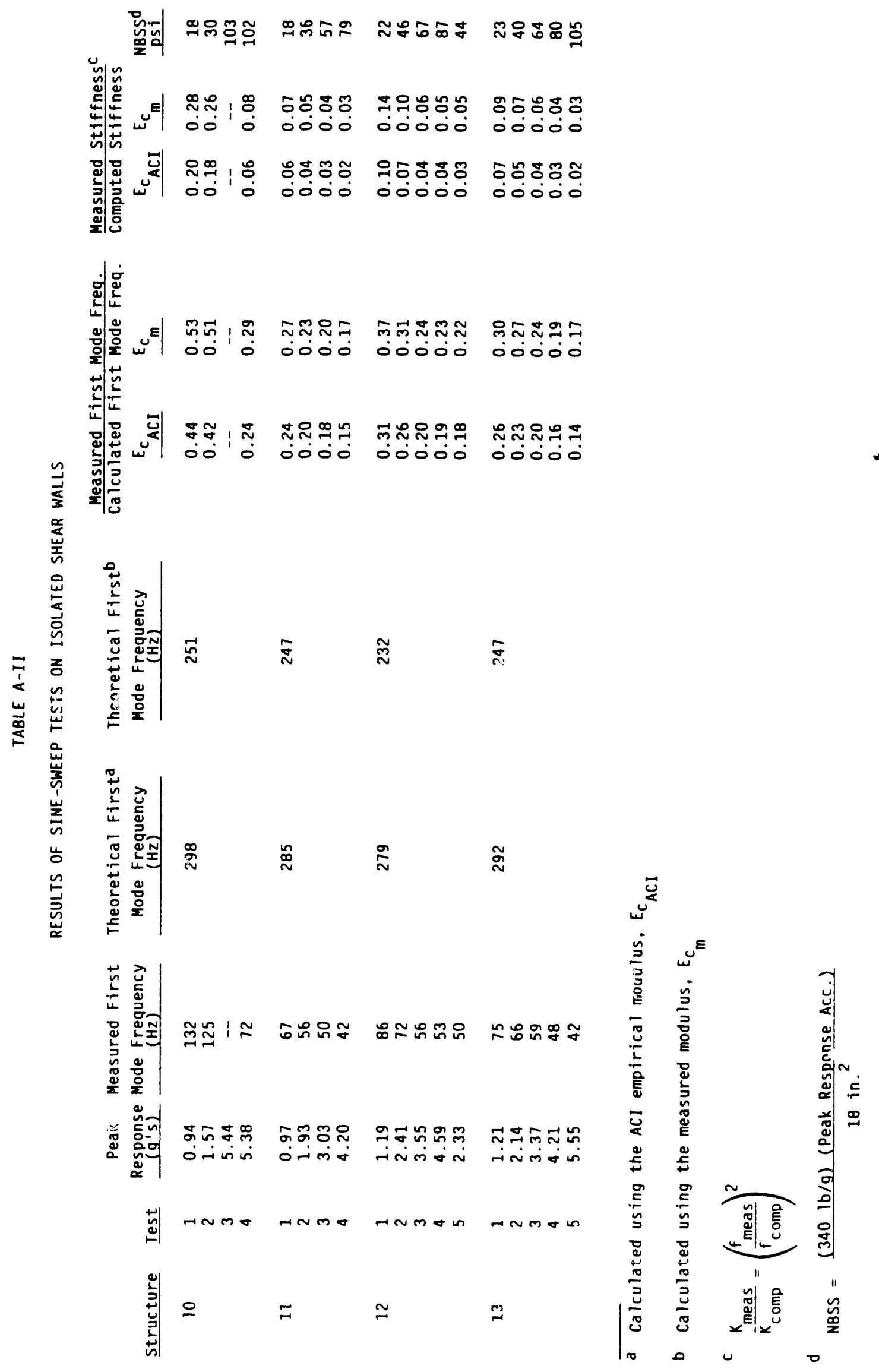




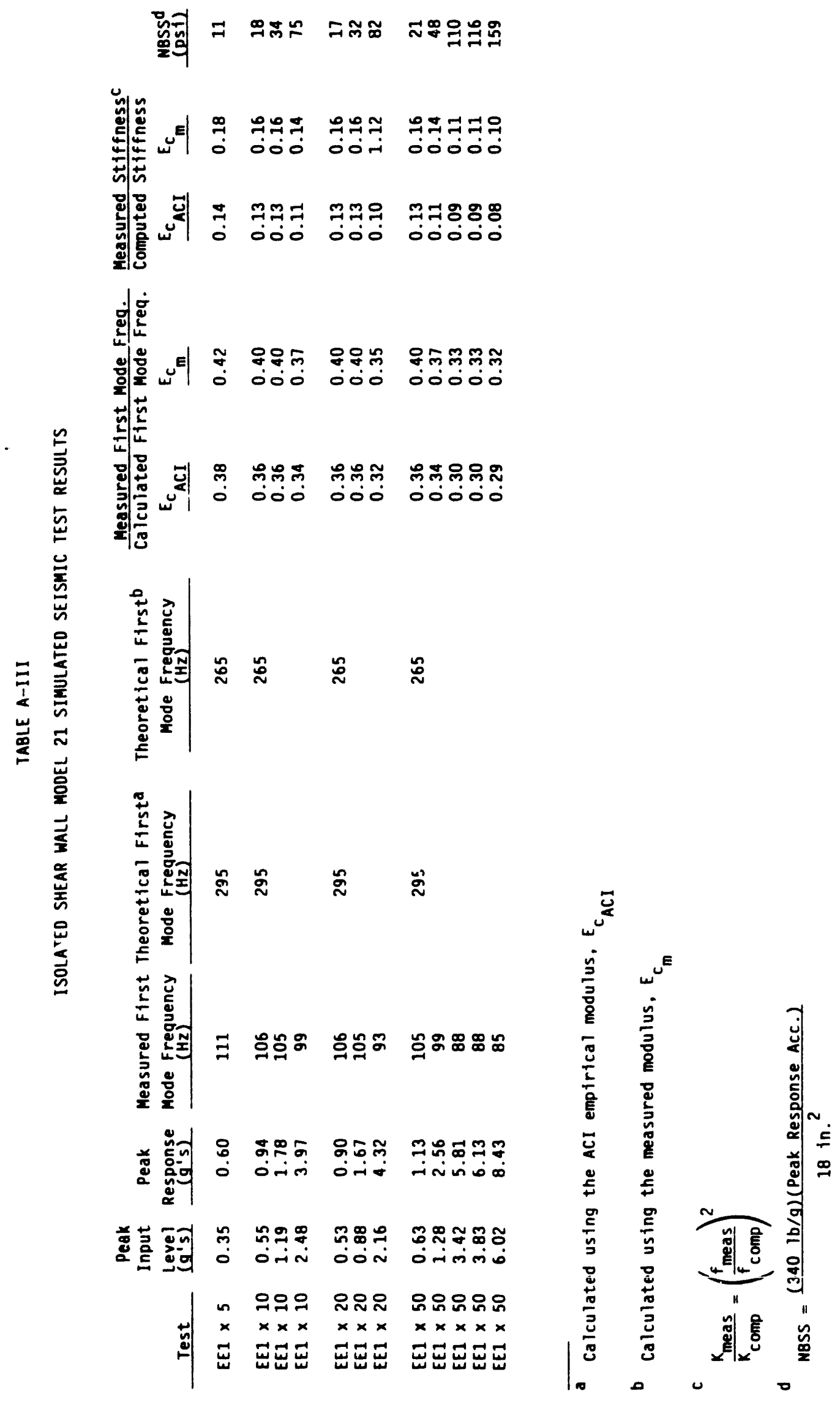

A -10 


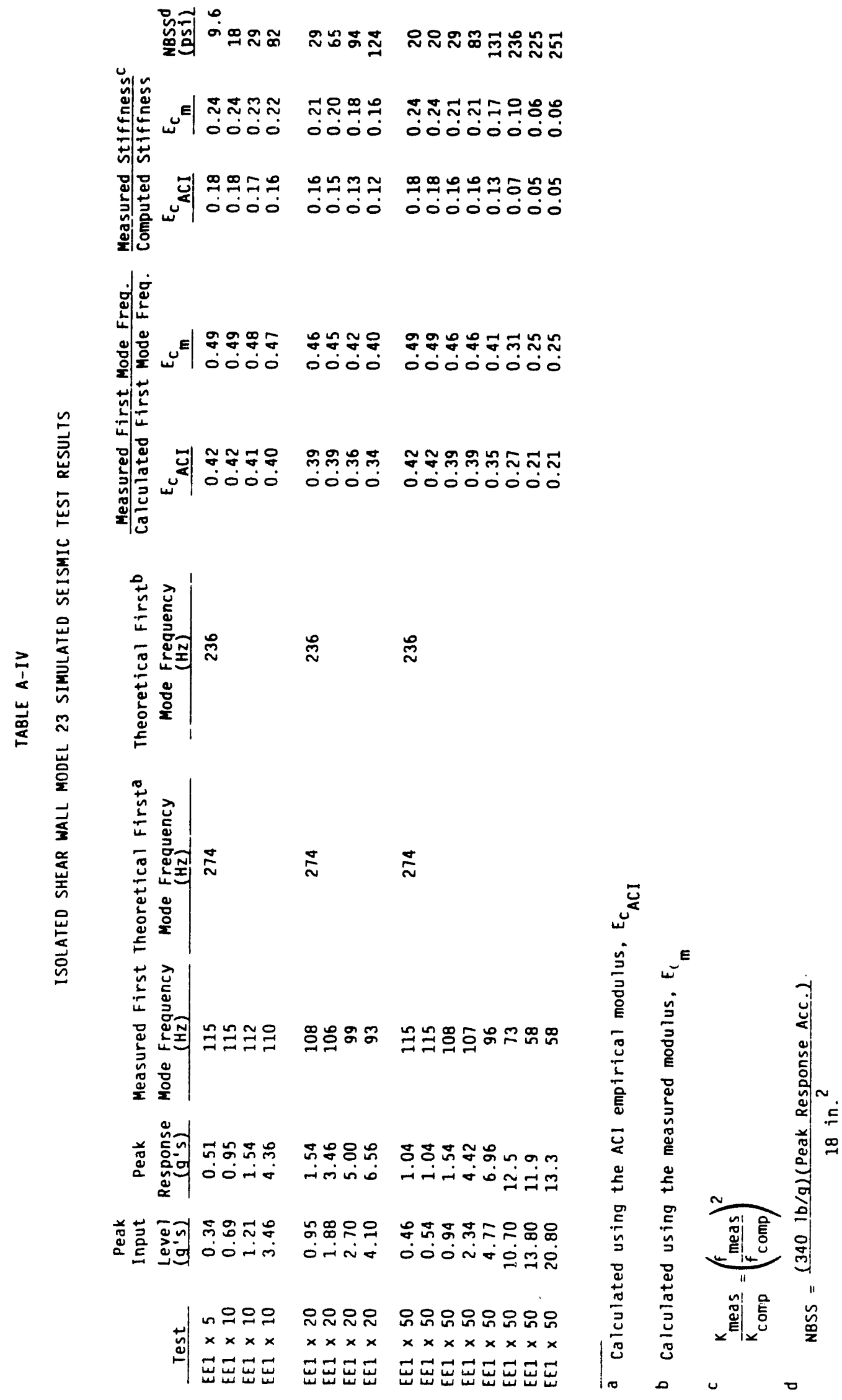

A - 11 
Finally, a two-story isolated shear wall structure was tested with simulated seismic and random inputs. The results from these tests are summarized in Table A-V. During all the dynamic tests, reductions in the resonant frequencies occurred before there were any visible signs of damage in the structures, and the reductions were greater during the sinesweep testing than during the simulated-seismic or random testing. A detailed discussion of this testing can be found in [17].

2. Diesel Generator Buildings. Two $1 / 30$-scale, single-story diesel generator building models were tested with random inputs. The results of these tests are summarized in Table A-VI. This table shows the indirectly determined stiffness compared with the theoretical stiffness obtained with an empirical modulus that assumes the entire end wall to be effective in resisting bending deformations.

Five two-story diesel generator models (three 1/30-scale and two 1/10-scale), shown in Fig. A-3, were tested with simulated seismic and random inputs. The results from these tests are summarized in Table A-VII. These tests demonstrated scalability among different-size microconcrete models. Again, the measured resonant frequencies were down by a factor of 1.74 or more; this result suggests that stiffnesses were down by a factor of 3.0 or more. The details of all the diesel generator building tests are summarized in [18].

3. Auxiliary Building. Two different scale models (1/14- and 1/42-scale) of an auxiliary building were tested, both with simulated seismic and random inputs. These structures are shown in Fig. A-4 and the results from the 1/42-scale models are summarized in Table A-VIII. The reductions in stiffnesses shown in Table A-VIII are consistent with the reductions observed in the two-story diesel generator buildings. An unplanned load excursion wicurred while the 1/14-scale model was on the shake table, and it produced visible cracking in the structure. Therefore, no data were obtained on this structure when it was in its initial condition. The details of these tests are summarized in [19].

4. TRG-Type Structures. TRG-1 and -3 were both tested with simulated seismic inputs. In addition, random inputs were applied to TRG-1 and haversine pulses were applied to TRG-3. Again, stiffnesses determined indirectly from resonant frequency measurements were found to be a factor of 2.6 to 4.0 below the theoretical stiffness values, using the measured modulus and assuming that the entire end walls were effective in their contribution to the bending stiffness.

When TRG-1 was subjected to a 0.5-g peak acceleration random input, it responded with a stiffness that was down by a factor of 2.6 from theory (as inferred from a resonant frequency that was a factor of 1.6 below theory), even though this excitation produced only 16.3-psi NBSS and 16.6 principal tensile stress (PTS). Similar stiffness values were obtained during a $0.5-\mathrm{g}$ seismic test. TRG-3 responded to a $0.73-\mathrm{g}$ seismic test with a stiffness that was down by a factor of 4.0 from the theory, at an NBSS of 91 psi and a PTS of 92 psi. 


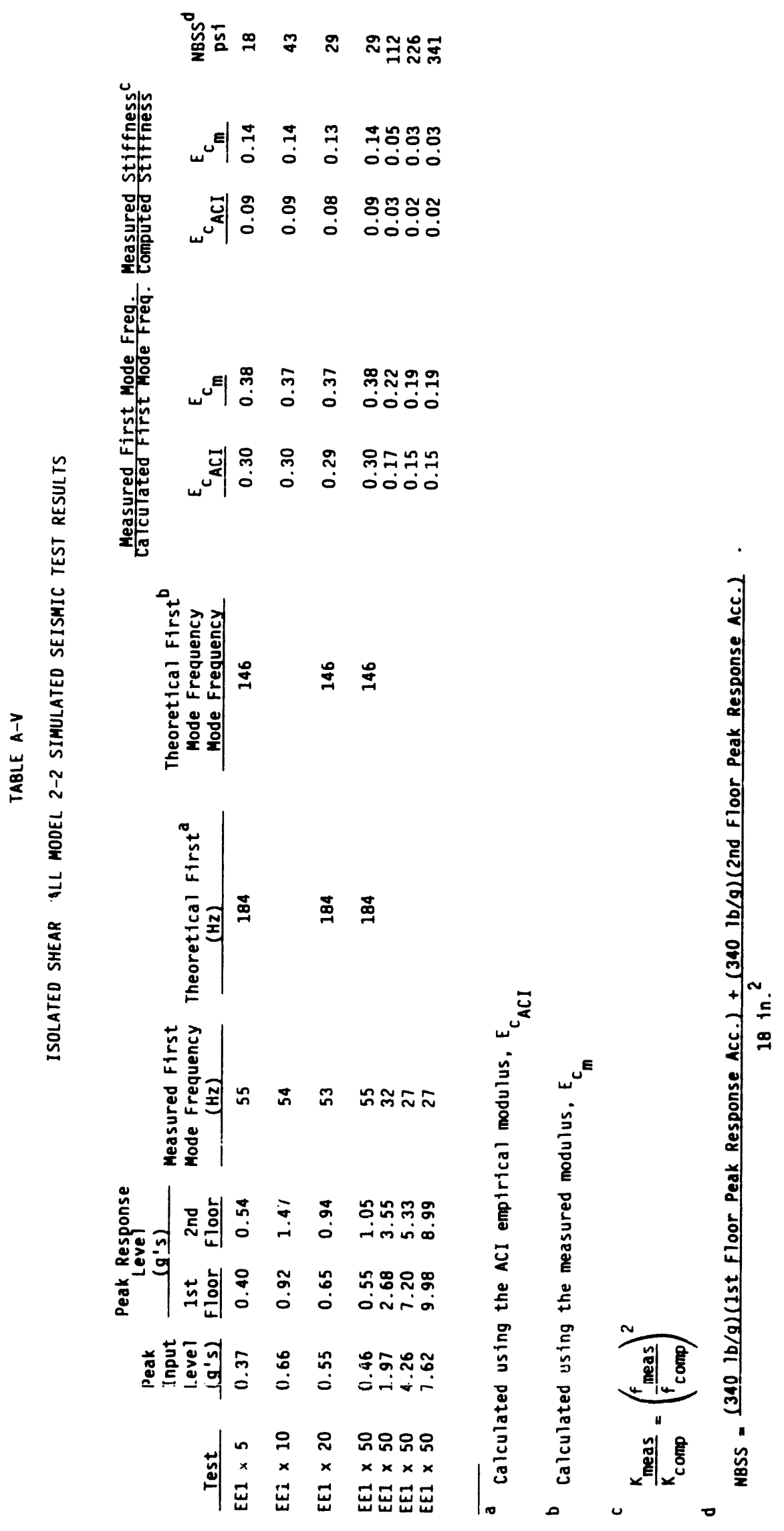




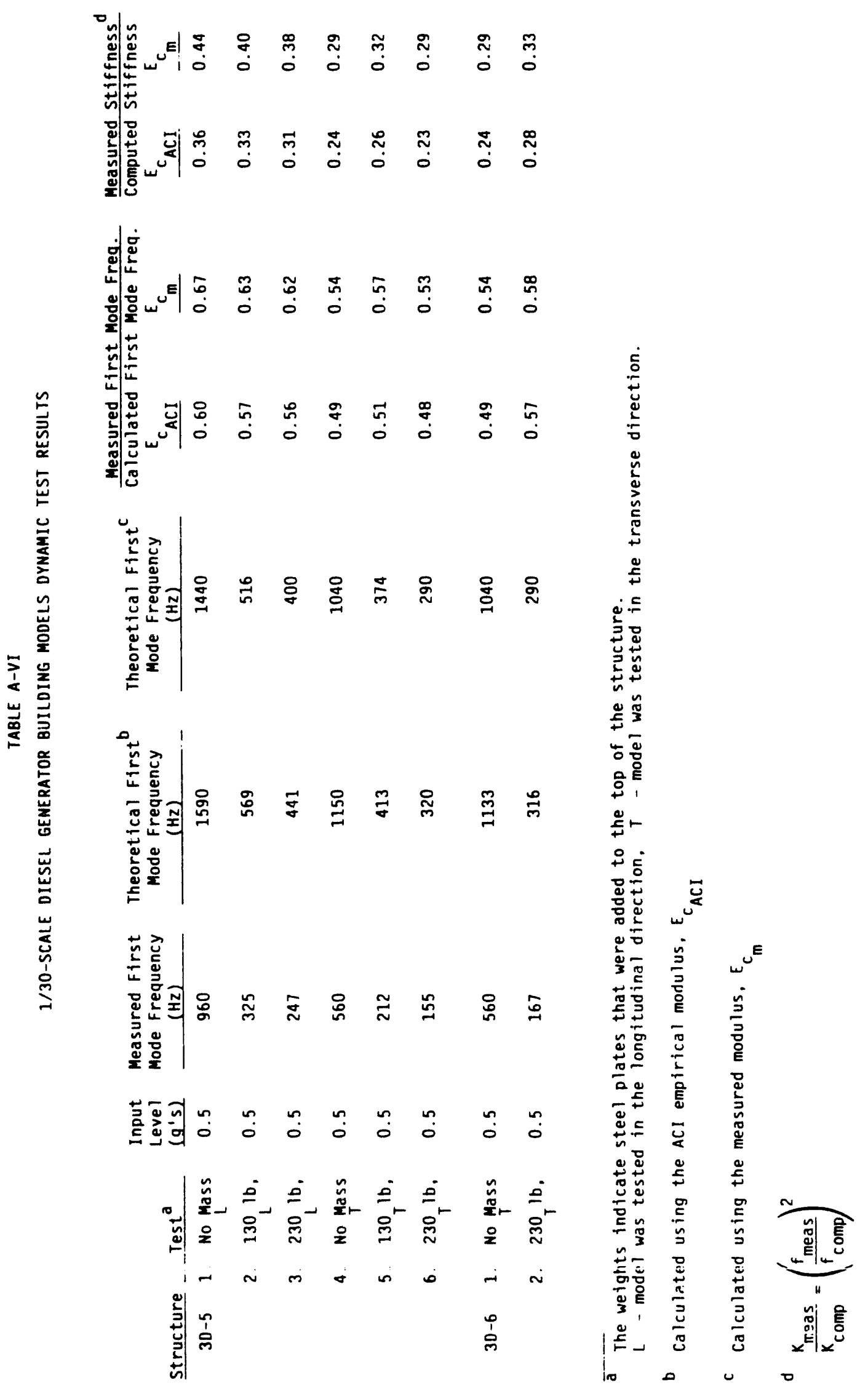

A- 14 


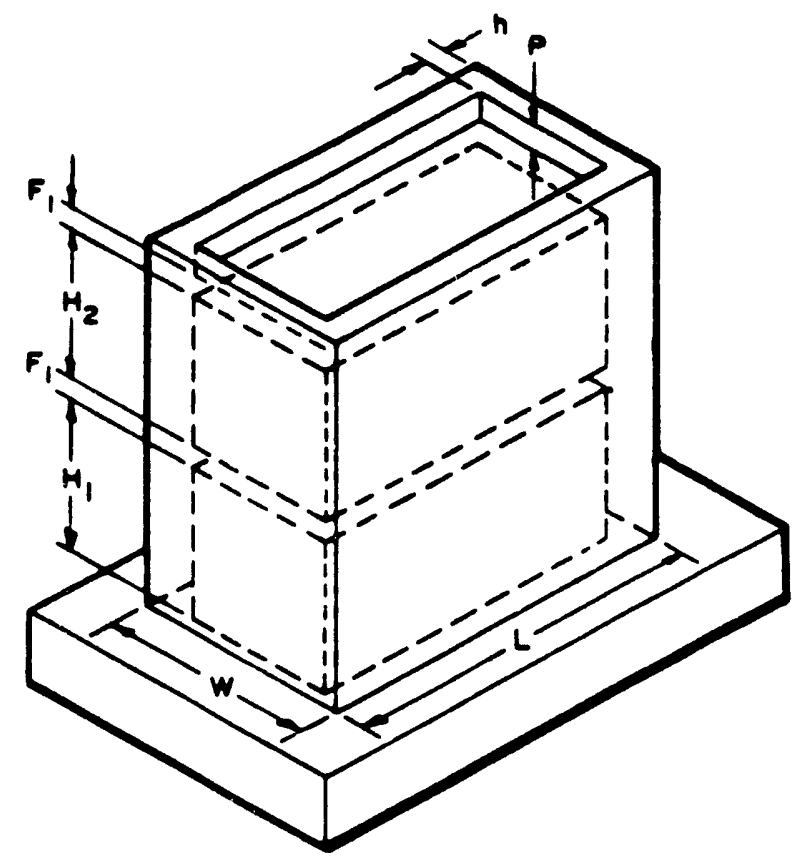

\begin{tabular}{|c|c|c|c|c|c|c|}
\hline & $h_{1} F_{1}, F_{2}$ & $w$ & $L$ & $\left|H_{1} \propto H_{2}\right|$ & $\mathbf{P}$ & WI/sTOAY(Ib) \\
\hline $\begin{array}{l}\text { ino seale } \\
\text { ino senes } \\
\text { motorres }\end{array}$ & $\begin{array}{c}1 \mathrm{im} . \\
3 \mathrm{~m} . \\
20 \mathrm{im} .\end{array}$ & $\begin{array}{ll}10 & m . \\
30 & n . \\
25 & n\end{array}$ & $\begin{array}{ll}10 \mathrm{in} \\
\mathrm{cos}\end{array}$ & $\mid \begin{array}{r}1.2 \mathrm{im} . \\
21 . \pi \mathrm{im} . \\
10 \mathrm{n.} 1.5 \mathrm{in} .\end{array}$ & $\begin{array}{l}1 \mathrm{im} . \\
3 \mathrm{~m} . \\
30 \mathrm{im} .\end{array}$ & $\begin{array}{c}47.7 \\
1200 \\
1.209 .000\end{array}$ \\
\hline
\end{tabular}

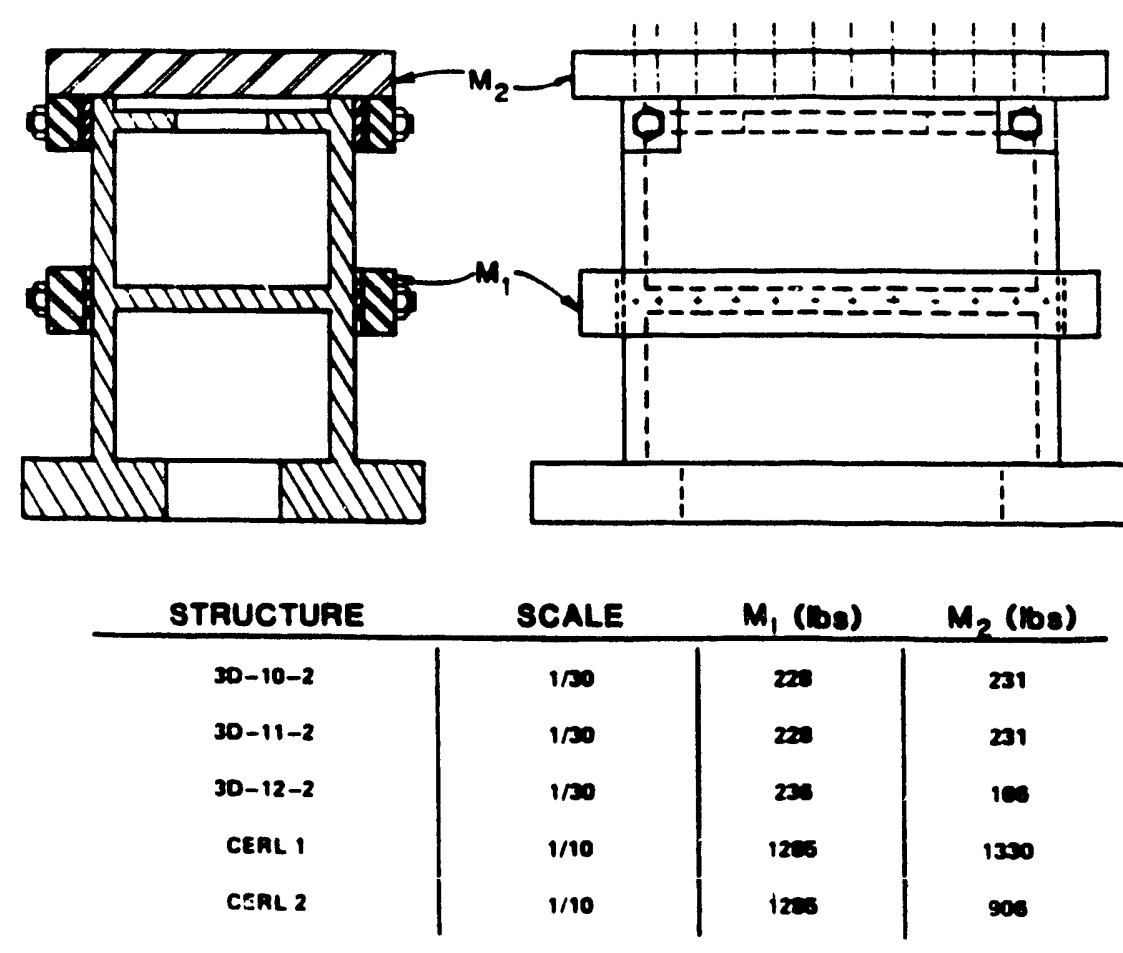

Fig. A-3. Two-story diesel generator building models. 

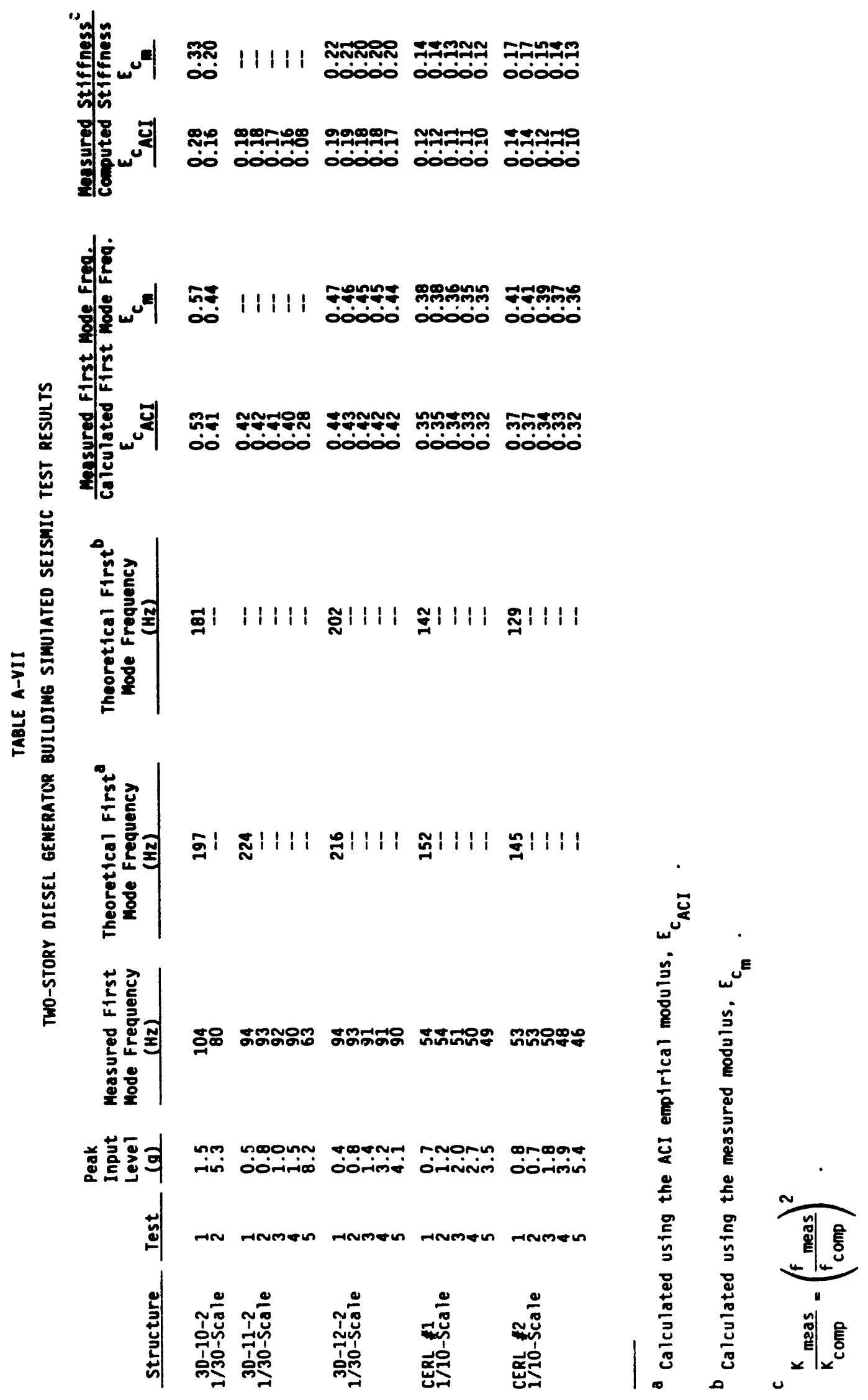

A- 16 


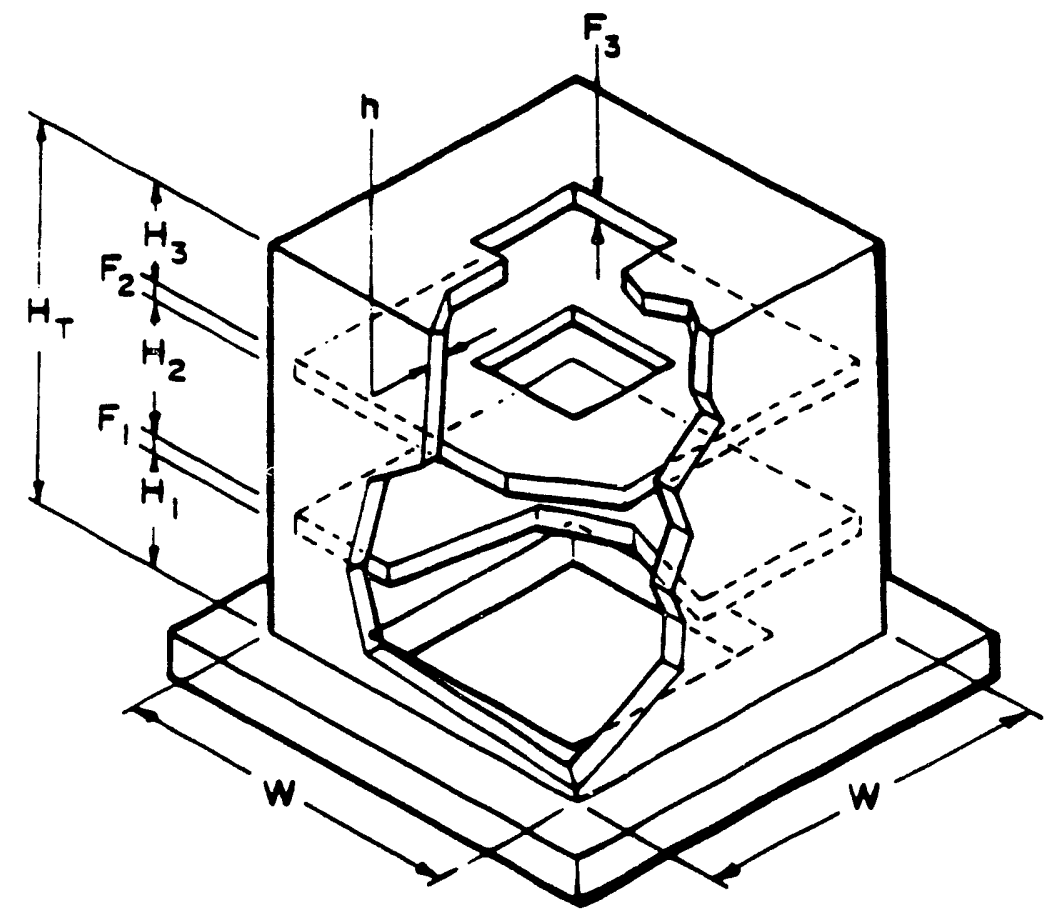

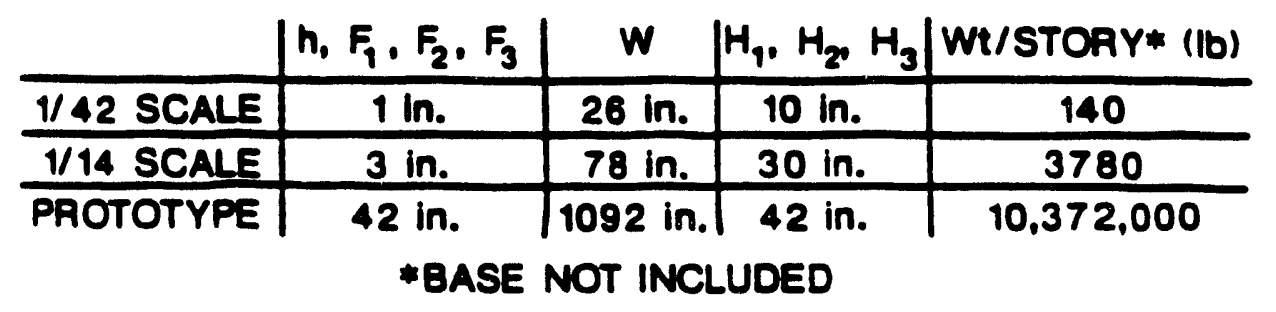

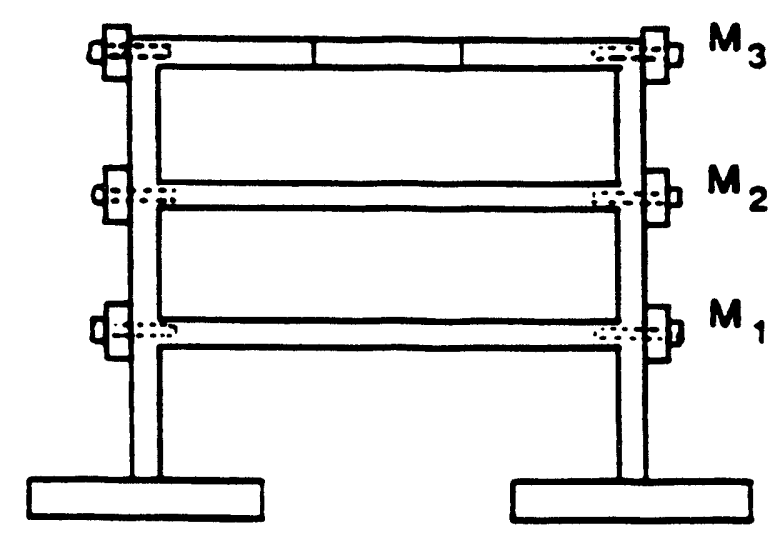

\begin{tabular}{c|c|c|c} 
STRUCTURE & $M_{1}$ (lbs) $M_{2}$ (lbs) $M_{3}$ (lbs) \\
\hline 1/42-SCALE & 500 & 460 & 395 \\
1/14-SCALE & 3334 & 3060 & 2631
\end{tabular}

Fig. A-4. Three-story auxiliary building models. 


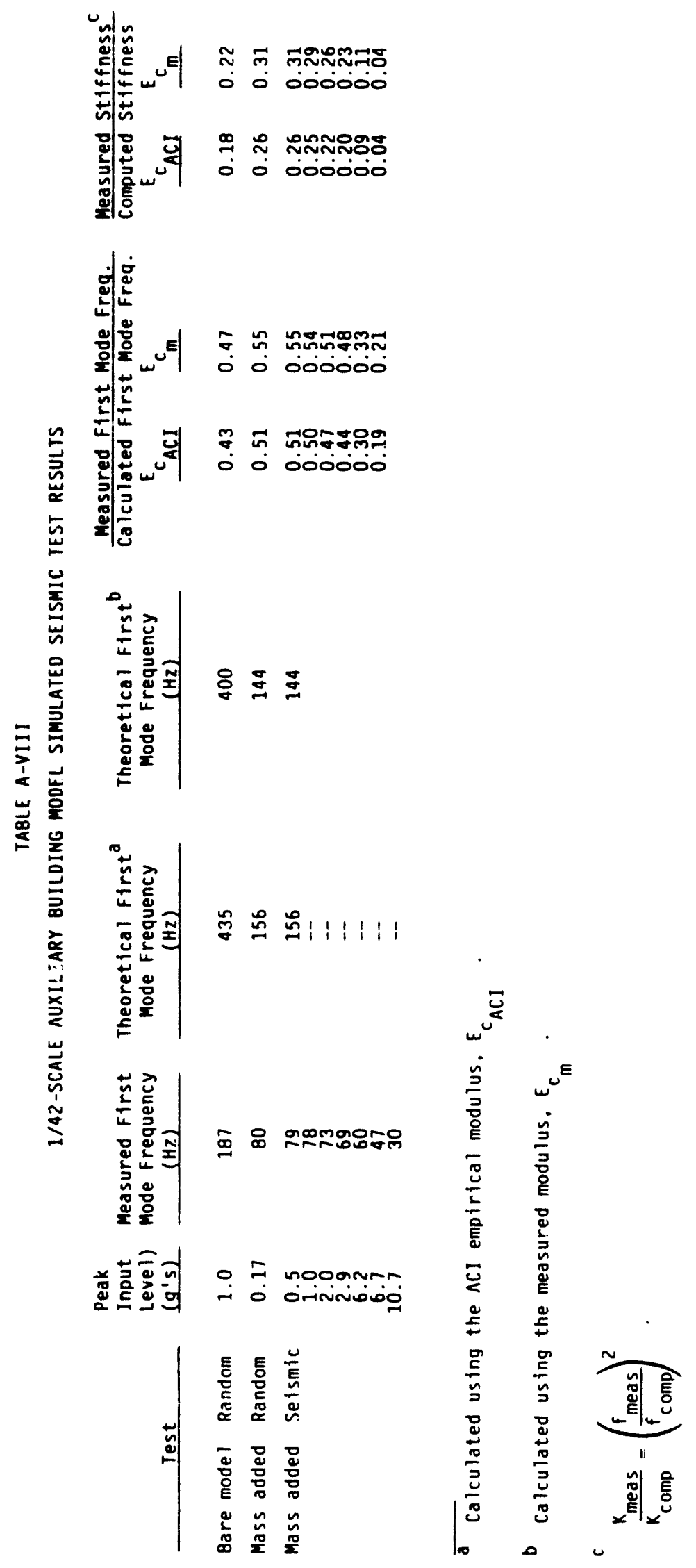

$\dot{A}-1 \overline{8}$ 
Experimental modal analyses were performed on all the TRG-type structures. Results of these analyses were compared with results from finite element modal analyses of the structures. In general, the experimental and analytical modal analyses agreed, implying that when the structures were subjected to the low-level random excitations used during experimental tests, they responded with a stiffness that finite element analyses would have predicted. Table A-IX summarizes the experimental modal analysis results. Dynamic tests and results for TRG-1 are discussed in [20]; TRG-3 results are discussed in [21]; TRG-4 modal analysis results are discussed in [1]; TRG-5 modal analysis results are discussed in [22]; and TRG-6 modal analysis results are discussed in [23].

\section{A-III. REVIEW OF PREVIOUS STATIC TEST RESULTS OBTAINED IN THE SEISMIC CATEGORY I STRUCTURES PROGRAM}

Previously in this program, measured stiffness values from static and dynamic tests have been compared with theoretical values that were determined using a modulus of elasticity calculated from the empirical formula in ACI 349-85. This empirical formula generally gave a higher value for the concrete's modulus than was measured from test specimens. In the following summary of previous tests results, theoretical stiffness values were determined using measured moduli, as determined from the ASTM standard test. This investigation is concerned with determining the proper values of stiffness to be used in the analysis of Seismic Category I structures; it is felt that the best estimate of actual material properties should be used when experimental results are compared with theory. The previously reported comparisons between measured and theoretical stiffness do, however, provide information concerning errors that could occur during the design process if material properties have yet to be measured. Table $A-X$ is a summary of the previous results, using both the measured and the design values for the concrete's modulus.

I. Isolated Shear Walls. The first static tests were performed on single-story isolated shear walls and reported in Ref. 17. Five walls were tested, two monotonically and three cyclically. These specimens were madewith microconcrete and wire mesh reinforcement. The amount of reinforcement at the interface of the shear wall base and the shear wall/top plate interface was varied with the amount of moment reinforcement in the form of threaded steel rods located at the ends of the sinear wall.

All specimens remained essentially linear, up to a load producing an NBSS of 200 psi and a PTS of 600 psi or more. The load at first cracking, as predicted from a strengthof-materials approach, agreed very well with the measured cracking strength of the walls and the average split cylinder tensile strength of 666 psi. Also, when the walls were subjected to repeated load cycles below the first cracking load, there was no evidence of stiffness degradation or of any increase in the area of the hysteresis loop for a given load level. Above the first cracking load, stiffness degraded and the area of the hysteresis loop increased with increased load and increased cycles at a constant load. The ultimate strength of the walls exceeds the provisions for shear capacity, as determined by $\mathrm{ACl}$ 349-85-11.10. The measured stiffnesses in the linear region were down by a factor of 1.90 to 2.05 from the calculated uncracked cross-section stiffness using a measured modulus. 


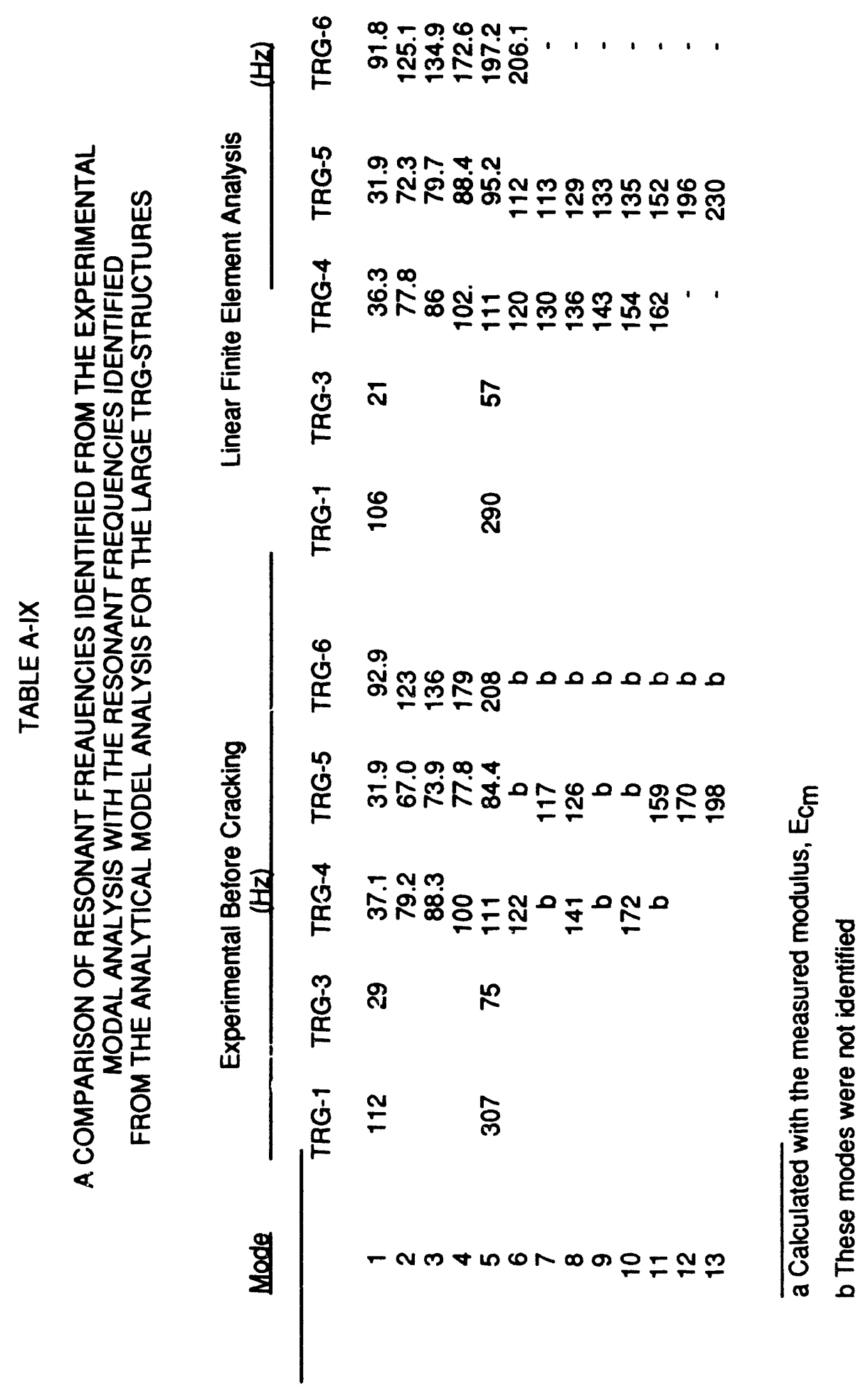


TABLE $A-X$

PREVIOUS STATIC TEST RESULTS

\begin{tabular}{|c|c|c|c|c|c|c|c|c|}
\hline & \multirow{2}{*}{$\begin{array}{l}\text { Measured } \\
\text { Stiffiness } \\
\text { before } \\
\text { Cracking } \\
(1 b / i n .) \\
1\end{array}$} & \multirow{2}{*}{$\begin{array}{c}\text { Ultimate } \\
\text { Compressive } \\
\text { Strength } \\
f_{c}^{\prime} \\
\text { (ksi) }\end{array}$} & \multirow{2}{*}{\multicolumn{2}{|c|}{$\begin{array}{l}\text { Theoreticalb } \\
\text { Stiffness Using } \\
\text { Measured } \\
\text { Modulus } \\
\text { (1b/in.) } \\
2\end{array}$}} & \multirow{2}{*}{$\begin{array}{l}\text { Theoreticalo } \\
\text { Stiffness Using } \\
\text { ACI Empirical } \\
\text { Modulus } \\
(1 b / i n .) \\
3\end{array}$} & \multicolumn{3}{|c|}{$\begin{array}{l}\text { Ratio of } \\
\text { Columns }\end{array}$} \\
\hline & & & & & & $\frac{2}{1}$ & $\frac{3}{1}$ & $\frac{2}{3}$ \\
\hline \multicolumn{9}{|c|}{ Isolated Shear Walls: } \\
\hline $\begin{array}{l}1 \\
2 \\
3 \\
4 \\
5\end{array}$ & $\begin{array}{l}0.78 \times 106 \\
0.79 \times 10^{6} \\
1.0 \times 10^{6} \\
1.06 \times 10^{6} \\
0.87 \times 10^{6}\end{array}$ & $\begin{array}{l}4.34 \\
5.89 \\
7.35 \\
6.86 \\
6.31\end{array}$ & $\begin{array}{l}1.60 \\
1.90 \\
1.75\end{array}$ & $\begin{array}{l}\times 10^{6} \\
-\bar{x} 10^{6} \\
\bar{x} 10^{6}\end{array}$ & $\begin{array}{l}2.33 \times 10^{6} \\
2.71 \times 10^{6} \\
3.03 \times 10^{6} \\
2.92 \times 10^{6} \\
2.80 \times 10^{6}\end{array}$ & $\begin{array}{l}2.05 \\
- \\
1.90 \\
- \\
2.02\end{array}$ & $\begin{array}{l}2.99 \\
3.43 \\
3.03 \\
2.75 \\
3.22\end{array}$ & $\begin{array}{l}0.69 \\
- \\
0.63 \\
- \\
0.63\end{array}$ \\
\hline \multicolumn{9}{|c|}{$\begin{array}{l}\text { 1/30-scale, I-Story, } \\
\text { Diesel Generator Buildings: }\end{array}$} \\
\hline $\begin{array}{l}3 D-2 \\
3 D-4 \\
3 D-7 \\
3 D-8 \\
3 D-9 \\
3 D-10 \\
3 D-11 \\
3 D-12 \\
3 D-13 \\
3 D-19 \\
30-20\end{array}$ & 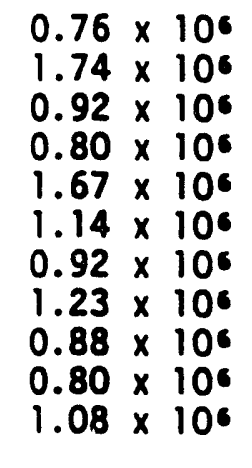 & $\begin{array}{l}2.70 \\
3.32 \\
2.35 \\
2.30 \\
2.69 \\
3.27 \\
3.09 \\
2.05 \\
2.04 \\
4.70 \\
4.30\end{array}$ & $\begin{array}{l}2.25 \\
4.82 \\
2.45 \\
2.36 \\
4.62 \\
\\
\\
\\
3.22\end{array}$ & $\begin{array}{ll}x & 106 \\
x & 106 \\
x & 106 \\
x & 106 \\
x & 106 \\
- \\
= \\
= \\
= \\
= \\
x & 106\end{array}$ & $\begin{array}{l}2.90 \times 10^{6} \\
6.08 \times 10^{6} \\
2.71 \times 10^{6} \\
2.68 \times 10^{6} \\
5.47 \times 10^{6} \\
3.19 \times 10^{6} \\
3.11 \times 10^{6} \\
2.53 \times 10^{6} \\
2.52 \times 10^{6} \\
3.83 \times 10^{6} \\
3.65 \times 10^{6}\end{array}$ & $\begin{array}{l}2.96 \\
2.77 \\
2.66 \\
2.95 \\
2.77 \\
- \\
- \\
- \\
- \\
2.98\end{array}$ & $\begin{array}{l}3.82 \\
3.49 \\
2.95 \\
3.35 \\
3.27 \\
2.80 \\
3.38 \\
2.06 \\
2.86 \\
4.79 \\
3.38\end{array}$ & $\begin{array}{l}0.78 \\
0.79 \\
0.90 \\
0.88 \\
0.84 \\
= \\
= \\
- \\
- \\
0.88\end{array}$ \\
\hline $\begin{array}{l}\text { TRG-1 } \\
\text { TRG-3 } \\
\text { TRG-4 } \\
\text { TRG-5 } \\
\text { TRG-6 }\end{array}$ & $\begin{array}{r}0.75 \times 10^{6} \\
4.4 \times 10^{6} \\
8.5 \times 10^{6} \\
6.9 \times 10^{6} \\
58.0 \times 10^{6}\end{array}$ & $\begin{array}{l}3.77 \\
3.81 \\
4.15 \\
5.03 \\
4.69\end{array}$ & $\begin{array}{r}1.2 \\
3.0 \\
8.4 \\
6.8 \\
48.0\end{array}$ & $\begin{array}{ll}x & 106 \\
x & 106 \\
x & 106 \\
x & 10^{6} \\
x & 10^{6}\end{array}$ & $\begin{array}{r}1.3 \times 10^{6} \\
5.0 \times 10^{6} \\
9.6 \times 10^{6} \\
7.1 \times 10^{6} \\
54.0 \times 10^{6}\end{array}$ & $\begin{array}{l}1.60 \\
0.68 \\
0.99 \\
0.99 \\
0.83\end{array}$ & $\begin{array}{l}1.73 \\
1.13 \\
1.13 \\
1.03 \\
0.93\end{array}$ & $\begin{array}{l}0.92 \\
0.60 \\
0.88 \\
0.96 \\
0.89\end{array}$ \\
\hline
\end{tabular}

aThe empirical modulus, $E_{C}$, is $57,000 \sqrt{f_{C}^{1}}$, and the measured modulus, $E_{C_{m}}$, can be computed by the following formula:

$$
E_{c_{m}}=57,000 \sqrt{f_{c}^{\prime}}\left(\frac{\text { Stiffness Col, 2 }}{\text { Stiffness Col. 3 }}\right) .
$$

bBased on the gross section. 
2. 1/30-Scale Single-Story. Diesel Generator Buildings, Eleven 1/30-scale, single-story, diesel generator buildings were statically tested to failure and are reported in [18]. Nine models were tested monotonically, eight in the transverse direction and one in the longitudinal direction. Two models were tested cyclically, one each in the transverse and longitudinal directions. These specimens were all made with microconcrete and wire mesh reinforcement. Other than the direction of applied load, the only parameters that were varied in these tests were the amount of cure time each model experienced before testing and the distance the reinforcement was embedded in the base of the structure.

As with the isolated shear walls, all specimens remained linear, up to the load that produced visible cracking. This load produced an NBSS on the order of $200 \mathrm{psi}$ and a PTS on the order of 340 psi. At a given load level below the first-cracking load, the area under the hysteresis loop remained constant when the load was cycled and the stiffness remained constant. Above the cracking load, stiffness again was observed to degrade and the area of the hysteresis loop increased with either increases in load level or with increases in the number of load cycles. The load at first cracking was in good agreement with the value predicted from mechanics-of-materials and the measured tensile stress of the concrete. Provisions for the shear capacity of the walls from $\mathrm{ACl}$ 349-85 were exceeded. Stiffnesses based on a secant from the origin to half the ultimate load were down by factors of 2.7 to 3.0 when compared with the calculated stiffness based upon a uncracked cross section and a measured modulus.

It should be noted that the moment of inertia used in the calculated stiffness value considered the entire end wall to contribute to the flexural stiffness of the shear wall. The modulus of elasticity was based on the measured values. No effect from cure time or embedment length was observed.

3. IRG-Type Structures. TRG-3 and its two $1 / 4$-scale models, TRG-1 and -2, were tested statically and monotonically at low-load levels that produced an NBSS of 28 psi and a PTS of 40 psi on TRG-3 and an NBSS of 53 psi and a PTS of 80 psi on TRG-1 and -2 . These tests were repeated several times and were intended to identify the initial stiffness condition of each model while introducing a minimum amount of damage into the test structure. TRG-3 was construsted with conventional concrete and No. 3 rebar and TRG-1 and -2 were made with microconcrete and wire mesh reinforcement.

TRG-3 showed a measured stiffness up by a factor of 1.47 from the uncracked cross-section stiffness and TRG-1 showed a reduction of 1.60 from the theoretical stiffness. However, in both cases, the theoretical stiffness was computed with a measured value of $E_{c}$. The measured modulus for TRG-3 was considerably less than the $A C I$ empirical modulus $\left(2.1 \times 10_{6}\right.$ psi compared with $3.5 \times 10_{6}$ psi). TRG-2 was found to have significant shrinkage cracks. Results from this model were no considered representative of an actual structure's response. When properly scaled, the static stiffness values for the two models were in good agreement, showing that stiffness can be scaled from microconcrete to conventional concrete in this low-load-level region.

TRG-4 through -6 were tested statically to failure in a cyclic manner. TRG-4 and -5 exhibited repeatable linear response with stiffnesses that were almost identical to theory until first-cracking. TRG-6 exhibited a repeatable linear response, but the stiffness was $20 \%$ greater than theory until first cracking. This increased stiffness was the 
poor displacement resolution in the measurements for this low aspect ratio structure. For TRG-4, first cracking occurred when an NBSS of 131 psi and a PTS of 171 psi was reached. For TRG-5 cracking occurred approximately at a NBSS of $167 \mathrm{psi}$ and at a PTS of 227 psi. "Approximately" is used with the TRG-5 value because an unplanned load excursion prevented the actual value from being recorded. The components of stiffness attributable to shear and bending were separated. These components also agreed with their respective theoretical values. After cracking, the structure again behaved in a linear manner when loaded to levels that did not exceed the peak load during the first-cracking cycle. During these cycles, the stiffness was down by a factor of 2 , with the loss occurring equally in each component of the stiffness.

\section{A-IV. COMPARISON OF STIFFNESSES MEASURED FROM STATIC AND DYNAMIC TEST RESUL.TS}

1. Isolated Shear Walls. When normalized to a common modulus of elasticity, the static stiffness values can be compared with those measured dynamically during sinesweep and simulated seismic tests of similar isolated shear wall models. At force levels that were $10 \%$ of the load required to produce first cracking in the static test (first cracking occurred around 200-psi NBSS, 600-psi PTS), stiffnesses measured during the sinesweep and simulated seismic tests were considerably lower than those obtained during static tests. They were even lower than those calculated by using an uncracked cross section stiffness value with a measured modulus. The sine-sweep and seismic resonant frequency values were down, on the average, by a factor of 2.7 and 2.2 from the calculated uncracked value, respectively. This result suggests that stiffness values were down by an average factor of 6.9 and 4.8 from the calculated uncracked value. In turn, the stiffness determined from the sine-sweep and seismic frequency values were down by an average factor of 2.9 and 2.0 from the average measured static value, respectively.

2. 1/30-Scale. Single-Story Diesel Generator Buildings. When these models were tested dynamically with a $0.5-\mathrm{g}$ peak acceleration random input producing an NBSS of 6.3 psi and a PTS of 10.6 psi, the models exhibited resonant ferquencies that were a factor of 1.7 to 1.95 below thenry, suggesting that stiffnesses were down by a factor of 2.9 to 3.8 from the strength-of-materials prediction using a measured modulus. These results can be compared with the static results that showed reductions in stiffness of 2.7 to 3.0 from the mechanics-of-materials prediction using a measured modulus. When normalized to a common modulus of elasticity, the dynamic stiffnesses were, on the average, down by a factor 1.15 from the static stiffness values. It should be reiterated that the static stiffnesses were determined by a secant from the origin to half the ultimate load when the NBSS was on the order of 200 psi and the PTS was on the order of 300 psi. These stress levels are significantly higher than the ones induced by the dynamic excitations.

3. TRG-1 and TRG-3. TRG-1 exhibited a stiffness that was a factor of 1.25 below theory when tested to a maximum NBSS of 53 psi and a maximum PTS of 28 psi. During the first 0.5-g peak acceleration random input, the stiffness was down by a factor of 2.6 at excitation levels that produced an NBSS of 16.3 psi and a PTS of 16.3 psi. 
TRG-3's stiffness was a factor of 1.47 above theory when the loads produced a maximum NBSS of 28 psi and a miximum PTS of 40 psi. When TRG-3 was subjected to a $0.73-\mathrm{g}$ seismic test that produced an NBSS of 91 psi and a PTS of 92 psi, the stiffness was down by a factor of 4.0 .

After TRG-3 had been shipped to the shake table facility in Champaign, Illinois, cracks became visible in the base of the structure; this suggested that the model had been damaged in shipping. 


\section{EVALUATING EQUIVALENT VISCOUS DAMPING RATIOS FROM HYSTERETIC ENERGY LOSSES}




\section{B-I. EVALUATING EQUIVALENT VISCOUS DAMPING RATIOS FROM HYSTERETIC ENERGY LOSSES}

The hysteretic energy loss is defined as the area between the load deformation curve (Fig. B-1). It was calculated numerically using a trapezoid integration rule. Several load cycles did not form a closed load deformation loop. In these cases, the integration scheme connected the terminal point with a straight line to the initial point. Errors induced by this scheme were considered negligible.

To obtain an equivalent viscous damping coefficient, the energy dissipated by viscous damping, UVD, in a linear, single degree-ot-freedom system during steady-state response to one cycle of harmonic forced excitation is equated to the hysteretic energy loss, $U_{H}$, measured during one cycle of static loading. The energy lost because of viscous damping is

$$
\mathrm{UVD}=\pi \mathrm{CA} 2 \omega \text {, }
$$

where

$$
\begin{aligned}
& C=\text { viscous damping coefficient, } \\
& A=\text { amplitude of steady-state vibration, } \\
& \omega=\text { frequency of steady-state vibration, }
\end{aligned}
$$

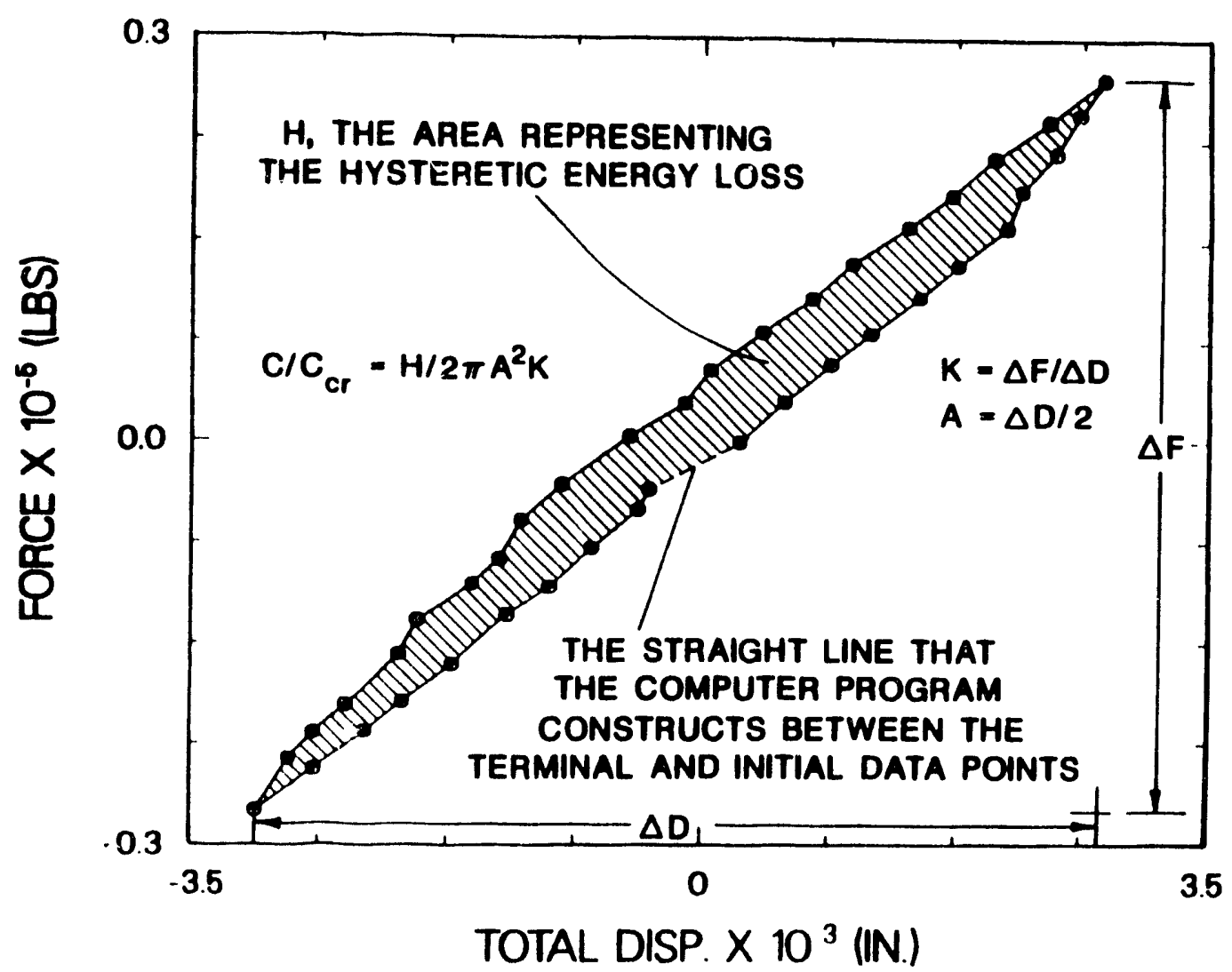

Fig. B-1. Quantities used to calculate the hysteretic energy loss and the associated equivalent viscous damping ratio. 
and

$$
U_{H}=H \text {, }
$$

where

$H=$ area within the hysteresis loop.

Equating Eqs. B-1 and B-2 yields

$$
C=\frac{H}{\pi A^{2} w} .
$$

For a single degree-of-freedom system, the critical damping coefficient, $\mathrm{C}_{c}$, is defineá as

$$
C_{c}=2 \sqrt{\mathrm{km}},
$$

where

$$
\begin{aligned}
& k=\text { the structure's stiffness, } \\
& m=\text { the structure's mass. }
\end{aligned}
$$

Dividing both sides of Eq. B-3 by $\mathrm{C}_{\mathrm{c}}$ yields

$$
\frac{C}{C_{c}}=\frac{H}{2 \pi A^{2} \omega \sqrt{k m}} \text {. }
$$

The most significant influence of damping occurs around the resonant frequency, and, for a single degree-of-freedom system, thai frequency can be expressed as

$$
\omega=\sqrt{\frac{k}{m}} .
$$

- Substituting Eq. B-6 into Eq. B-5 yields the expression used to calculate the equivalent viscous damping ratio.

$$
\frac{C}{C_{c}}=\frac{H}{2 \pi A^{2} k} \text {. }
$$

This calculation gives the most accurate results during cycles in which the response is linear and where the stiffness is well defined. The stiffness was calculated as shown in Fig. B-1. 


\begin{tabular}{|c|c|}
\hline $\begin{array}{l}\text { MRC FORM } 335 \\
\text { 2891 } \\
\text { MACM } 1102 . \\
3201.3202\end{array}$ & 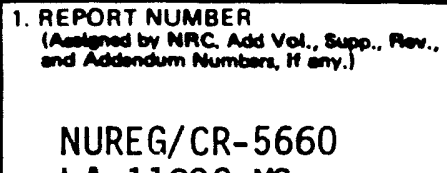 \\
\hline \multicolumn{2}{|l|}{ 2. TITLE AND SUBTITLE } \\
\hline Shear Wall Structures & \begin{tabular}{c|c} 
MONTH & YEAA \\
September & 1 ngl
\end{tabular} \\
\hline & $\begin{array}{l}\text { 4. FIN OR GRANT NUMBER } \\
\text { A7221 }\end{array}$ \\
\hline 5. AUTHOR(S) & $\begin{array}{l}\text { 6. TYPE OF REPORT } \\
\text { Technical }\end{array}$ \\
\hline & 7. PEA1OD COVEAED (Inelwain Dares) \\
\hline
\end{tabular}

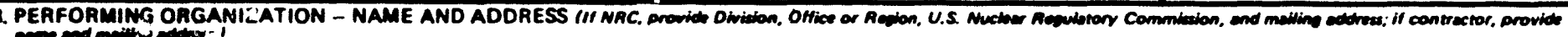

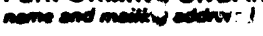

Los Alamos National Laboratory IUniversity of New Mexico, Albuquerque, NM 87131

Los Alamos, NM 87545

2Consultant at Los Alamos, 0764 C.R. 65, Del Norte, CO 81132

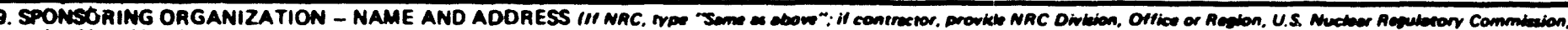
and

Division of Engineering

Office of Nuclear Regulatory Research

U.S. Nuclear Regulatory Commission

Wasinington, DC 20555

10. SUPPLEMENTARY NOTES

11. AESTAACT (200 mont or mal

Results from the static, simulated seismic base excitation, and experimental modal analysis tests performed on the TRG-7 through -16 structures are reported. These results were used to establish the scalability of static and dynamic response measured on small structural models to the dynamic response of conventional concrete structures. In addition, these tests provided information concerning cumulative damage effects that occur in concrete structures when they are subjected to different dynamic load sequences. In contrast to previous results obtained in the early part of this program, TRG-7 through -16 responded to simulated seismic excitatioris with theoretical stiffness values until peak nominal base shear stress levels of 150 psi were reached. A summary of all experimental data obtained during this program is provided.

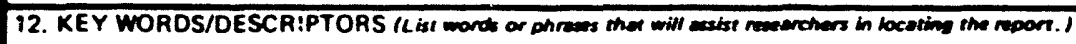

Shear wall, stiffness, damping, seismic, experiments

\begin{tabular}{|c|}
\hline $\begin{array}{l}\text { 13. AVAILABILITY STATEMENT } \\
\text { Unl imited }\end{array}$ \\
\hline 14. SECUAITY CLASSIFICATION \\
\hline TThas Papol \\
\hline Unclassified \\
\hline (This Aesport \\
\hline Unclassified \\
\hline 15. NUMBER OF PAGES \\
\hline 16 PQICE \\
\hline
\end{tabular}



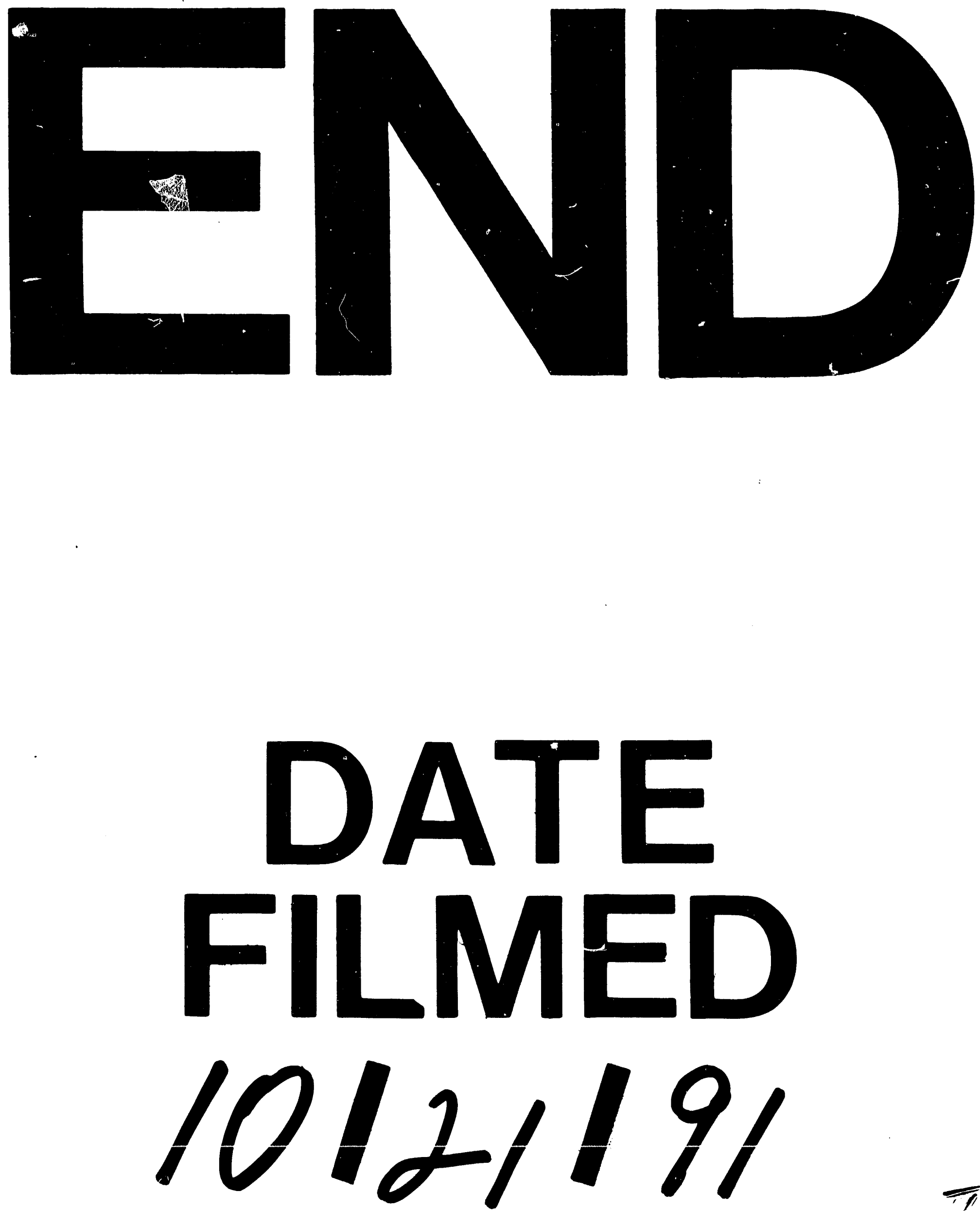

T" 
